\title{
Prisoners' Experiences of Foundation Skills - an Intensive Adult Literacy and Numeracy Programme Delivered in New Zealand Prisons
}

\author{
Alana (Lana) Moriarity
}

\author{
A thesis \\ submitted to Victoria University of Wellington \\ in fulfilment of the requirements for the degree of \\ Master of Education
}

Victoria University of Wellington

New Zealand

March 2014 


\section{Abstract}

This transcendental phenomenological study addresses a gap in the current literature by exploring prisoners' experiences of Foundation Skills, an intensive Adult Literacy and Numeracy (ALN) programme delivered in New Zealand prisons. Research with prisoners may help to improve the effectiveness of existing programmes and policies and thus contribute towards rehabilitation aims. In this study, ten male prisoners were interviewed about their experiences of Foundation Skills. The data was analysed using Creswell's (2007) simplified version of the Stevick-Colaizzi-Keen method outlined by Moustakas (1994) to arrive at a description of the essence of the participants' experiences. The study found that the essence of the participants' experiences was an increased interest and enjoyment in learning and education. The men all valued the programme as well as the opportunity to learn collaboratively. The participants' aspirations for a better life and a better future for themselves and their whānau had a significant influence on their decision to learn and participate in education. Benefits of the programme, as well as factors that support or create barriers to learning were identified. The study outlines the implications of the findings for policy and practice and provides suggestions for future research. 


\section{Acknowledgements}

Education is the most powerful weapon which you can use to change the world ${ }^{1}$ - Nelson Mandela

I wish to give heartfelt thanks to my participants for their time and contributions. It was an honour to collaborate with you on this project and to hear your remarkable stories. Ngā mihi nui ki a koutou katoa.

I am grateful to the Department of Corrections and Workforce Development for supporting this research. I am also grateful to the Foundation Skills teachers and corrections officers at Rimutaka prison for making me feel so welcome. I would particularly like to thank Annie Rainford for her help. Tēnā koutou katoa.

I am indebted to Dr Stephanie Doyle, my supervisor, who helped me to reach my personal best. Ngā mihi nui ki a koe, Stephanie. To Lynzi Armstrong, Irene Sattar, Pania Matthews, Pania Te Maro, and my cohort group ( $\mathrm{Ha}$, Liz, and Kalyan) - Kia ora, your feedback was greatly appreciated. Thanks also to Victoria University for providing me with a thesis scholarship.

I wish to single out several individuals who made a significant difference to this journey. Tēnei te mihi maioha ki a kōrua, Mum and Dad. Thanks for your love and believing in me. To Deke, Kaiara and whānau - Ngā mihi mahana ki a koutou. Thank you for your support. Finally, I would like to acknowledge those researchers that laid the path before me and showed wisdom and foresight in listening to the voices of learners in prison.

This thesis is dedicated to my participants:

Whāia e koe te iti kahurangi: ki te tuohu koe, me he maunga teitei'.

Seek the treasure you value most dearly: if you bow your head, let it be to a lofty mountain.

\footnotetext{
${ }^{1}$ Nelson Mandela Centre of Memory. (2012)

${ }^{2}$ Te Ara - The Encyclopedia of New Zealand (2014).
} 


\section{Table of Contents}

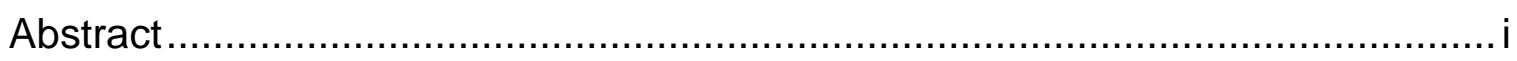

Acknowledgements ........................................................................ ii

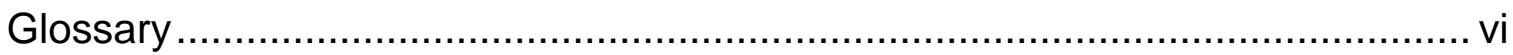

CHAPTER 1: Introduction ........................................................................

Personal Experiences Leading to the Topic ................................................... 1

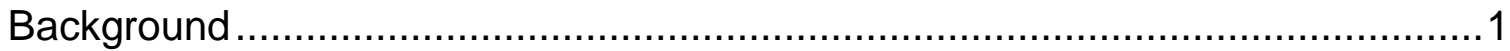

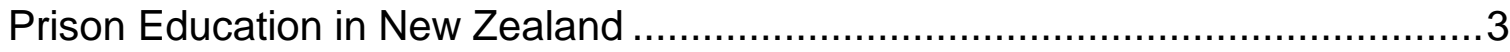

Changes in prison education provision in New Zealand ...........................3

Current prison education policy .......................................................... 4

Influences on prison education policy ............................................. 5

Different forms of adult literacy and numeracy provision ........................... 7

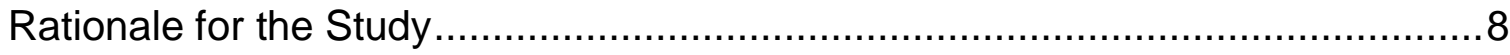

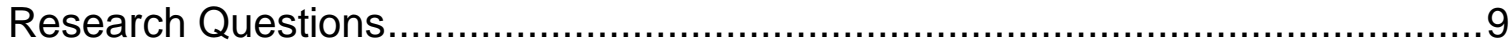

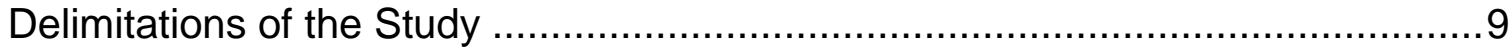

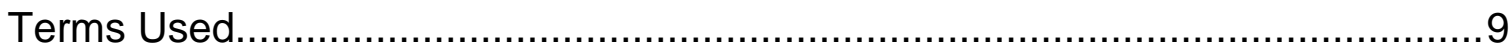

Concluding Comments ....................................................................... 10

CHAPTER 2: Literature Review ...............................................................11

Theories of Adult Literacy and Numeracy ....................................................11

Reading the word to read the world ...................................................12

Literacy as social practices ............................................................... 12

Literacy practices and literacy events ...............................................14

Literacy as discourses ...................................................................... 15

Māori perspectives of literacy ............................................................ 16

Theories of ALN in a Prison Context ................................................................ 18

Participatory literacy practices ........................................................... 19

Third space theory ................................................................. 19

Social-constructivist approaches ..................................................20

Education as empowerment .......................................................... 21

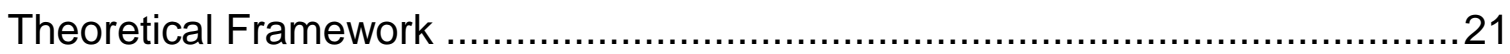

Previous Research Related to the Topic ................................................ 21

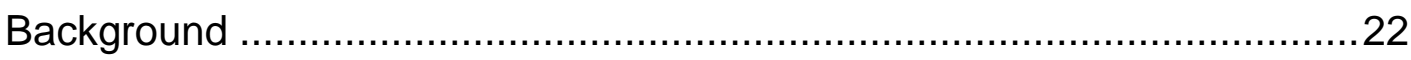

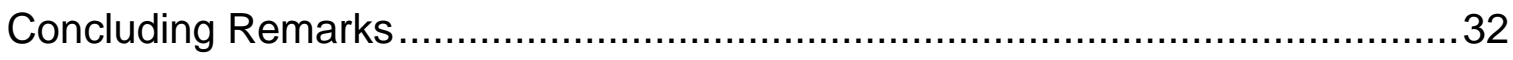




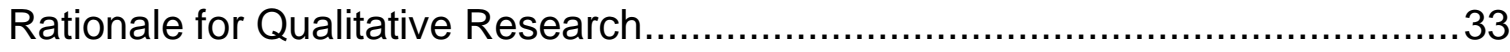

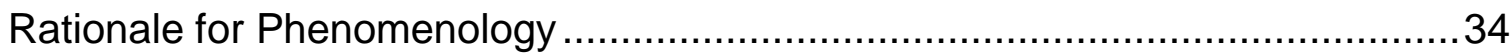

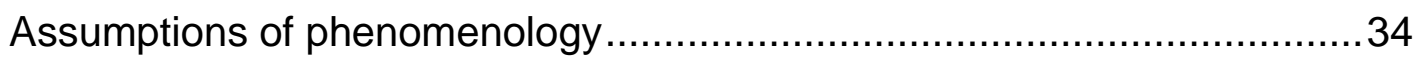

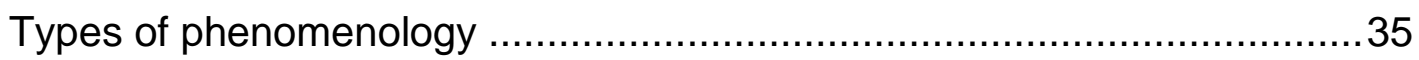

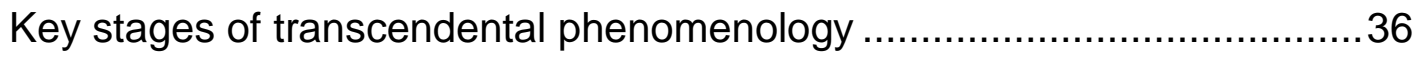

Strengths and challenges of transcendental phenomenology ...................37

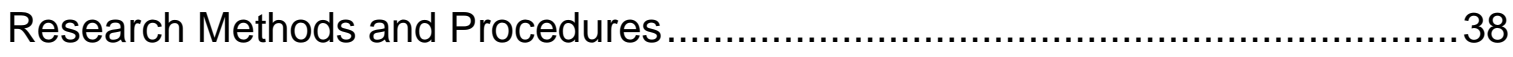

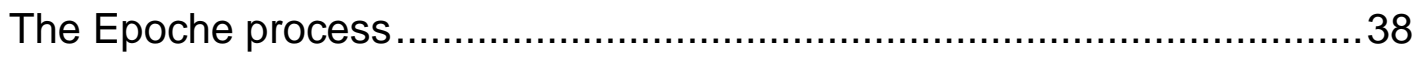

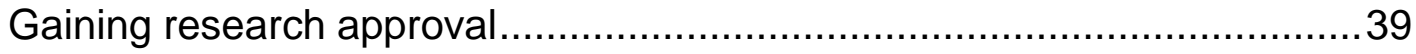

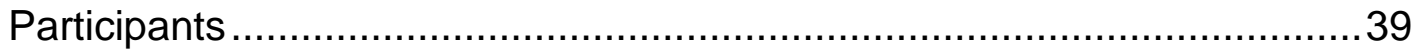

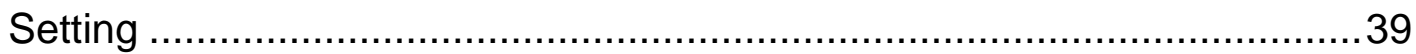

Sampling method

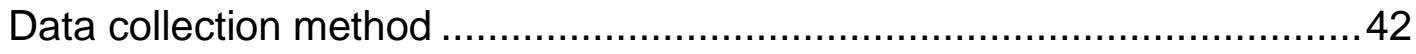

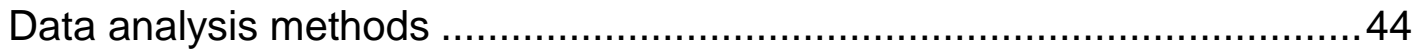

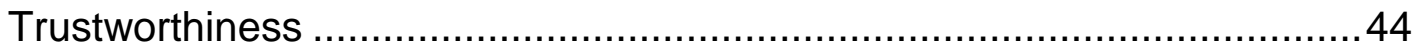

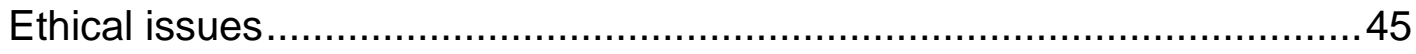

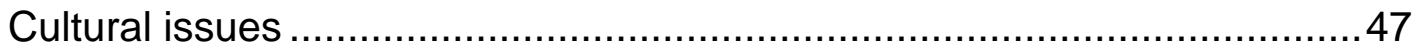

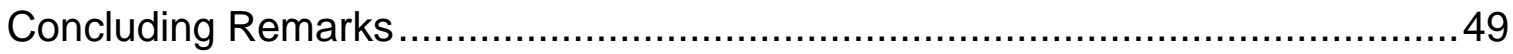

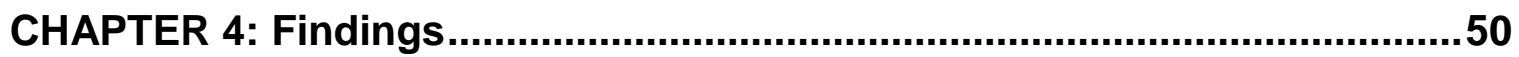

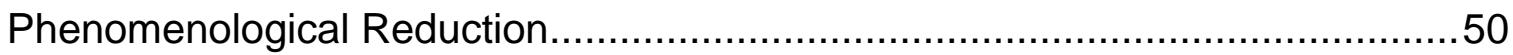

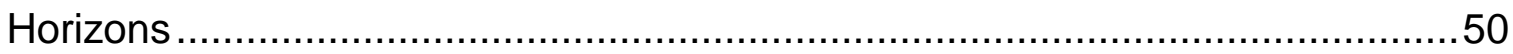

Themes

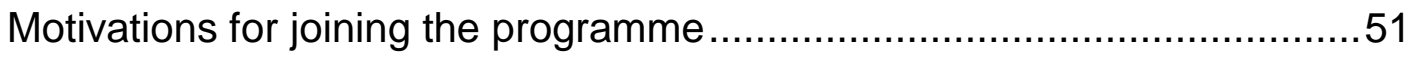

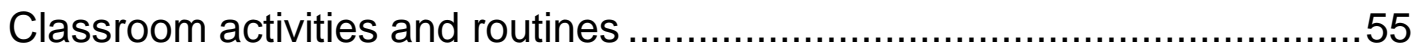

Relationships between learners and teachers ......................................60

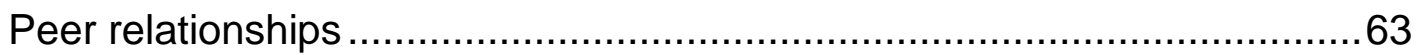

Improvements in learners' literacy and numeracy skills ............................66

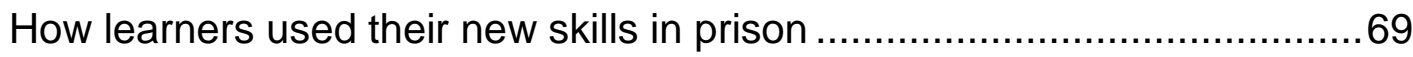

Other effects of the programme ...............................................................

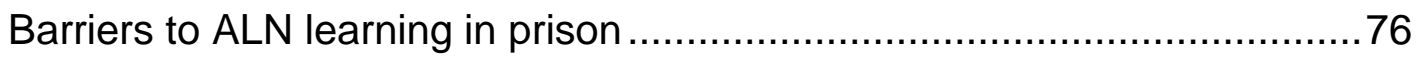

Learners' overall feelings about the programme and suggestions for

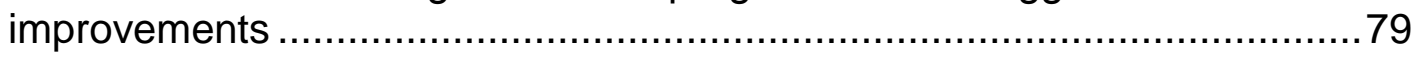

Textual Description of Prisoners' Experiences of Foundation Skills...................83

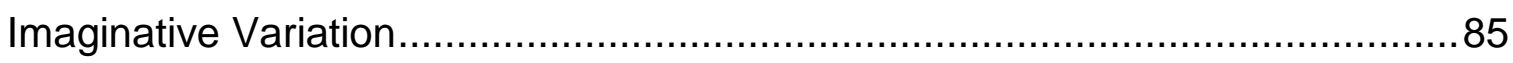

Structural Description of Prisoners' Experiences of Foundation Skills ................85 


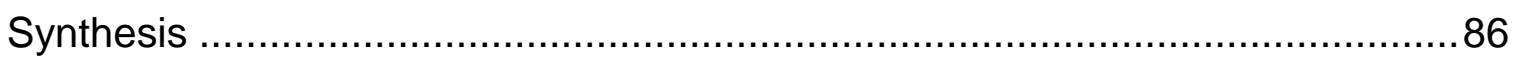

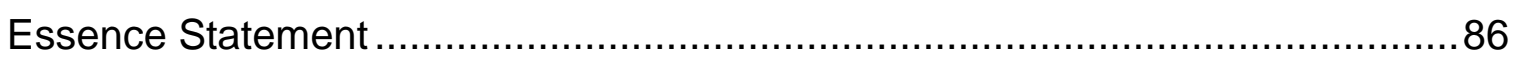

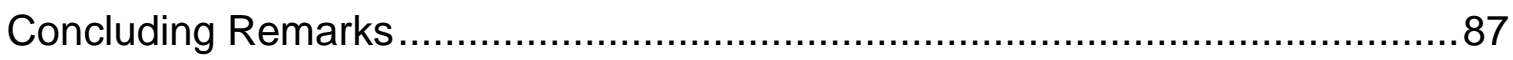

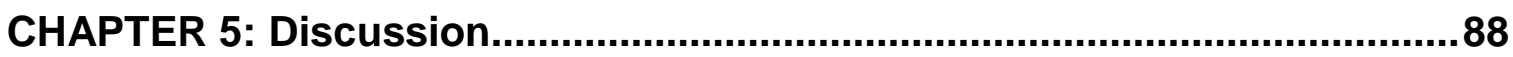

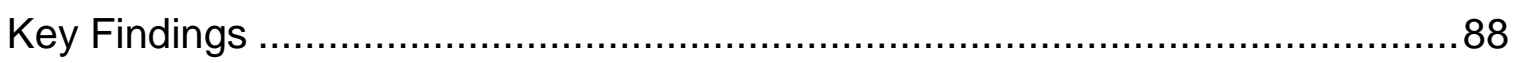

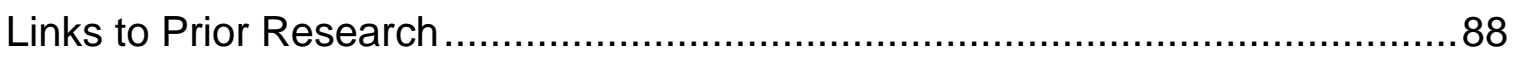

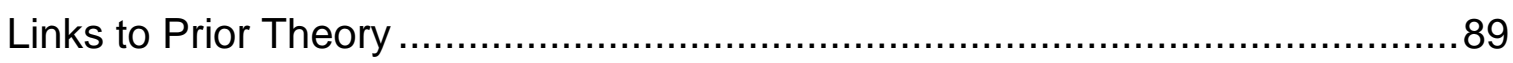

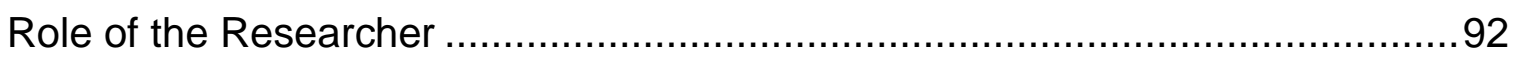

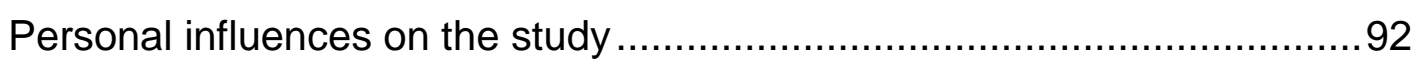

Establishing relationships in a prison setting .........................................92

Demonstrating reflexivity .......................................................................

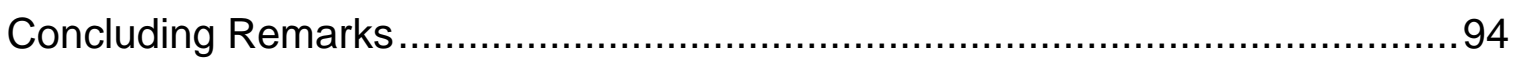

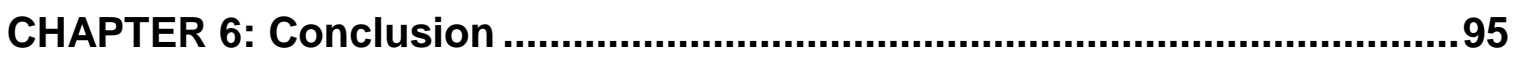

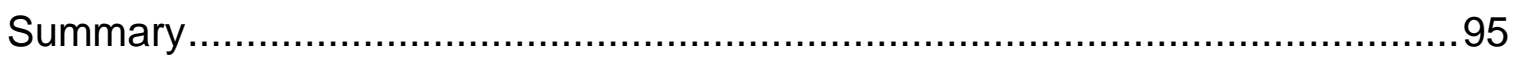

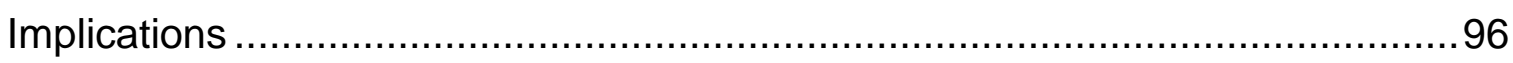

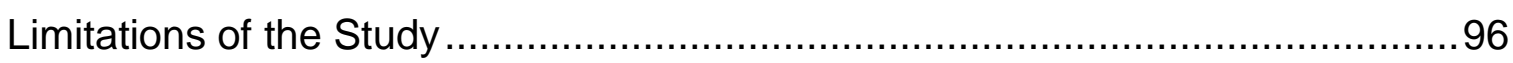

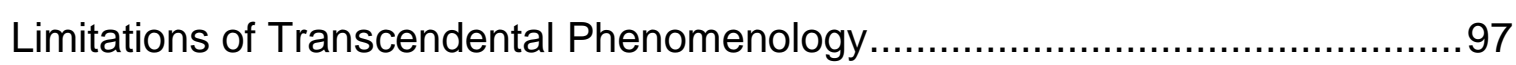

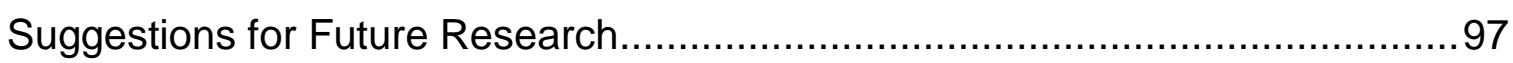

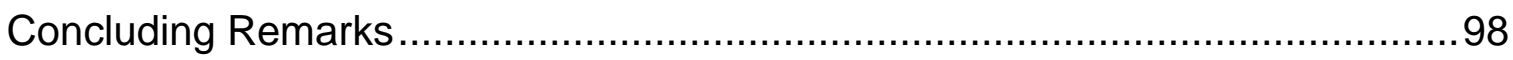

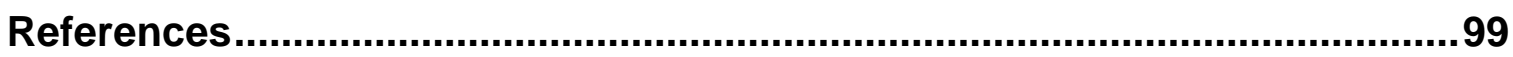

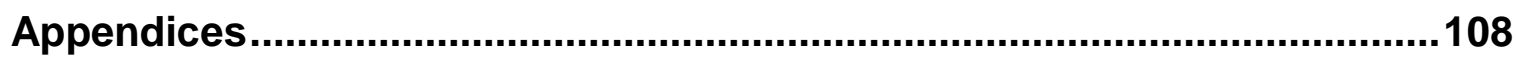

Appendix A: Approval for Research Proposal .............................................109

Appendix B: Description of Participants ...................................................110

Appendix C: Information Sheet and Consent Form......................................115

Appendix D: Themes and Examples of Significant Statements......................119 


\section{Glossary}

ALN

Kōhanga Reo

NZQA

OIC

P119

POD

Te Reo Māori

Te Tiriti o Waitangi

TEC

Tikanga Māori

Tuakana/teina

Wānanga
Adult Literacy and Numeracy

A total immersion preschool for young children centred on tikanga and te reo Māori

New Zealand Qualifications Authority

Officer in Charge

A form that prisoners use to purchase small items (e.g., toiletries, food) using their trust fund

A type of unit for high-medium security prisoners

Māori language

An agreement signed by representatives of the British Crown and Māori chiefs in 1840. Also known as the Treaty of Waitangi.

Tertiary Education Commission

Māori customs and traditions

A traditional learning practice in which an older sibling assists a younger sibling of the same sex. In the classroom, it can refer to a learner with more expertise helping a learner with less expertise.

A publicly owned tertiary institution based on Māori cultural principles established under the Education Act 1990. Traditionally, the term referred to tribal knowledge and learning, a wise person, or meeting to discuss issues. 
Whaea

Whānau

WINZ
Mother, aunty. May be used as term of respect.

\section{Family}

Work and Income New Zealand 


\section{CHAPTER 1: \\ Introduction}

This chapter describes personal experiences leading to the research topic. Background information on prison education policies and programmes is outlined. In addition, the chapter shows how the current study will contribute to existing literatures, outlines the main research questions of the study, and describes key terms.

\section{Personal Experiences Leading to the Topic}

My decision to explore prisoners' experiences of ALN education was influenced by my prior experiences of education. I left school early and with no formal qualifications. I eventually returned to study in my early twenties, and completed a Diploma in Health Psychology at my local polytechnic. As a result of my experiences, I developed an interest in assisting other adult learners that had left school at a young age. My first experience of teaching adults was in prison, where I worked as a volunteer literacy tutor and a relief teacher for Foundation Skills, an intensive ALN programme delivered in New Zealand prisons. To better support my learners, I decided to complete an adult teaching qualification and postgraduate diploma. Afterwards, I received a scholarship to complete a Masters by thesis. I decided to explore prisoners' experiences of the Foundation Skills programme given my interest in this area.

\section{Background}

Traditionally, prison education has been highly functionalistic and focused on the goal of reforming prisoners (Collins, 1995; Wilson, 2007). The last decades have witnessed a shift in attitudes towards prison education alongside an increased emphasis on the value of prison education (Hawley, Murphy, \& Souto-Otero, 2013). Europe has adopted a holistic model of prison education (Devine, 2010). Prisoners' right to education is outlined in legislation, such as the European Convention for the Protection of Human Rights and Fundamental Freedoms, the 1990 Recommendation on Education in Prison, and European Prison Rules (Council of Europe, 2013a, 2013b, 2013c). These assert that prisoners should be 
provided with a range of education and training opportunities in prison. In the United Kingdom (UK), some prisons have been set up as training centres and prison staff are involved in education provision.

The recent emphasis on prison education has been influenced by several key factors. To begin, research has found that prison education can help to reduce recidivism and its associated costs to society through improving prisoners' employability and changing their personal attitudes and perceptions (Jensen \& Reed, 2006; Vacca, 2004). Some authors (Clark \& Dugdale, 2008) caution that literacy education by itself is unlikely to reduce recidivism as the causes of crime are complex. Most prisoners experience multiple problems including poor mental and physical health, drug and alcohol addiction, and family dysfunction (National Health Committee, 2010; Social Exclusion Unit, 2002). These problems are largely structural and linked to "social, educational, financial and cultural disadvantage" (Meatheringham, Snow, Powell, \& Fewster, 2007, p. 179). A range of interventions are therefore needed for successful reintegration (Hawley et al., 2013).

Secondly, prison education can help to mitigate the negative effects of imprisonment (Behan, 2008; Hawley et al., 2013). Prison may reduce prisoners' chances of gaining employment on release through eroded employment skills, large employment gaps, and the stigma associated with a criminal record (Holzer, Raphael, \& Stoll, 2003). Prisoners may lose their home or job while in prison, lose contact with their children and family, and be introduced to drugs (Social Exclusion Unit, 2002). Prison education can help to improve prisoners' employment skills (Department of Corrections, 2009). It can reduce incidents of violence in prison (Vacca, 2004), enable prisoners to participate more effectively in the prison environment (Searcy, 2008), facilitate participation in rehabilitation programmes (Department of Corrections, 2009); provide hope and aspirations for the future (Hawley et al., 2013); and help prisoners to maintain communication with their families (Wilson, 2007).

Thirdly, prison education has become an important human rights issue (Devine, 2010; Hawley et al., 2013; Muñoz, 2009). The Standard Minimum Rules for the Treatment of Prisoners (United Nations Office on Drugs and Crime, 2013) and 
the 1990 Basic Principles for the Treatment of Prisoners (United Nations, 2013) outline member states' obligations for prison education. The Basic Principles asserts that all prisoners "have the right to take part in cultural activities and education aimed at the full development of the human personality" (p. 1). It proposes that prison education should be comparable to provision in the community.

In most countries, a range of stake holders are involved in the provision of prison education, including government ministries and private education providers. Current challenges for stakeholders include catering for the increasing diversity of the prison population, keeping pace with new innovations in education and training; and utilising new information technologies. In addition, growing prison populations and associated funding costs may lead some prison authorities to give less priority to education. These concerns arise at a time when prisoners most need to improve their employment skills due to competitive labour market conditions (Hawley et al., 2013).

\section{Prison Education in New Zealand}

In New Zealand, the Department of Corrections has primary responsibility for prison education, although it works closely in collaboration with other government departments and non-government organisations (Department of Corrections, 2013a). The Corrections Act 2004 outlines the Department's requirements for prison education (Parliamentary Counsel Office, 2013). The Act states that prisoners have an entitlement to education that the prison manager believes will assist in "(i) his or her rehabilitation; or (ii) a reduction in his or her reoffending; or (iii) his or her reintegration into the community" (p. 83). In addition, the Standard Minimum Rules for the Treatment of Prisoners (UNODC, 2013) and the 1990 Basic Principles for the Treatment of Prisoners (UN, 2013) outline the government's obligations for prison education.

\section{Changes in prison education provision in New Zealand}

Prison education in New Zealand has undergone a number of changes. In the mid-20th century, prisoners had access to a range of education and training opportunities, including "reading lessons for the illiterate, post-primary tuition in academic and technical subjects, opportunities to do extra-mural university work, 
many kinds of trade training allied to prison industry, and a wide variety of cultural and recreational activities" (Department of Justice, 1959, as cited in Devine, 2007 , p. 55). However, from the 1980s, attitudes towards prison education changed. Prisoners' access to education and training reduced, and there was increased emphasis on programmes designed to improve public safety (Devine, 2007). John Belgrave and Mel Smith, in their 2005 Ombudmen's report on the detention and treatment of prisoners, identified a widespread view amongst key stakeholders that prisoners' access to work, education and rehabilitation programmes had "diminished severely in recent years" (Office of the Ombudsman, 2005, p. 43). Possible explanations for these changes are neoliberalism, which strongly influenced government policy from the early 1980s, and punitive approaches to crime and punishment emanating from the US (Devine, 2010).

\section{Current prison education policy}

Recent government policy suggests that prison education in New Zealand is undergoing further change. The government's current focus is on "reducing reoffending through rehabilitation" (New Zealand Government, 2013, p. 1). It aims to reduce reoffending by 25 percent by 2017 . To achieve its target, the government is increasing prisoners' access to education and training, as well as alcohol and drug treatment. Minister of Corrections Anne Tolley suggests that "it makes sense to focus on giving prisoners education opportunities, which can then help them gain qualifications, skills training and work experience" (New Zealand Government, 2013, p. 1). She says "this is often the crucial difference between accessing training or employment and making a positive contribution to society on release, or returning to crime and ending up back inside the wire" (p. 1).

The Department of Corrections (2013a) has developed a new education strategy to support its recidivism aims. A significant element of the strategy is ensuring that a wider range of prisoners can access literacy and numeracy training (e.g., people on remand and serving short sentence), as this is viewed as a key means to improve employability on release. The Department's target over the next five years is to have "2,000 prisoners per year receiving literacy and numeracy training and in-work support, an increase of 1200 prisoners per year" (p. 1). 
Another feature of the strategy is improved education planning for all prisoners (New Zealand Government, 2013).

\section{Influences on prison education policy}

Recent changes in prison education policy have been influenced by two key factors. The first is international research on prisoner literacy and numeracy, which shows that many prisoners have poor literacy and numeracy skills and limited formal qualifications (Clark \& Dugdale, 2008; US Department of Education, 2007; United Nations Educational, Scientific and Cultural Organization, 2012). This may be attributed to unidentified health problems, youth offending, and lack of family support (Department of Corrections, 2009). In addition, research shows that prison education may help to support rehabilitation aims through improving prisoners' employability (see for example, Hawley et al., 2013).

Past screening by the Department of Corrections (2009) found that up to 90 per cent of prisoners in New Zealand had low literacy skills, and around 80 percent had poor numeracy skills. Māori prisoners, who are overrepresented within the prison population $^{3}$, were found to have a greater literacy and numeracy need than non-Māori prisoners. However, prior assessments of prisoner literacy and numeracy have tended to lack methodological rigor (Bowman, in press). A more recent study by the Department involving a representative sample of 592 prisoners has provided a more accurate picture of prisoners' literacy and numeracy skills (Bowman, in press). This study suggests that around 71 percent of prisoners do not have the literacy skills needed to participate effectively in a knowledge-based society, compared to 43 percent of a comparable sample in the general population. This finding is consistent with international research. Approximately 65 percent of prisoners were found to have low numeracy skills ${ }^{4}$. Female prisoners had slightly better reading and numeracy scores than male prisoners. Māori and Pasifika prisoners were underrepresented amongst those

\footnotetext{
${ }^{3}$ Māori make up around 14 percent of the general population. However, over half the prison population identify as Māori (Department of Corrections, 2009).

${ }^{4}$ The Literacy and Numeracy for Adults Assessment Tool was used to measure prisoners' literacy and numeracy skills.
} 
prisoners scoring in the higher levels of literacy and numeracy. No relationship was identified between re-offending risk and literacy ability, indicating that having low literacy does not necessarily lead to offending. Instead, low literacy may create barriers to achieving a life free of crime.

Secondly, current prison education policy has been strongly influenced by broader policy trends. Adult literacy and numeracy became a key political issue in New Zealand as a result of the OECD's 1996 International Adult Literacy Survey (IALS) and 2006 Adult Literacy and Life Skills Survey (ALL) (Artemiev, 2008). Findings suggest that around half the population do not have the literacy and numeracy skills to participate effectively in a knowledge-based society (Tertiary Education Commission, 2008a). Māori and Pasifika populations were disproportionately represented amongst those with the lowest literacy and numeracy skills (Lawes, 2009; Satherley \& Lawes, 2009; Tertiary Education Commission, 2008a). Literacy and numeracy skill was linked to level of education achieved, computer use at work and home, and main language spoken (Lane, 2010). Furthermore, higher literacy and numeracy skills were associated with higher educational participation and income (Ministry of Education, 2013).

Successive government policy documents have recognised the importance of literacy and numeracy to New Zealand's social and economic development beginning with the New Zealand Adult Literacy Strategy (Ministry of Education, 2001). Other key reports include the Literacy, Language and Numeracy Action Plan 2008-12, the Strengthening Literacy and Numeracy Theoretical Framework, the Tertiary Education Strategy 2010/15, and the Adult Literacy and Numeracy Implementation Strategy (Ministry of Education, 2010; Tertiary Education Commission, 2008b, 2009, 2012) A key national initiative has been the Tertiary Education Commission's (TEC) Learning Progressions for Adult Literacy and Numeracy, a six stage model for teachers and learners which outlines how people develop expertise in literacy and numeracy (Tertiary Education Commission, 2008a). The Literacy and Numeracy for Adults Assessment Tool was developed to measure learners' skills and progress against the Learning Progressions (National Centre of Literacy and Numeracy for Adults, 2013). 


\section{Different forms of adult literacy and numeracy provision}

The Department of Corrections (2013b, 2013c) delivers education and training opportunities to prisoners to improve their job prospects on release. Examples include literacy and numeracy training, National Certification of Educational Achievement (NCEA), self-directed tertiary study, classroom-based training, and on-the-job training (Offender Employment or OE; formerly known as Corrections Inmate Employment or $\mathrm{CIE}$ ). Prisoners involved in trade and technical training can earn NZQA credits (see Glossary) that count towards National Certificates on the New Zealand Qualifications Framework.

Several forms of literacy and numeracy education are available in New Zealand prisons. Foundation Skills is an intensive ALN programme designed to support learners at the lower steps of the Learning Progressions (Bulliff, 2013) . $^{5}$ Prisoners are referred to the programme based on a literacy and numeracy screening assessment. Their progress is regularly assessed using the Literacy and Numeracy for Adults Assessment Tool (Department of Corrections, 2012). According to the Department's Annual Report (2012), "89 percent of the 2,363 prisoners on a literacy and numeracy course demonstrated an improvement in their skills" as measured against the Learning Progressions (p. 12).

Embedded literacy and numeracy is delivered within a range of trade training courses in prison, such as painting, engineering, carpentry, and forestry. Bulliff (2013) states that "As at 31 January 2013, 1324 prisoners had participated in 139 vocational courses embedded with literacy and numeracy" (p. 35). Research in New Zealand and internationally indicates that embedded approaches can help to improve student engagement, course retention, and achievement rates in prison and community settings (Bulliff, 2013; Casey et al., 2006).

One-on-one literacy and numeracy tuition is delivered by volunteer tutors. Some volunteers are independent. Others are associated with the Howard League for Penal Reform's Storybook Dads programme, which aims to improve relationships between parents and their children (Joyce, 2013). The programme is similar to

\footnotetext{
${ }^{5}$ The programme is delivered by an external provider, Workforce Development, on contract to the Department.
} 
the Storybook Dads and Mums programme in the UK (Storybook Dads, 2013). Reports indicate the programme has been successful. A Corrections spokesperson reported that, "Participants had developed new relationship and parenting skills, and 'new knowledge about things like empathy, children's behaviour and positive role-modelling"' (Joyce, 2013, p. 9).

The Department of Correction's (2013a) education strategy outlines several new ALN initiatives. The Short Gains programme is a 32-hour intensive literacy and numeracy course available to prisoners on remand. Work Ready is designed to prepare prisoners on remand or serving short sentences for employment. The Prisoners as Mentors programme trains prisoners to support other inmates with learning needs. It is similar to the Toe by Toe project in the UK (The Shannon Trust, 2012) and the L.I.F.E program in the US (Video Verite, 2008). In addition, the Department is trialling the use of online literacy and numeracy resources, and attempting to better align embedded and intensive literacy and numeracy courses (Bulliff, 2013). For example, prisoners now undertake intensive literacy and numeracy training before beginning trade and technical training (T3) courses, and receive support from Foundation Skills teachers with homework tasks. Bulliff (2013) notes that learner retention and achievement rates on T3 courses have improved since the introduction of these initiatives, indicating that an integrated approach "has great merit" (p. 36).

\section{Rationale for the Study}

Previous studies indicate that ALN education can be beneficial to prisoners (see for example Department of Corrections, 2009; Jensen \& Reed, 2006; Wilson, 2007). However, research on prisoners' experiences of ALN education is limited both internationally and in the New Zealand context (Benseman, Sutton, \& Lander, 2005; Parkhill \& Davey, 2012). Smiling Hall and Killacky (2008) observe that "with little research on prisoner perceptions of the correctional education experience, there are many questions about the life of the prisoner student to be answered" (p. 303).

Exploring prisoners' experiences of ALN education may help to improve the effectiveness of existing policies and programmes, and thereby contribute to rehabilitation aims (Prisoners Education Trust, Inside Time, \& RBE Consultancy 
Ltd, 2009; Reuss \& Wilson, 2000). Reuss (2000) notes that "A full understanding of prisoner education can only be achieved by asking the prisoner - as student what perceptions he or she had of the experience of learning the subject in question" (p. 42). Moreover, there is an ethical and moral imperative to listen to the voices of learners, whose views often go unheard in broader discussions on literacy (Papen, 2005).

This phenomenological study addresses a gap in the current literature by exploring prisoners' experiences of Foundation Skills, an intensive ALN programme delivered throughout New Zealand prisons. It aims to describe the essence of participants' collective experiences of the programme. The research is particularly timely given the governments' current focus on improving prisoners' access to literacy and numeracy education as part of their overall goal to reduce re-offending (Department of Corrections, 2013f).

\section{Research Questions}

The two main research questions in this study are based on Creswell's (2007) recommendations for a phenomenological study: What are prisoners' experiences of Foundation Skills? What contexts or situations have influenced their experiences of Foundation Skills?

\section{Delimitations of the Study}

This study explores the experiences of a small group of learners on a specific ALN programme (Foundation Skills), at one prison, and at one point of time. It is not intended to represent the experiences of other prisoners involved in ALN education, including other prisoners attending Foundation Skills.

\section{Terms Used}

The Department of Corrections $(2012,2013 f)$ generally uses the terms 'prisoner' or 'offender' to refer to individuals in prison. This study likewise adopts the term 'prisoner'. For convenience, I use the shortened term 'ALN' to refer to adult literacy and numeracy. I sometimes use the term 'literacy' to refer to both literacy and numeracy practices in line with the theoretical literature (see for example Papen, 2005). 


\section{Concluding Comments}

This chapter has provided a background and rationale for the current study. The study aims to increase knowledge of an important but little known topic: Prisoners' experiences of intensive ALN education in New Zealand. Talking to prisoners about their educational experiences may help to improve the effectiveness of existing programmes and policies and thereby support rehabilitation aims. Furthermore, there is an ethical and moral obligation to listen to the voices of adult learners who are key stakeholders in ALN provision. This study may be of interest to prison authorities, policy makers and practitioners involved in prison education and training. 


\section{CHAPTER 2: \\ Literature Review}

A literature review was conducted to provide a background to the current study. Literature was located using online databases (including ERIC and ProQuest Central), the library catalogue, the reference lists of articles and books, and government websites. In addition, past and current issues of the Journal of Correctional Education were searched given its pertinence to the topic. Search terms included prisoners, offenders, prison education, literacy, numeracy, prison, experiences, views and perspectives. This chapter outlines the findings of the literature review. Firstly, theories of adult literacy and numeracy, including theories of ALN in a prison context, are described, and the study is located within a theoretical framework. Next, previous research related to the topic is outlined and key themes identified.

\section{Theories of Adult Literacy and Numeracy}

Adult literacy and numeracy is a highly contested concept (Papen, 2005). Identifying the different ways that ALN has been conceptualised can help to situate literature on the topic and identify the assumptions underlining policies and programmes (Street, 2005b). In this section, I draw on the work of leading literacy theorists (Barton \& Hamilton, 1998; Freire, 1970; Papen, 2005; Street, 1995) to illustrate the diverse ways in which literacy has been conceptualised and utilised by theorists, practitioners, and policy makers. This is followed by a discussion on Māori views of literacy. The literature illustrates a shift away from studying literacy and learning from individual and cognitive perspectives, towards studying literacy and learning from a social and cultural perspective. The latter perspective views learning and literacy as inherently situated, and being about relationships, including those of power. On the other hand, the various works have different points of focus or emphasis. For example, Freire theorises literacy in relation to social and political transformation, whereas Papen highlights the implications of a social practices approach for teaching and curriculum. 


\section{Reading the word to read the world}

Freire (1921-1997) focused on the association between literacy and power. He saw literacy as a means to achieve social justice for marginalised groups within society. His work echoes that of the Italian philosopher Gramsci, who highlighted that language can be a tool of oppression or social empowerment (Giroux, 1987).

Freire (1970) identified two competing views of literacy: the banking approach and problem-posing education. In his early years as an educator, Freire saw the banking approach as the prevailing and mainstream approach to literacy. Within a banking concept of education, literacy is reduced to a set of functional skills which the teacher "deposits" into the learner (p. 72). The teacher is positioned as an expert and the learner as a passive recipient of knowledge. Freire believed that the banking approach inhibited critical thought and served to uphold the interests of powerful groups within society.

In contrast, problem-posing education positions literacy as the ability to think critically about the world, leading to actions that transform the world (Freire, 1970). Critical thinking is developed through a process of dialogue between teachers and learners on issues of significance to the learners. Teachers and learners share responsibility for learning and engage in reciprocal teaching and learning. Freire envisioned that through reading "the word", learners would be able to read "the world" in order to change that world and thus achieve greater social justice (Freire \& Macedo, 1987, p. viii).

Some authors suggest that Freire may have been overly optimistic about the potential for literacy to lead to social transformation (Street, 2005b). Nonetheless, his work has been highly influential within the field of ALN (Spener, 1992). Some authors (Boudin, 1993; Collins, 1995; Kett, 2001) argue that Freirean pedagogy has relevance in prison settings given that many prisoners come from disadvantaged communities.

\section{Literacy as social practices}

Despite being more cautious about the transformative possibilities of literacy, Street $(1995,2005 b)$, like Freire, views literacy as embedded within power 
relations and influenced by historical and cultural forces. Street (2005a) asserts the same is true for numeracy.

In earlier work, Street (1995) differentiates between an autonomous model and an ideological model of literacy. Within the autonomous model, literacy is conceptualised as a set of functional skills acquired through formal education. It positions people as either 'literate' or 'illiterate'. Street noted that this approach was often adopted by politicians and the media. Conversely, the ideological model positions literacy as a set of social practices acquired through informal and formal processes. It includes multiple literacies related to different social and cultural contexts (Street, 1995). The model highlights that literacy is highly political, as some views of literacy are accorded greater status than others within society.

Towards the end of the 20th century, there was a growth in interest in literacy both nationally and internationally, and with it debates and competing practices (Hawley, Murphy, \& Souto-Otero, 2013). To capture these changes, Street (2005b) conceptualises four approaches to teaching and learning: literacy and learning, cognitive approaches to literacy, social practices approach, and literacy as text. Those working within these approaches have different ideas about the goals and purposes of literacy education.

The literacy and learning approach is based on theories of reading acquisition. Programmes based on this approach focus on teaching adults to read using textbooks or primers. Cognitive approaches conceptualise literacy as a set of decontextualised skills located in a person's head. Street notes that these approaches underpin most modern literacy programmes but are being challenged by a social perspective of literacy. The social practices approach (also known as the New Literacy Studies) is an elaboration of Street's (1995) ideological model of literacy. Programmes based on this approach contextualise instruction to ensure lessons are meaningful to people's everyday lives. Street acknowledges that the social practices approach has been criticised for ignoring the value of 'outside' literacy programmes for marginalised groups, but argues that it provides a more culturally responsive approach to literacy. The literacy as text approach views literacy as one form of communicative practice among many. It highlights that 
learners use various modalities to develop understanding, such as text and visual images. Programmes based on this approach incorporate information technology (IT) into lessons. Street (2005b) suggests that an integration of the social practices and multi-modal approach may enhance future ALN programmes.

\section{Literacy practices and literacy events}

Barton and Hamilton (1998) share strong commonalities with Street (1995), in contrasting individual and cognitive perspectives of literacy with a social practices approach. They focus on two key concepts of a social practices approach: literacy practices and literacy events. Literacy practices are the "general cultural ways of utilising written language which people draw upon in their lives" and are bound by social rules and conventions (p. 7). Literacy practices shape literacy events, the everyday literacy tasks people carry out which involve both oral and written language.

Barton and Hamilton's (1998) description of key assumptions of a social practices approach echo those of Street. Firstly, the model assumes that there are multiple literacies related to different domains of life. In these domains, people share unique ways of "talking, acting, valuing, interpreting and using written language" (p. 11). There are also multiple literacies in the sense that literacy involves different modalities and languages.

In addition, the social practices approach distinguishes between dominant and vernacular literacy practices (Barton and Hamilton, 1998). Dominant literacies are shaped by powerful social institutions, tend to be highly formalised, and are usually based on the dominant language of a society. Access to dominant literacies is controlled by experts.

Conversely, vernacular literacies are related to people's everyday literacy practices in the home and community. As such, they tend to be accorded less value than dominant literacies. People may engage in vernacular literacies to address practical needs or pursue personal interests (e.g., reading online health information, instant messaging, and blogging). They may be subversive and used to resist dominant literacies, such as graffiti. Consequently, the social practices 
approach rejects categories such as 'literate' or 'illiterate'. Instead, it assumes that all people have difficulties in some aspects of literacy while being strong in others (Barton \& Hamilton, 1998).

\section{Literacy as discourses}

Papen (2005) identifies four major approaches to literacy: critical, liberal, functional/technical, and social practices. These approaches share similar features to the models described earlier (Freire, 1970; Street, 2005b; Hamilton \& Barton, 1998).

The critical approach focuses on supporting learners to think critically about the world. In contrast, the liberal approach, which is based on a humanist perspective, argues that people have a right to education and associates literacy with personal development. The functional literacy approach is underpinned by psychological perspectives that focus on the individual (Papen, 2005). It associates literacy with social and economic growth: "There are worries that lack of literacy - or 'illiteracy' - hinders employability, leads to social exclusion and poor health, and is correlated with crime and anti-social behaviour" (p. 7). Papen points out that the functional approach is the dominant model of literacy internationally. In contrast, a social practices approach assumes that literacy involves social and cultural knowledge, not just functional skills. It presumes that literacy does not transfer easily across different domains of life, and recognises that people's understandings of literacy differ.

Like the theorists previously discussed (Barton and Hamilton, 1998; Street, 2005b), Papen is a strong proponent of a social practices approach. However, she provides a different perspective by highlighting how literacy can be understood as discourses. Discourses include themes, attitudes, and values. Papen points out how powerful discourses shape the public's views of literacy, influence literacy policy and programmes, and construct people as 'literate' or 'illiterate'. 


\section{Māori perspectives of literacy}

\section{Background}

Māori perspectives of literacy share some common features with the models of literacy previously discussed (Freire, 1970; Street, 2005b) in viewing literacy as shaped by historical and cultural forces, including processes of colonisation. Te Kāwai Ora: Reading the world, reading the word, being the world, a report by the Māori Adult Literacy Working Party (2001) observes that Māori had positive views of English literacy when it was first introduced by European settlers. However, over time their own literacies were marginalised within society. For instance, Māori children were historically punished for speaking Te Reo Māori (the Māori language) at school (Ministry for Culture and Heritage, 2013). This had a devastating impact on the Māori language and Māori whānau and communities (Rawiri, 2007).

Over the last few decades, there has been a strong push by Māori to revitalize the Māori language in recognition that "it is language that gives expression to culture" (Māori Adult Literacy Working Party, 2001, p. 9). In addition, there have been efforts to develop culturally responsive teaching practices for Māori students (Meyer et al., 2010). Nevertheless, concerns remain that the mainstream education system continues to fail a large number of Māori students (Bishop \& Berryman, 2006; Macfarlane, 2004; Penetito, 2010).

Negative schooling experience for Māori can result in low self-esteem, feelings of incompetence, negative attitudes towards education, early school leaving, and poor literacy and numeracy skills (May, 2009; Potter, Taupo, Hutchings, McDowall, \& Isaacs, 2011; Rawiri, 2007). Research suggests that low literacy and numeracy can create education and employment barriers for Māori adults and make it difficult for them to contribute to the education of their tamariki (children) and mokopuna (grandchildren) (Potter et al., 2011). The desire to contribute to the wellbeing of their whānau (family) is often a strong motivator for many to attend ALN programmes.

Māori views of literacy emphasise the importance of both Māori literacies and English language literacy (Māori Adult Literacy Working Party, 2001; Rawiri, 2007). In addition, they emphasise community self-determination - the power of 
Māori communities to determine their own literacy needs and aspirations. They thus share similarities with Freirean (1970) and social practices (Street, 2005b) approaches.

Echoes of Freire can be seen in the Te Kawai Ora definition of literacy as "the lifelong journey of building the capacity to 'read' and shape Māori and other worlds" (Māori Adult Literacy Working Party, 2001, p. 11). The report positions literacy for Māori as being about developing both reading and writing skills and cultural knowledge. This includes knowledge of Māori symbols such as whakairo (carving), Te Reo Māori, and whakapapa (genealogy). In addition, it emphasises the importance of political knowledge for Māori. It recommends the adoption of a biliteracy approach in New Zealand based on Te Tiriti o Waitangi (an agreement signed by representatives of the British Crown and Māori chiefs in 1840).

Rawiri (2007) provides a similar perspective to the Working Party report. She remarks that for Māori, "being literate is not simply about performing functional tasks - more fundamentally, it is about understanding and participating as a member of a community/wider social group" (p. 8). She notes that literacy includes knowledge of cherished tribal values and beliefs handed down from one generation to another.

\section{Effective ALN programmes for Māori}

Rawiri (2007) contends that effective ALN provision for Māori requires a shift away from current orthodox approaches to a multiliteracy approach which values both Māori literacies and English language literacy, provides meaningful contexts for learning, and promotes community empowerment. This argument is supported by research which shows that effective ALN programmes for Māori emphasise Te Reo Māori and tikanga Māori, provide meaningful curriculum, utilise traditional Māori teaching pedagogies such as tuakana/teina (see Glossary), recognise individual learning needs, include whānau in the learning process, and are strengths-based (May, 2009; Potter et al., 2011; Rawiri, 2007; Tangaere, 1997; Te Puni Kōkiri, 2011; Workbase, 2002). These factors have been found to support Māori achievement at all levels of education (Kerehoma, Connor, Garrow, \& Young, 2013; Meyer et al., 2010; Te Kupenga Mātauranga o Taranaki, 2011). 


\section{Benefits of ALN programmes for Mãori}

Research indicates that ALN programmes connected to Māori contexts can result in greater community involvement, improved employment prospects, increased independence, enhanced understanding of self and others, and increased interest in learning (Potter et al., 2011). The benefits of ALN learning extend to learners' whānau. Their study reported that learners were better able to assist their children with learning, support their whānau to become self-determining, and increase whānau cultural knowledge. Participating in ALN education also helped to strengthen relationships within whānau through enhancing learners' communication skills. Participants said that they were "better able to plan together as a whānau and work through painful past issues" ( $p$. xi). These findings suggest that ALN education can help to support whānau development.

\section{Challenges facing Māori literacy programmes}

Māori providers have helped to change the nature of ALN provision in New Zealand through adopting a biliteracy approach (Māori Adult Literacy Working Party, 2001). Acknowledgement of Maori perspectives on literacy is evidenced in guidance provided by government agencies to education providers. For instance, the New Zealand Qualifications Authority (2013) notes that "Literacy for Māori includes a diversity of knowledge taken from Mātauranga Māori and mainstream theoretical frameworks" (p. 1). Nevertheless, some tensions may still exist. Zepke's (2011) study of discourses of literacy in a wānanga (see Glossary) found that the institution adopted a holistic approach to literacy. The wānanga felt that the government's adult literacy policy, on the other hand, focused primarily on employment outcomes. The wānanga sought to develop learners' critical, cultural, and functional literacy skills. These were all viewed as equally important by the wānanga: "They all support each other in the emancipation and conscientisation of our students so that we can improve the lot of others and they can experience higher levels of wellbeing and freedom" (p. 436).

\section{Theories of ALN in a Prison Context}

Theorists (Collins, 1995; Muth, 2008; Reuss, 1999; Wilson, 2000) have identified competing approaches to literacy and learning within a prison context. In accordance with the previously discussed literature (Freire, 1970; Street, 2005b) the approaches include individual and cognitive perspectives of learning, and 
social and cultural understandings of learning. The specific perspective adopted by the prison institution has implications for the design and delivery of education programmes.

\section{Participatory literacy practices}

Collins (1995) classifies approaches to ALN learning in prison into four models: the medical model, the opportunities model, the moral deficiency model, and alternative or participatory literacy practices.

The medical model is based on theories of psychology. It conceptualises the prisoner as a "mental patient requiring treatment" (p. 51). Programmes based on this model utilise standardised learning materials and measure progress against steps or levels. The overall focus is on reducing recidivism. The model is thus similar to a functional approach to literacy (Barton \& Hamilton, 1998). The opportunities model assumes that prisoners have experienced gaps in their learning. Programmes based on this approach aim to provide prisoners with a broad range of educational opportunities in prison. The moral deficiency model assumes that prisoners have deficiencies in their moral reasoning. The focus of programmes is to improve prisoners' moral reasoning through liberal arts education (Collins, 1995).

While the first three models are deficit approaches which focus on ensuring people conform to socially accepted norms, alternative or participatory literacy practices are more learner-centred. Associated with the critical pedagogy of Freire (1970), they emphasise the transformative potential of education. Collins (1995) points out that although most prison education programmes are based on the medical and opportunities models, there is scope to adopt alternative literacy practices in prison because prison authorities are primarily concerned with ensuring prisoners are kept meaningfully occupied and safe from harm. There is some evidence that participatory literacy practices show promise in prison settings (Boudin, 1993; Kett, 2001).

\section{Third space theory}

Wilson $(2000,2002)$ differentiates between an autonomous or top-down model of prison literacy, which focuses on addressing individual skill deficits, and a social 
practices approach. She thus shares much in common with other social practices theorists (Papen, 2005). Prisoners' social or vernacular literacies include poetry, letter writing, graffiti, working out the length of time left to serve on one's sentence, and working out debts owed by other inmates (Wilson, 2007). Wilson points out that most prisoners do not recognise their informal literacy practices as forms of literacy, instead associating literacy with formal academic work.

Third space theory highlights how prisoners incorporate their personal literacies into the formal classroom context (Wilson, 2000, 2007). In the third space, education moves from being "a serious business, intent on raising standards, core curriculum and identifiable outcomes" to a place where teachers treat students as individuals, and prisoners can socialise with other inmates in a comfortable environment (Wilson, 2007, p. 199). This supports the maintenance of a social identity in prison. Teachers that value the social aspects of learning provide opportunities for third space classrooms.

\section{Social-constructivist approaches}

Muth (2008) contends that most literacy programmes in the US are based on a responsibility model that is functionalist in approach. Programmes based on this model adopt an individualised approach to instruction, teach decontextualised skills, and allow learners limited control over their own learning. These practices can result in learner disengagement and position student's own knowledge and experiences as inferior. The responsible model echoes Collin's (1995) medical model and Wilson's (2000) autonomous model of literacy.

Muth (2008) contrasts the responsibility model with social-constructivist approaches. Social-constructivist approaches involve a collaboration of two or more people exploring issues in a safe learning environment, and position the learner as expert. Related theories include a social practices approach to literacy, Freirean pedagogy, Knowle's (1994) theory of andragogy, and Wenger's (1999) communities of practice. Relevant programmes seek to build on learners' prior skills and knowledge, and encourage dialogue and critical reflection. Muth (2008) asserts that social-constructivist approaches may help to empower prisoners. However, some may initially demonstrate resistance to the methods involved due 
to fears that the information disclosed in the classroom may be used against them in some way.

\section{Education as empowerment}

Reuss (1999) echoes previous authors (Collins, 1995) in advocating a shift away from the current dominant paradigm of prison education, which focuses on recidivism outcomes, to a more empowering model. Her education for empowerment model emphasises personal choice and self-control, and focuses on personal development goals: "Successful classroom learning in a prison environment is... about enabling, about facilitating processes of achievement and personal development. It is therefore about fostering self-esteem" (pp. 122-123).

Although focusing more on personal development than social transformation, the education for empowerment model shares similarities with Freirean pedagogy (Freire, 1970). Reuss (1999) contends that the model can help to counter "the negative sense of self that many prisoners have assimilated as a result of sentencing and imprisonment" and promote pro social thinking (p. 126). A collaborative learning environment is viewed as a necessary means to this goal.

\section{Theoretical Framework}

This phenomenological study privileges the voices of participants while being grounded in a social practices approach and Māori views of literacy. These approaches were chosen because they accord with my personal belief that literacy and learning are strongly influenced by social and cultural factors. Moreover, I have come to recognise and value multiple literacies within society as a result of my personal experiences of tikanga and Te Reo Māori. While not a key paradigm in this study, I wish to acknowledge the value of a Freirean approach to literacy education. It was not used in this study as the focus was on understanding participants' personal experiences of Foundation Skills, rather than examining the link between literacy and social transformation.

\section{Previous Research Related to the Topic}

This section provides an outline of previous research related to the topic. Key themes in the literature are identified. 


\section{Background}

Internationally, there is limited research on prisoners' experiences of ALN education (see for example, Moeller, Day, \& Rivera, 2004; Tewksbury \& Stengal, 2006; Wright, 2001). In New Zealand, the few studies conducted on the topic have focused on ALN within vocational training and employment contexts (Artemiev, 2008; Bulliff \& Griffiths, 2012; Vaccarino, Comrie, Franklin, Sligo, \& Murray, 2009), the impact of teaching on prisoners' learning and understanding of mathematics (Bulliff \& Young-Loveridge, 2012), and the experiences of youth offenders (Parkhill \& Davey, 2012; Sutherland, 2006). The literature review failed to identify any studies exploring adult prisoners' experiences of the Foundation Skills programme or other intensive ALN programmes.

Most research related to the topic has focused on measuring prisoners' literacy and numeracy skills or investigated the relationship between literacy and recidivism. Findings suggest that prisoners tend to have lower ALN than the general population (Bowman, in press; US Department of Education, 2007; United Nations Educational, Scientific and Cultural Organization, 2012) and that prison education may help to reduce recidivism (Hawley et al., 2013). However, some authors (Clark \& Dugdale, 2008) caution that literacy education should be considered one element of effective rehabilitation, rather a means of reducing reoffending by itself. Other research relevant to the topic has been written from the perspective of teachers working in prison (Carr, 2000; Wright, 2008).

This study aims to fill a gap in the current literature through exploring prisoners' experiences of Foundations Skills, an intensive ALN programme delivered in New Zealand prisons. Themes from the available literature are presented in the next section to provide a background to the study.

\section{Theme 1: Debates on prisoner literacy}

There is a common assumption that low literacy causes crime, and that the majority of prisoners are functionally illiterate (Meatheringham et al., 2007). These beliefs have been influenced by research which shows that prisoners tend to have lower literacy and numeracy skills than the general population (Department of Corrections, 2009; US Department of Education, 2007; United Nations Educational, Scientific and Cultural Organization, 2012). 
The legitimacy of these beliefs has been challenged in recent years. Currently, there is no strong evidence to indicate that low literacy is predictive of criminal behaviour (Hawley et al., 2013). The causes of crime are complex, and cannot be attributed specifically to poor literacy (Clark and Dugdale, 2008). In addition, most prisoners are not 'functionally illiterate' (Black, 2001; Wilson, 2007). Standardised literacy and numeracy tests are often misleading as they only measure a narrow range of skills (Wilson, 2002). Most prisoners identified as functionally illiterate are able to manage adequately both in prison and outside through drawing on networks of support, a practice common amongst adults in general (Black, 2001). Many prisoners come from migrant and indigenous communities based largely on an oral literacy. Their level of literacy meets their basic needs (Meatheringham et al., 2007). In the New Zealand context, Artemiev's (2008) study of Literacy in Corrections Inmate Employment found that low literacy did not prevent prisoners from participating in two industries: the Print Shop and Central Kitchen.

While a deficit view of prisoner literacy has been challenged, it is generally agreed that prisoners have literacy difficulties, and that ALN education is an important element of rehabilitation (Clark \& Dugdale, 2008). What is important is how prisoners with literacy difficulties are positioned: adults with expertise or people with deficiencies?

\section{Theme 2: Competing views of prison education}

Prison authorities, the public, teachers and prisoners tend to have different views of the purposes and goals of prison education. Prison authorities generally view education as a means to reduce reoffending through improving prisoners' employment prospects on release (Reuss \& Wilson, 2000). On the other hand, the public tends to view prison education as a privilege rather than a right, "paid for by taxpayers whose money should be better spent" (Reuss, 1999, p. 114). In contrast, prison teachers emphasise the transformative nature of prison education (Boudin, 1995; Collins, 1995; Muth, 2008; Reuss, 1999). They view education as a means to empower prisoners to take greater control over their lives.

Research suggests that prisoners highly value prison education and gain a number of benefits from attending education programmes (Hughes, 2000; Moeller 
et al., 2004; Tewksbury \& Stengal, 2006; Wright, 2001). Prison education can be a "lifeline, a time-maker, a strategy for 'survival'...a means of keeping sane, a means of 'keeping in touch', achieving personal goals, therapeutic, a form of rehabilitation and even 'fun'" (Reuss, 1999, p. 122). This indicates that prison education has value beyond that of recidivism aims.

\section{Theme 3: Prisoners' previous experiences of schooling}

Research indicates that most prisoners with low literacy and numeracy have a history of negative or disrupted education experiences (Mageehon, 2003; Muth, 2008; Wilson, 2007). Similarly, studies in New Zealand with youth offenders show that most did not enjoy school, leading to low attendance, truancy, and disengagement from education (Parkhill \& Davey, 2012; Sutherland, 2006).

Early school leaving for prisoners is associated with family dysfunction, learning difficulties, structural failures within the mainstream education system, and social, economic and cultural disadvantage (Department of Corrections, 2009; Devine, 2007; Meatheringham et al., 2007). Artemiev's (2008) research found that prisoners and staff were aware that prisoners often had lower literacy and higher unemployment than other groups. They attributed these issues to social factors: "Participants talked about how these variables were closely linked to poor family support or inadequate role models; an inflexible education system; and glass ceilings and other barriers created by social class, social structure, and cultural capital" (p. 54). Nonetheless, study participants believed that individuals must take responsibility for changing their lives for the better.

Prisoners' early education experiences have a significant influence on their later self-perceptions. Wilson (2007) argues that "[Education] is an experience that stays with them, something by which they are judged, something by which they critique their own ability and something that goes on to influence the way they perceive themselves long after their involvement with the school system" (p. 191). In addition, prisoners' previous schooling experiences influence their attitudes towards learning. "Education providers simply cannot be too conscious of the negative images to education that many adults bring back with them to the learning process" (Kett, 2001, p. 64). Prisoners who are initially reluctant to participate in education can often be drawn back to learning given the right 
circumstances (Kett, 2001). Research in New Zealand suggests that negative early experiences of mathematics may have a long term impact on prisoners' self-esteem and career prospects (Bulliff \& Young-Loveridge, 2012). The authors identified factors that help to facilitate mathematics learning, such as developing a positive and supportive learning environment.

\section{Theme 4: Prisoners' views of literacy}

Prisoners often hold traditional views of literacy, viewing tidy writing, correct spelling, and proper grammar as evidence of academic success. Many do not see their practices outside of class (e.g., poetry writing, tattooing, and graffiti) as forms of literacy (Wilson, 2007). Some prisoners view literacy as a commodity which can be exchanged for other items of value in prison (Shethar, 1993). For other prisoners, literacy is associated with strong feelings of shame and embarrassment (Black, 1989; Boudin, 1993; Muth, 2008). This issue has also been identified in research with adult learners in the community (Tilley et al., 2007).

In the New Zealand context, Artemiev's (2008) research found that prisoners' associated literacy with learning and education. Higher literacy levels were linked with choice and opportunity: "Prisoners and staff in both industries tell me how literacy is a prerequisite for work, up-skilling, and learning in today's society and how those people with low literacy levels are disadvantaged" (p. 53). Literacy was measured against the individual's ability to understand or develop meaning from situations of relevance. Another study by Vaccarino et al. (2009) found that prisoners associated literacy with the ability to read and understand written texts, communicate meaning, use correct punctuation and grammar, and complete mathematical equations.

\section{Theme 5: Prisoners' motivations for attending ALN education}

Research indicates that prisoners attend ALN classes for a variety of reasons, such as to improve their skills, move onto further education and training, get a good job, socialise with other inmates, and spend time away from their cells (see for example Loewen, 1997; Searcy, 2008). Friends, family, children, and teachers can also influence prisoners' motivation to learn (Moeller et al., 2004). 
Prisoners' employment goals have a particularly strong influence on their decision to participate in learning and education. Research indicates that prisoners want to work in a job they enjoy after prison, and understood this required further training (Smiling-Hall \& Killacky, 2008). Another key motivation is spending time in a positive space inside prison. Many prisoners view prison classrooms as "sanctuaries" where they can express opinions and be listened to without being judged (Loewen, 1997, p. 10). Others view classes as an opportunity to socialise with other inmates and get help with personal literacy tasks (Wilson, 2007). In addition, a study of several European nations found that most prisoners involved in learning were motivated by the desire to do something "sensible and useful" with their time, and viewed prison education as a second chance to learn (Hawley et al., 2013, p. 11).

Black $(1991 ; 2001)$ devised a continuum of participatory behaviour for prisoners. At one end of the continuum, prisoners were motivated to attend ALN programmes for rational reasons (e.g., they perceived it would benefit them in some way). At the other end of the continuum, prisoners were motivated to attend classes for emotional reasons (e.g., they would only participate if they felt safe). In addition, he noted that the experience of imprisonment could trigger attitudinal changes, including an increased interest in learning. Likewise, Artemiev (2008) found that prisoners' participation in literacy education within prison-based employment "depends on whether it is safe or suitable to participate in literacy activities in each workplace; where there is an opportunity to participate... and whether prisoners are interested or see benefits in participating" (p. 57).

\section{Theme 6: Benefits of ALN programmes for prisoners}

Research shows that prison education, including ALN courses, may provide prisoners with a number of important benefits, some of which cannot be easily measured (Geraci, 2000, Taylor \& McAtee, 2003). Research with ALN learners in the community echoes these findings (Ivanic, Appleby, Hodge, Tusting, \& Barton, 2006; Tilley et al., 2007). 
To begin, studies suggest that participating in ALN programmes can result in measurable literacy and numeracy skill gains for prisoners (Department of Corrections, 2012; Shaw \& Berg, 2009; Shippin, 2008). Prison education may help to alleviate boredom, provide opportunities for socialisation, reduce involvement in illegal activities inside prison, enable prisoners to maintain communication with friends and family, and help individuals to manage the literacy demands of prison life (Searcy, 2008; Wilson, 2007). Black (2001) notes that "Just about every significant decision a prisoner makes involves writing a request to the prison authorities" (p. 3).

In addition, prison education has the potential to empower prisoners, and facilitate a process of personal change (see for instance Boudin, 1993; Collins, 1995; Kett, 2001; Reuss, 1999). Nelson Mandela (1918-2013), President of South Africa from 1994 to 1999, and a former political prisoner for over 27 years, asserted that "Education is the most powerful weapon which you can use to change the world" (Nelson Mandela Centre of Memory, 2012). For prison education to be transformative, it must be holistic, and focus on more than just employment skills (Hawley et al., 2013).

There are various ways in which prison education can be transformative. Education can change prisoners' personal attitudes and perceptions (Hawley et al., 2013). Through education, a prisoner may come see themselves as a 'learner', someone capable of achieving academically (Hughes, 2000; Shethar, 1993). In addition, education can help to improve decision making skills, enhance personal autonomy, reduce feelings of shame and fear, and build confidence (Muth, 2008; Wright, 2001). Gordon (2000), a prisoner who mentors other inmates, asserts "prison education has given me tremendous self-confidence and the belief that I have something worthwhile to offer society" (p. 169). He argues that prison education enables prisoners to see how "hard work and patience pays off in the long term. Many stop acting on impulse and start to think situations through" (p. 170).

Furthermore, ALN education can provide individuals with a sense of hope, and affirm their worth as members of the community (Boudin, 1993; Loewen, 1997). Pedro, a prisoner in Wright's (2001) study of prison literacy discourse, explains 
that "Education is like the mythical bird, the Phoenix, from out of the ashes and fire comes a fresh new beginning. Education gives us hope - hope for a better future for our children, our grandchildren, and our civilization as a whole" (p. 88).

Lastly, ALN education can increase prisoners' interest in learning and mentoring other inmates (Loewen, 1997). The Toe-by-Toe project in the UK (The Shannon Trust, 2012) and L.I.F.E. programme in the US (Video Verite, 2008) are examples of two peer mentoring programmes that have demonstrated success. Research in New Zealand has found that the opportunity to participate in learning and education in prison can increase engagement and enjoyment in learning (Artemiev, 2008; Parkhill \& Davey, 2012).

\section{Theme 7: Factors that support ALN learning in prison}

There is limited research on the features of effective ALN programmes in prison (Benseman, Sutton, \& Lander, 2005). Available research on the topic identifies several factors which support learning: providing opportunities for ALN learning, specific teacher behaviours and attitudes, learner-centred pedagogical approaches, learners' own motivation, and prison staff that support and value prison education (Moeller et al., 2004; Tewksbury \& Stengal, 2006; Honeycutt, 1995).

To begin, prisoners must have opportunities to access ALN courses for learning to occur. "Access to opportunity is critical in enabling learning", and can increase interest and motivation (Artemiev, 2008, p. 55). However, reports suggest that some prisoners may find it difficult to access prison education (Muñoz, 2009). The New Zealand Department of Corrections (2013a) has recently expanded access to ALN education to a wider range of prisoners as part of their goal to reduce recidivism by 25 percent by 2017 .

Secondly, specific teacher behaviours may support ALN learning in prison. Honeycutt (1995) found that "the teacher's instructional role was the most significant factor that these men identified as fundamental to quality education" (p. 8). Effective teachers maintain professional boundaries, share power with learners, treat students with respect, use evidence-based strategies, and are aware of release issues for prisoners (Moeller et al., 2004; Tewksbury \& Stengal, 
2006). In addition, they develop a safe space for learning based on a non-punitive teaching approach (Loewen, 1997; Taylor \& McAtee, 2003). These findings echo the broader ALN literature highlighting the importance of relationships for motivation and achievement, particularly for Māori learners (Benseman et al., 2005; Ivanic et al., 2006; May, 2009). As Tilley et al. (2006) argue, "people have to be seen holistically, as having needs to feel supported and valued...before other learning or change can take place" (p. 103).

Some authors contend that prison teachers should receive specialised training given the specific challenges of the role (Hollingsworth, 2008). France is an example of a country that has moved to increase the professionalism of prison teaching through job specific training (Hawley et al., 2013). While the role has challenges, it appears that many prison teachers gain immense satisfaction from their work (see for example Carr, 2000).

Thirdly, specific teaching pedagogies are linked to effective ALN education. Research suggests that learner-centred approaches which recognise the different learning styles, backgrounds and needs of prisoners and utilise meaningful contexts for learning can increase motivation and achievement (Glasgow, 1994, Searcy, 2008; Vacca, 2004). Similar findings are reported in the broader ALN research (Ivanic et al., 2006). For example, embedded literacy and numeracy approaches show promise in supporting vocational learning (Bulliff, 2013; Casey et al., 2006). Instructors report that prisoners on embedded courses achieve better academically, and become "better communicators, decision-makers and leaders of their own lives" (Bulliff et al., 2013, p. 1). In addition, a Freirean or participatory approach has demonstrated success with prisoners (Kett, 2001; Stino \& Palmer, 1999). Boudin (1993) argues that a participatory approach provides a "powerful hope" for prisoners as it is holistic, learner-centred, and emphasises personal development goals (p. 231).

Fourthly, prisoners' own commitment and motivation is associated with learning success. Research suggests that mandatory prison education programmes are counterproductive. Prisoners tend to view mandatory classes as "boring", "ineffective" and a "waste of time" and feel they take away control over their learning (Honeycutt, 1995, p. 8). Many prisoners believe that motivation for 
learning has to come from the individual. Frank, a prisoner in Artemiev's (2008) study of literacy within prison-based employment, says that "motivation for training...comes from a desire of "bettering yourself...[It's] up to each individual... How much drive you've got"' (p. 55). A model of prison education that empowers prisoners is thus "grounded in personal choice and self-control" (Reuss, 1999, p. 116).

Lastly, the prison environment has an important influence on student motivation and achievement. Having a safe and dedicated space for learning provides an environment conducive to learning (Loewen, 1997). Likewise, prison officers, the prison governor, and senior management all have "a vital role to play in promoting prison education and shaping the positive learning environment in which it can develop" (Hawley et al., 2013, p. 45). In addition, political support, collaboration between key stakeholders, and appropriate funding and resources are essential to effective provision.

\section{Theme 8: Barriers to ALN learning in prison}

Two types of barriers to prison education stand out from the literature: dispositional barriers (characteristics of the individual) and institutional barriers (factors related to the institution) (Hawley et al., 2013). Dispositional barriers include personal feelings of shame and embarrassment, low self esteem, lack of motivation, and perceiving literacy to be of little value (Black, 1991; Boudin, 1993; Muth, 2008). Similar barriers are identified in the broader ALN literature (Tilley et al., 2006). In addition, prisoners' fears related to personal disclosure may present barriers to teaching and learning (Boudin, 1993; Muth, 2008). Parkhill and Davey's (2012) study of youth offenders in New Zealand identified several dispositional barriers to learning: some learners had experienced past conflict, several of the youth vied for dominance, and the learners' diligence on tasks varied. Moreover, cooperative and competitive activities "were very challenging for the young men" (p. 11).

Institutional barriers to prison education include competing work demands, and waiting lists (Black, 1991), movements between prisons (Prisoners Education Trust et al., 2009), inadequate resources (Moeller et al., 2004), the absence of individualised instruction and lack of qualified teachers (Searcy, 2008). Others 
include using recidivism as a measure of programme success (Kerka, 1995; Reuss, 1999), mandatory attendance requirements (Honeycutt, 1995), problems with knowledge transfer (Reuss, 1999), and lack of access to IT due to its perceived security risks (Hawley et al., 2013). In short, "correctional education, programs, and services in correction institutions are often limited, antiquated, shorthanded, erratic, scarce, and lack key resources" (Searcy, 2008, p. 70).

Vernor Muñoz (2009), the Special Rapporteur on the Right to Education, identified a range of institutional barriers to learning in prison similar to those previously discussed. In addition, he highlighted that negative public attitudes towards crime and punishment are a key barrier to prison education. These attitudes are influenced by ill-informed media reporting, and result in a political apathy to prison education. Women and children in prison face additional barriers to education. Programmes for women tend to be of lower quality than those for men, and based on a limited range of traditional female roles, while programmes for children generally do not cater for their needs.

Lastly, policy makers and prison management can create barriers to learning through imposing their own views of education onto teachers and learners (Boudin, 1993; Wilson, 2007). This is echoed in the broader ALN research which highlights that teachers often struggle to balance the needs of learners and policy requirements, leading many to teach decontextualised skills (Ivanic et al., 2006). Likewise, the negative attitudes and behaviours of prison staff can create barriers to learning. Research shows that many prisoners feel that prison officers do not support prison education, and are more interested in security issues (Hawley et al., 2013). 


\section{Concluding Remarks}

This study is grounded in a social practices approach to literacy and Māori perspectives of literacy. Previous studies suggest that prisoners value prison education and find ALN programmes beneficial. In addition, the research highlights factors which support, and create barriers to, ALN learning in prison. However, research on prisoners' experiences of ALN learning is limited, particularly within the New Zealand context. This phenomenological study will address a gap in the literature by exploring prisoners' experiences of Foundation Skills, an intensive ALN programme delivered in New Zealand prisons. 


\section{CHAPTER 3: \\ Methodology}

This chapter describes the methods used for the study. Firstly, I provide a rationale for using qualitative research and a transcendental phenomenological research design. This is followed by a description of the specific methods and procedures used for the study.

\section{Rationale for Qualitative Research}

There are two key approaches within social science research: quantitative research and qualitative research. These approaches differ in terms of ontology (views about the nature of reality), epistemology (ideas about knowledge), axiology (assumptions about the place of values in research) and methodology (approaches to acquiring knowledge) (Morrow, 2007).

Quantitative research is based on a positivist approach that views scientific knowledge as the source of authoritative knowledge. It assumes that there is an objective reality outside of human consciousness (Laverty, 2003). Quantitative research usually aims to describe, predict, and explain behaviour through testing theories and hypotheses. Data are collected using methods that rely on observation and measurement, such as experiments. The data is typically analysed using software programmes to identify statistical relationships, and the findings are often generalised from the original sample to a wider population. Throughout the process of conducting the study, the researcher attempts to maintain an objective and detached position (Johnson \& Christensen, 2008).

Conversely, qualitative research is based on an interpretivist framework (Laverty, 2003). Interpretivism assumes that human behaviour cannot be studied using natural science methods, that reality is socially constructed, and that behaviour is malleable. Qualitative research aims to understand, explore, and describe human experience. Data are collected using methods that produce rich data, such as in-depth interviews. The data is then analysed to identify patterns or themes. The intention is not to generalise the findings but to develop a better understanding of 
human experience (Johnson \& Christensen, 2008). Researchers using this approach acknowledge their personal influence on the research process. They aim to develop collaborative relationships with research participants based on values such as "egalitarianism, cultural sensitivity, and respect" (Morrow, 2007, p. 218). In addition, they strive to ensure the trustworthiness of the research through accurately representing participants' views. In this study, a qualitative approach was chosen because the aim was to describe prisoners' experiences of ALN education.

\section{Rationale for Phenomenology}

There are a number of approaches within qualitative research including narrative research, grounded theory, ethnography, case study, and phenomenology (Creswell, 2007). The approach selected for this study was phenomenology because its primary focus is to describe the essence of people's experience of a phenomenon. Phenomenology has been used to explore a wide range of human experiences including guilt, midlife career change, insomnia, being left out, child abuse, and criminal victimization (Moustakas, 1994).

\section{Assumptions of phenomenology}

Phenomenology derives from German philosophy (Creswell, 2007). It rejects Cartesian dualism, which views subjects as separate from objects. Instead, phenomenology considers subjects and objects interdependent: "Reality of an object... is inextricably related to one's consciousness of it" (p. 59). The 'life-world' is used to describe a person's "inner world of consciousness and experience" (Johnson \& Christensen, 2008, p. 395). It includes a person's thoughts and feelings at any moment in time.

Phenomenology aims to understand and describe human lived experience, particularly taken for granted or common aspects of existence. At the same time, it acknowledges that people's experiences of a phenomenon will differ to some extent. In phenomenology, the common features of human experience are known as the "essence" of the experience (Moustakas, 1994). 
Given its philosophical assumptions, phenomenology is not compatible with experimental methods. Instead, it uses qualitative methods of inquiry. The most typical method of data collection is in-depth interviews, as these enable the researcher to develop a rich understanding of a people's experiences (Moustakas, 1994). However, other forms of data, such as visual and written texts, may be collected (Creswell, 2007). During phenomenological interviews, the researcher uses open-ended questions which allow for a rich range of responses and attempts to create an environment in which participants feel at ease. The participant is viewed as the expert and the researcher a learner.

\section{Types of phenomenology}

There are two major approaches within phenomenology: hermeneutic phenomenology and transcendental phenomenology. Both approaches share in common the key philosophical tenets of phenomenology. However, they differ in the methods used to understand human experience (Laverty, 2003).

\section{Hermeneutic phenomenology}

Hermeneutic phenomenology is associated with the German philosopher Martin Heidegger (1889-1976). A modern proponent of this approach is the educator Max van Manen (1990). Laverty (2003) describes hermeneutics as "the study of human cultural activity as texts with a view towards interpretation to find intended or expressed meanings" (p. 9). Texts included written or verbal communication, arts and music. Hermeneutic phenomenology is both descriptive and interpretive. Heidegger claimed that "to be human was to interpret" in that in every situation we encounter we make an interpretation based on our background (Laverty, 2003, p. 9). Consequently, hermeneutic phenomenology assumes that the researcher's thoughts and feelings cannot be separated from the study. Data analysis within hermeneutic phenomenology is based on a hermeneutic circle, in which the researcher cycles between "readings, reflective writing and interpretations" (Laverty, 2003, p. 21). It is therefore a process of co-constructing meaning: "the result of this process includes the self-interpreted constructions of the researcher and each participant, thus reflecting many constructions or multiple realities" (p. 21). 


\section{Transcendental phenomenology}

Transcendental phenomenology derives from the work of German philosopher Edmund Husserl (1859-1938), who is often called the father of phenomenology (Laverty, 2003). The American psychologist Clark Moustakas (1994) was a leading expert of this approach and has been instrumental in developing transcendental phenomenology as a research approach. Transcendental phenomenology is distinct from hermeneutic phenomenology (Creswell, 2007; Laverty, 2003). It focuses more on participant description and less on researcher interpretation. Furthermore, it emphasises Husserl's concept of Epoche (described below), and has systematic methods of data analysis (Creswell, 2007).

Transcendental phenomenology was chosen for this study because of its strengths as a research design. For example, the approach privileges the voices of participants and has systematic methods of data analysis which are helpful for new researchers (Moerer-Urdahl \& Creswell, 2004). I will return to the strengths and limitations of transcendental phenomenology shortly.

\section{Key stages of transcendental phenomenology}

There are four key stages of transcendental phenomenological analysis: Epoche, phenomenological reduction, imaginative variation, and synthesis (Moustakas, 1994). In the Epoche process, the researcher brackets or sets aside their thoughts and feelings from the research to view the phenomenon "as if for the first time" (Moustakas, 1994, p. 85). According to Moustakas (1994) it is an "opportunity for a fresh start, a new beginning, not being hampered by voices of the past that tell us the way things are or voices of the present that direct our thinking" (p. 85). The idea is to free ourselves from the influences of society and people close to us in order to allow fresh ideas and understandings to emerge. While Moustakas acknowledges that "the Epoche is rarely perfectly achieved", he argues that it can significantly reduce researcher bias (p.90).

Phenomenological reduction is the next stage of transcendental data analysis (Moustakas, 1994). The researcher develops a list of significant statements from the transcripts. These are initially viewed to be of equal value. Repetitive or overlapping statements are then removed. The remaining statements are the 
horizons or invariant constituents of the phenomenon (Moustakas, 1994). The horizons are then clustered into themes. Lastly, from the horizons and themes, the researcher writes a textural description that describes "what" the participants experienced in relation to the phenomenon (p. 97).

Following the phenomenological reduction process is imaginative variation. The researcher imagines all the "possible structural qualities or dynamics that evoke the textural qualities" (Moustakas, 1994, p. 181). Key themes include "time, space, relationship to self, to others; bodily concerns, causal or intentional structures" (p. 181). The researcher then writes a structural description of the participant's experiences which describes "how" the experience occurred.

The final process in the transcendental phenomenological model is synthesis. Using the textural and structural descriptions, the researcher develops a composite statement which describes the essence of the participants' experiences of the phenomenon. Moustakas (1994) notes that "the essences of any experience are never totally exhausted" as further research may produce new insights (p. 100). The essence statement therefore captures the essence of the experiences of a particular group of people at a particular time and place.

\section{Strengths and challenges of transcendental phenomenology}

Transcendental phenomenology has a number of strengths (Moerer-Urdahl \& Creswell, 2004). It can provide policy makers and practitioners with an understanding of the experiences of a group of people, has structured methods of data analysis, and privileges participant voice which may help to increase research trustworthiness. In addition, Moerer-Urdahl and Creswell contend that transcendental phenomenology eliminates the subject-object dichotomy "by allowing researchers to develop an objective "essence" through aggregating subjective experiences of a number of individuals" (p. 32).

On the other hand, there are challenges specific to transcendental phenomenology (Moerer-Urdahl \& Creswell, 2004). To begin, the researcher needs a good understanding of the philosophical assumptions and terminology of transcendental phenomenology to conduct the study. Unlike hermeneutic phenomenology, the approach gives limited attention to broader historical, 
cultural and social contexts and how these may influence the study. It may be difficult to describe the essences of participants' experiences of a phenomenon if the individuals come from highly disparate backgrounds. In addition, the Epoche process may be difficult to achieve as it seems impossible for a researcher to fully set aside all personal thoughts and feelings from a study. Despite these challenges, transcendental phenomenology provides researchers with a systematic method to explore human lived experience (Moerer-Urdahl \& Creswell, 2004).

\section{Research Methods and Procedures}

The following section outlines the methods and procedures for conducting the study. It describes the strategies used to ensure research trustworthiness, and discusses ethical and cultural issues related to the study.

\section{The Epoche process}

Epoche is the first stage involved in conducting a transcendental phenomenological study. The researcher sets aside any preconceived ideas or assumptions in order to view the phenomenon "as if for the first time" (Moustakas, 1994, p. 85). I began the Epoche process by thinking about my personal experiences of education. Like most of my participants, I left school early (at fifteen years old) with no formal qualifications. In my early twenties, I decided to enrol in a course at a local polytechnic. There, I met a teacher who encouraged me to continue on to university. Returning to education improved my confidence, changed my worldview, and enhanced my employment prospects. However, it also involved a great deal of hard work and sacrifices. Luckily, I had my whānau and various mentors to support me.

Next, I thought about my experiences as an ALN educator in prison. While a research assistant at university, I was involved in a study on prison education. I realised there was a need for volunteer literacy tutors in prison and decided to apply. Soon after, I completed an ALN teaching qualification to improve my teaching skills. My decision to become an ALN teacher was influenced by my personal experiences of education. Educated had changed my life for the better, and I wanted to help others in need of learning support. 
Lastly, I reflected on my experiences as a contract researcher for the Department of Corrections. The last project I was involved in explored the literacy and numeracy needs of the prison population. My role involved conducting assessments and interviewing prisoners at Rimutaka prison. I enjoyed the work and learned a great deal about the prison environment.

After reflecting on these experiences, I made a conscious decision to put them aside, suspend all judgement, and be open to what I would find. While, I found the bracketing process difficult to achieve entirely, it is my belief that it helped to reduce research imposition and ensure participants' concerns guided the study.

\section{Gaining research approval}

A key challenge for researchers working in prison settings is gaining approval for the research (Patenaude, 2004). Prison authorities must believe that the benefits of the research justify any disruptions to the prison routine. I outlined the potential benefits of the study in my research application to the Department of Corrections. My application was also guided by the Department's (n.d.-a) Effectiveness for Māori guide. After I had gained formal approval for my study (see Appendix A), I signed a research agreement with the Department. I was then allocated a contact person at Rimutaka prison to assist with practical aspects of the research (such as arranging interviews), and completed a Health and Safety induction at the prison.

\section{Participants}

The participants in this study were 10 male adult prisoners on the Foundation Skills programme at Rimutaka prison (see Appendix B for a description of each learner). All participants on the programme had an identified literacy and/or numeracy need based on screening by the Department of Corrections.

\section{Setting}

The setting for this study was Rimutaka prison in Upper $\mathrm{Hutt}^{6}$, one of New Zealand's largest prisons for minimum to high security male prisoners

\footnotetext{
${ }^{6}$ Permission was given by the Department of Corrections to name the prison involved in this study as participants' identities were kept confidential.
} 
(Department of Corrections, 2013d). The prison was chosen due to its close proximity and the fact it had a large number of Foundation Skills classes.

Rimutaka prison holds up to 942 prisoners and employs around 570 staff (Department of Corrections, 2013d). The prison is made up of various units, pods, and specialised units (n.d.-c). Units house a group of prisoners with similar security classifications or requirements. Pods are a special type of unit for prisoners with high-medium security classifications. Specialist units (e.g., Drug Treatment Units, Māori Focus Units, and Special Treatment Units) provide prisoners with intensive rehabilitation interventions within a therapeutic community environment (2013e).

At the time of the study, there were fifteen Foundation Skills classes spread among the various units and pods, each with a maximum of eight learners. Responsibility for the classes was divided between five teachers. The teachers were employed by Workforce Development, the organisation contracted by the Department of Corrections to deliver the programme.

My participants attended two two-hour classes each week. Lessons were conducted in the programmes room of the unit or pod. The room contained several large desks, plastic chairs, and a whiteboard. Some classrooms had posters and student work on the walls. Teachers brought with them the preapproved resources needed for each lesson (e.g., calculators, dictionaries, worksheets). Restrictions applied to resources considered a security risk, such as digital devices.

\section{Sampling method}

In phenomenological studies, the researcher typically interviews between 5-25 individuals to develop a rich understanding of the phenomenon under study (Polkinghorne, 1989). Ten participants were recruited for this study. The main sampling method chosen for the study was criterion sampling (also known as purposive sampling) (Creswell, 2007; Johnson \& Christensen, 2008). In criterion sampling, participants have to meet certain criteria to be included in a study. The researcher recruits individuals that match the study criteria until they have the required number of participants. This form of sampling is commonly used in 
phenomenological studies as all participants should have experience of the phenomenon under study. My criteria were as follows: Male sentenced prisoner; 18 years or older; currently attending Foundation Skills; a person I had not taught.

A further important consideration in this study was ensuring that Māori prisoners and learners from different foundation education classes were adequately represented in my study. Adequate representation of Māori learners was important given the disproportionate number of Māori prisoners with literacy and numeracy needs (Department of Corrections, 2009). In addition, I wanted to interview learners from a range of different Foundation Skills classes as their experiences may have differed in some way.

\section{Sampling strategies}

My initial strategy to recruit volunteers involved distributing information sheets to all prisoners attending Foundation Skills. I then planned to compile a list of volunteers, split the volunteers into Māori and non-Māori, and randomly select five of each. I anticipated that this would ensure adequate representation of Māori and learners from different classes in the study.

The strategy was not successful. My contact person at the prison asked the unit managers to distribute the information sheets to all the men in their unit who attended Foundation Skills. This resulted in only seven volunteers. Furthermore, none of the volunteers met the inclusion criteria for the study because they were not currently attending the programme.

After my first approach failed, I developed another plan to recruit volunteers. My contact person at the prison arranged with Workforce Development and the Principal Corrections Officers for me to visit the Foundation Skills classes to request volunteers. I visited 13 of 15 Foundation Skills classes. This had the added benefit that I was able to meet the teachers, informally observe classes ${ }^{7}$, and find out more about the programme. Afterwards, the teachers sent me a list of volunteers.

\footnotetext{
${ }^{7}$ In every class I visited, the teachers invited me to talk about the research at the beginning of the lesson. I was then allowed to remain in class and observe the lesson.
} 
My second strategy was successful and I ended up with fifty volunteers. Unfortunately, I was not able to compare the total number of volunteers against the total number of learners attending Foundation Skills at Rimutaka prison, as this information is not recorded. However, I was able to identify that the volunteers were evenly spread across the various Foundation Skills classes. In addition, the majority identified as Māori, which may partly reflect the high proportion of Māori on the programme.

Given the large number of Māori volunteers, I decided it was not necessary to split the volunteers by ethnicity. I put all the names of the volunteers into a bowl and asked my contact person at the prison to randomly select ten. As I had hoped, there was adequate representation of Māori learners (the total breakdown by ethnicity was seven Māori, two Pasifika and one Pākehā) and learners from different classes (8 from a total of 13). After going through the list of names, my contact person identified that one had moved prisons. Consequently, another name was selected from the bowl.

\section{Data collection method}

The primary data collection method used in phenomenological studies is in-depth interviews, as they allow researchers to develop a rich understanding of people's experiences (Moustakas, 1994). In-depth interviews were therefore chosen for this study. Dresler-Hawke and Vaccarino (2010) observe that there are specific ethical issues involved in using focus groups in prison. Furthermore, they note that prisoners may feel more comfortable and disclose more significant information in an interview than a focus group. I therefore decided to use one-toone interviews rather than focus groups in this study.

The Department of Corrections (n.d.-b) states that conducting interviews in a prison setting presents some level of risk to the researcher, although the likelihood of harm is low. The guidelines outline safe working practices for researchers working in prison. These include ensuring staff know where you are at all times, monitoring a prisoner's emotional state, and ensuring there are no objects in the room that could be used as a weapon. Furthermore, researchers and other specified visitors working in the pods must carry a Personal Duress Alarm (PDA) at all times. 


\section{The interview process}

Interviews were conducted within the learners' unit or pod. Staff within the various units made me feel welcome and provided a quiet space to conduct the interviews. Each interview took between 30 to 60 minutes. Whenever possible, I conducted interviews outside of class time so as not to disrupt learning.

Participants were provided with written and verbal information on the study at the beginning of the interview and given an opportunity to raise questions. Several learners checked to confirm the purpose of the research. Participants were then invited to sign a consent form stating that they agreed to take part in the research (see the section on Ethical Issues for more information). Subsequently, I asked the participants to describe their experiences of the Foundation Skills programme. Interviews explored the following topics: motivations for learning; learning activities and lesson topics; classroom relationships; impacts of the programme; ideas for potential improvements.

\section{Audio recording the interviews}

Permission was sought to audio record the interviews from the Department of Corrections and my participants. Prisoners may not want to be audio recorded in case the information is used against them (Patenaude, 2004). However, all the participants in this study agreed to be audio recorded. This is possibly because I explained the purpose of the audio recorder and indicated that the device could be turned off at any time. One interview was not audio recorded due to an error on my part. It is possible that using an audio recorder may have limited the information disclosed by my participants. For example, I turned the audio recorder off at the end of one interview. Upon seeing this, the participant recounted a story of a sensitive nature.

\section{Transcribing the interviews}

I had originally planned to transcribe the interviews myself. However, due to a prolonged period of illness, I had the interviews professionally transcribed. This enabled me to obtain feedback from my participants more quickly which was a priority in this study given that participants could transfer prisons or be released at any time. In addition, it enabled me to adhere to the original deadlines of the 
study. The transcriber was asked to sign a confidentiality agreement prior to receiving the tape recordings.

\section{Data analysis methods}

The method of data analysis used in this study was Creswell's (2007) simplified version of the Stevick-Colaizzi-Keen method outlined by Moustakas (1994). This approach streamlines the data analysis process while still providing a rich description of the phenomenon under study. It was considered an appropriate method for this study given time constraints. Creswell's approach contains the following procedures. Firstly, describe personal experiences of the phenomenon. Any personal biases or assumptions are set aside to focus on the participants' experiences. Secondly, identify significant statements from the transcripts. Initially, these statements are held to be of equal worth. Overlapping statements are then removed. Thirdly, cluster the significant statements into themes. Then, using the horizons and themes, develop a textural description of the phenomenon that describes "what" the participants' experienced. Fourthly, based on the textural features, construct a structural description that describes "how" the phenomenon was experienced. Lastly, synthesise the textural and structural descriptions into a statement that reflects the essences of the experience for the participants.

\section{Trustworthiness}

A phenomenological study demonstrates trustworthiness when it accurately captures participants' experiences (Laverty, 2003). To ensure trustworthiness in this study, I followed Creswell's (2007) standards for assessing the validity of a phenomenological study: Does the study discuss the key philosophical tenets of phenomenology? Is the phenomenon clearly described? Are phenomenological data analysis procedures used? Is there a unifying statement that describes the essence of the participants' experiences of the phenomenon? Does the researcher consider their personal influence on the study? Furthermore, I sought participants' feedback on my initial findings to ensure they adequately represented their experiences (Creswell, 2007). In addition, the Epoche process may have helped to reduce researcher imposition and increase the trustworthiness of the findings (Moustakas, 1994). 


\section{Ethical issues}

There are ethical issues involved in interviewing prisoners with literacy and numeracy difficulties, particularly from an informed consent perspective. Ethics approval for this project was granted by the Victoria University of Wellington Faculty of Education Ethics Committee (SEPP/2012/36 RM 19400). The research adheres to the New Zealand Association for Research in Education (2010) Ethical Guidelines and the Victoria University of Wellington (2007) Human Ethics Policy.

\section{Informed consent}

Research participants should be fully informed of the purpose of a study prior to their involvement, freely give their consent to participate without undue pressure, and be able to withdraw from the study at any time without penalty (NZARE, 2010). Informed consent was a particular concern in this study given that participants represented two vulnerable populations: (1) prisoners, and (2) adults with low literacy. Informed consent in this study was sought for the collection of data and the use of the data for a conference report, publication and thesis.

Informed consent is a fraught issue in prison settings, as prisoners may assume that they may be penalised if they do not participate in the study or assume they will receive some reward if they do participate (Department of Corrections, n.d.b). To manage this issue, I informed participants that they had the right to decline to take part in the study, and that there were no material rewards for participating. This was also outlined in the information sheet for the study.

Likewise, there are specific issues informed in gaining informed consent from adults with literacy and numeracy difficulties (Davis, Holcombe, Berkel, Pramanik, \& Divers, 1998). Adults with low literacy and numeracy skills may have problems understanding both written and oral information, but feel too embarrassed to ask for clarification. In addition, some may feel anxious about signing forms or talking to researchers.

Most research related to gaining consent from adults with poor literacy and numeracy derives from the field of medicine, wherein there are concerns that many people do not comprehend consent forms for medical research because 
they are too complex (Davis et al., 1998; Paasche-Orlow, 2012; Sudore et al., 2006; Winslow \& Hagan, 2003). The literature indicates that while simplifying consent forms can make them less intimidating and easier to read, it does not necessarily improve comprehension (Davis et al., 1998). Researchers should therefore use multiple strategies to ensure informed consent, such as providing both written and verbal information on the study, checking to ensure understanding, and translating forms into participants' native languages (Davis et al., 1998; Paasche-Orlow, 2012; Sudore et al., 2006, 2006; Winslow \& Hagan, 2003).

Given the preceding concerns, I developed simplified consent and information forms using the strategies outlined by Winslow and Hagan (2003) (see Appendix $C$ for a copy of these forms). In addition, I provided participants with a verbal explanation of the research and checked to see if they had any questions. Once I was satisfied the participants were fully informed about the research, they were invited to sign a consent form.

\section{Confidentiality}

To ensure confidentiality in this study, access to the data was restricted to myself, my supervisor, and the person who transcribed the interviews. All electronic information was password protected, and all hard copy documents were stored in a secure location. Pseudonyms were used to protect participants' privacy. Participants were given the option of choosing their own pseudonyms. Half the participants chose their own pseudonyms, while the others were assigned names. In addition, to protect the identity of both participants and teachers, I made all references to teachers included in the quotes gender neutral.

\section{Harmful effects}

People's experiences of ALN education and their previous experiences of learning are sensitive issues. There are many examples of participants recounting negative learning experiences with the potential to cause distress (see for example May, 2009; Rawiri, 2007; Tilley et al., 2007). I monitored participants' emotional state during the conduct of the interviews to ensure they were not experiencing undue stress. In addition, participants were given the contact details 
of the Victoria University Faculty of Education Ethics Committee should they have any concerns about the conduct of the research.

\section{Incentives and rewards}

Researchers must not bring anything into the prison for a prisoner, or take anything out of the prison for a prisoner (Department of Corrections, n.d.-b). Participants in this study were therefore not given any material incentives or rewards. While researchers cannot give physical goods to prisoners, they can provide different types of incentives. This may be "as simple as a break in the daily regime exchanged for insight into that same regime" (Patenaude, 2004, p. 76). I sang a waiata (song) at the end of the interview to thank each participant for their time and effort ${ }^{8}$. Participants appeared to appreciate this gesture. In addition, I hoped that participants would value the opportunity to reflect on their learning and have their views presented to prison authorities.

\section{Participant feedback}

I visited all the participants to gain their feedback on my initial findings. In most cases, the participant and I took turns to read the findings aloud. However, one participant asked for me to read the document to him. At the end of each section, I invited the participants to provide feedback on the contents. Overall, the participants were happy with the findings, and felt they accurately reflected their experiences of the programme. In addition, they elaborated on certain points, which helped to enrich the findings. During the feedback sessions, learners often talked about their progress on the programme and other activities they were currently involved $\mathrm{in}^{9}$.

\section{Cultural issues}

Māori are disproportionately represented within the prison population. Māori make up 14.5 percent of the general population; however, more than half of all

\footnotetext{
${ }^{8}$ I didn't do this for my first interview as I was too whakama (shy). However, I managed to overcome my shyness in subsequent interviews.

${ }^{9}$ Three participants were no longer on the programme as they were identified by a teacher as no longer having a relevant level of ALN need. One of these individuals had begun a trade training course in small motors. The other men wanted to do further training but were not on any courses.
} 
prisoners identify as Māori (Department of Corrections, 2009). Māori prisoners have greater literacy and numeracy needs than other prisoners, and are less likely to have any formal qualifications. Given these findings, it was imperative that Māori learners were represented in the study. Furthermore, researchers are required to consider how their project impacts on Māori prisoners (Department of Corrections, n.d.-a). Beyond these imperatives, I have a strong interest in culturally responsive research practices.

Strategies I used in this study were as follows: Seeking input from a senior Māori academic on the project; developing culturally responsive information and consent forms; ensuring strong representation of Māori in the study; exploring issues of culture in relation to learning; and using karakia (prayer) and waiata to open and close interviews.

The design of the information form was particularly important as it could influence prisoners' perceptions of the study. To make the form more culturally responsive, I used te reo Māori and Pasifika greetings, translated key terms into te reo Māori, included drawings of Māori and Pasifika learners ${ }^{10}$, and ended with a whakatauk ${ }^{11}$ (proverb).

\footnotetext{
${ }^{10}$ The drawing on the information form was designed by a friend. It was inspired by a photo taken by Alan Raymond for the How Do You Spell Murder documentary. Permission was sought from the author to use the photograph for this study.

${ }^{11}$ The whakatauki used on the information form was a modified version of one taken from the Massey University website (Massey University, 2010). The original version said: Whāia te mātauranga hei oranga mō koutou - Seek after learning for the sake of your wellbeing. With the help of my Māori advisor to the project I modified it to read: Whāia te mātauranga hei oranga mō koutou tatou - Seek after learning for the sake of your wellbeing and that of others, including your whānau and future generations. This statement better reflects my personal views on the goals of education.
} 


\section{Concluding Remarks}

Transcendental phenomenology was used in this study to explore prisoners' experiences of the Foundation Skills programme. The aim was to describe the essence of my participants' collective experiences of the programme. Data was collected through in-depth interviews and analysed using transcendental phenomenological data analysis. The chosen methodology allowed me to gain rich information on my participants' experiences (for more information, see Findings). Ethical and cultural issues specific to conducting research in a prison context were carefully managed throughout the study to ensure the research met best practice guidelines. 


\section{CHAPTER 4:}

\section{Findings}

This chapter outlines the main findings of the study. These are set out according to the following stages of transcendental phenomenological analysis: Phenomenological Reduction, Imaginative Variation, and Synthesis (Moustakas, 1994). Epoche, the first stage of analysis, was previously discussed in related to methods and procedures for conducting the study.

\section{Phenomenological Reduction}

Phenomenological reduction is the next stage of transcendental phenomenological analysis. The researcher develops a list of non-overlapping significant statements from the transcripts. These are the horizons of the phenomenon. The researcher then clusters the horizons into themes. Using the horizons and themes they then develop a textural description of the participants' experiences. This describes "what" the participants experienced in relation to the phenomenon (Moustakas, 1994, p. 98).

\section{Horizons}

I identified 79 non-overlapping significant statements from the transcripts (see Appendix D). At this stage, the statements were not grouped in any specific way. The horizons helped me to begin to understand my participants' experiences of ALN education in prison.

\section{Themes}

My analysis of the significant statements resulted in nine themes (see Appendix D). These are described below using verbatim statements from the prisoners. While the participants' experiences of ALN education in this study were very similar, some learners' voices are heard more often than others based on their tendency to elaborate on issues. Some learners talked extensively on issues raised, while others were more reticent. 


\section{Motivations for joining the programme}

The learners in this study all voluntarily attended Foundation Skills. The men's hopes and aspirations for a better life and a better future had a strong influence on their decision to reengage with education. They wanted to stay out of prison, contribute to their children's learning, and work in a job they truly enjoyed. In addition, two participants initially joined the programme to alleviate boredom and do something positive with their time in prison. While on the programme, these men developed their own goals and aspirations for the future.

\section{Parenting goals and aspirations}

Māori Tane Hard felt that improving his literacy and numeracy skills would lead to "a better existence" in the future. He wanted to stay out of prison and step up to his responsibilities as a father:

At the end of the day the most important thing for me is preparing myself for when I'm out there because I have to be a father when I get out there. It's my turn to step up. I want to step up. I don't want to carry on being a dickhead asshole the rest of my life. Otherwise what's the point in living? There's better things out there for me.

Similarly, Latu wanted to build a "new life" with his children and felt that education would contribute to this goal:

My goal is to be with my kids, to build a new life, start all over again. So if I really just have a go, give myself a chance, maybe I can get there, one day.

He spoke about the power of education to transform a person's life for the better:

Someone always told me, 'Look, don't forget that English is a power'. Like I say, if my reading and spelling they come, it's huge freedom; it's bigger than freedom that word, if I get that. 'Cos everything in my journey, all the paper you are going to go through all your life, computer technology, you're going to fill out all those forms, wherever you travel, everything go by reading and writing.

Tyson discovered he had literacy difficulties when he first came to prison and started reading books: "To be honest, I didn't really read much out on the outside 
but when I come in here I came across words that I couldn't pronounce properly or understand in some books". He joined the programme so he would be able to help his children when they came to him with questions:

...because you know having three kids I didn't want them to grow up to ask me questions I didn't know or have no clue about.

Grey wanted to improve his academic skills so he would be able to help educate his four year old son. He didn't want his son to "go down that track or horror of being an angry person":

...I can only just write letters at the moment to him and ask his mother to keep teaching him, keep reading to him...turn the TV off. Just keep giving him that...She's asked if he wanted a Playstation, he's four years old. And I went, 'Oh no there's a lot of stuff else out there better than just sitting around playing the Playstation all day'.

He was particularly interested in improving his English speaking skills so he could talk more like his friends:

I want to learn how speak properly, proper English. English is a good thing for me because I have got a lot of mates and they talk highly above me and that. They speak highly above me and I am still trapped in that, 'Yeah bro, fuck that, that's good shit', and really that's not good English.

Wirihana's son had recently had a daughter. He wanted to do Foundation Skills so he could help his granddaughter "build a good start with her life". He asked for extra worksheets from his teacher and posted them to her. He said that his son could put them away "until she was old enough to do them".

\section{Employment goals and aspirations}

Māori Tane Hard wanted to work as a diver once he left prison. He felt the skills he learned on the programme would help him in his role:

For me, the profession and the skills I go back to. Basic mathematics to fill out the PSI balances for the oxygen tanks for diving. Being able to calculate the weight balance to be able to sink properly. Helping out with navigation skills. Being able to read oxygen times, the depths you're diving at and how 
long you can dive at that depth for. Being able to know the temperature to wear the appropriate wetsuits.

Latu felt that improving his literacy and numeracy would help him to find a job once he left prison and manage everyday tasks easier:

I think it's better for myself... you know with looking for job, filling out forms, you know, for a license, or for how to use your money too, like income. 'Cos everything is paper. It's really important for me those things.

Trade training was a popular goal for many of the learners. Tyson wanted to do a mechanics' course after he left prison and believed the programme would help him achieve this goal:

...when I get out of prison I want to be a mechanic, I want to do a mechanic course and I'm pretty sure there's maths in the mechanics, so yeah I think it will help me.

Jaye was interested in carpentry: "Oh carpentry. Yeah that's why I want to know my maths". He was working to develop the literacy and numeracy skills needed to complete a course.

Grey realised he needed to "go back and learn the basics again" after failing a hospitality course outside of prison due to literacy and numeracy difficulties. He wanted to attempt the course again in future: "I would really like to go and give hospitality another shot, I guess that's a good goal for me to work towards when I get out, to see if I can do hospitality again". He was aware of the barriers to learning he faced upon release:

I will be basically really realistically getting out to nothing, so it's a bit of a debate on whether to do a course or maybe do some work first, so I can maintain a household, hold a house down and deal with those. Basically starting all over again.

Similarly, Zadok wanted to overcome barriers to employment created by poor literacy and numeracy skills: 
I found out over the years, I've had top jobs and yet sometimes l've been very embarrassed. I wouldn't know a key word or wasn't able to work a mathematical problem out as quickly as I should have, because I somehow had missed key foundations through bad health or just not paying attention which handicapped me at times in my promotions. When you've got to report to the managing director and say instead of saying 'there', going 'their', something like that. It's little things like that.

He recounted an incident that he found particularly embarrassing, where he was "told off" by his boss for making a mistake:

Especially, I was a manager and one of my bosses told me off about my English, it was really embarrassing. 'Cos he took my notes to a big top manager meeting and he was relying on me and I put a few things wrong and it made him look stupid. And I got really roasted.

Zadok felt that having good literacy and numeracy skills was important for anyone in employment:

So it is important your foundations of your English. For jobs of any kind. Even if you are self employed you still need to write a business letter and use the right English and say the right words.

\section{Making positive use of time in prison}

Two participants initially had a different reason for joining the programme. They saw the course as a means of keeping active and doing something positive with their time in prison.

Tāmati said that he had initially joined the programme out of boredom: "There was nothing else to do so I thought l'd put a bit of knowledge in my head". During his time on Foundation Skills, he had developed new goals and aspirations for the future: "I've had enough of jail. I think I've learned my lesson". He wanted to pass his skills onto his children, who were both in Kōhanga Reo (see Glossary). He said that he knew "a bit of the Māori side" for Kōhanga but was less familiar with English. In addition, he hoped to get a job in the fisheries or the army once he left prison. Tāmati took his lessons seriously and was annoyed when people came to class just to fool around: "All these months l've been with her/him I 
always seen a lot of people just going there just to get out of, get out of the unit. I try tell them, 'You know, come on man, just be here for our work', you know?"

Similarly, Māori went on the programme to keep himself busy and active in prison: "I think a lot of it was to keep my brain going, keep active in a lot of activities here and I think it does a lot of good for recapping when you get back out again". He wanted to pass his skills onto others: "I would like to pass my skills onto the younger generation and I think a lot of the older generation need it too". In addition, Māori felt the skills he learned in the course would be helpful for future employment roles.

\section{Classroom activities and routines}

The men completed a range of activities in class. They generally enjoyed the lesson topics and were happy with the level of difficulty of the work. Two learners indicated that on occasions they had found lessons "boring". However, on the whole, both looked forward to their weekly classes. The participants' classroom experiences were similar even though they were from a range of different classes and had different teachers.

\section{A typical day in class}

Lessons generally followed a similar format across the different Foundation Skills classes. Within the classroom, the men completed a range of activities including worksheets, games, and group discussions. The work was usually set as individual tasks that the learners helped each other with. In addition, the learners provided teachers with feedback on their learning and completed regular formal assessments.

Tyson described a typical day in class:

As soon as we come in s/he likes to play Hangman with us to figure out what we are learning today. Then s/he pretty much gets straight into it. S/he will put some examples on the board of what we will be doing and then hand us our worksheets to do. Yeah and once we get a certain picture of how to do it then s/he will hand out the worksheets for us to do on our own. We do them individually but we end up helping each other if people get stuck. 
Jaye said that his class always began with a warm up activity: "We do warm up papers...Just to what do you call it? Warm up our minds". After that, the learners played a literacy game:

We play the spelling game heaps with these cards. You get an amount of letters and you have to try and make a word out of it. Or we play this dictionary one. S/he'll give us a word and you try to find it and say the meaning. It's all good it's pretty helpful as well.

The participants in this study found class discussions particularly helpful. Tyson explained that "It's easier if we discuss it as a class because some people pick it up faster than others... If we discuss it together then...we find out where we have gone wrong". Māori Tane Hard said that class discussions helped build rapport between the learners: "Some of us have different levels of schooling and skills...class discussions help us to get on a familiar basis with each other". In addition, he joked that you could find out what people were good at and sit next to them!

The learners preferred to work collaboratively on tasks rather than alone. Grey said that he preferred to "team up" on tasks. Similarly, Tāmati felt the "whole point of the course" was to help each other. Through working collaboratively, learners were able to ask for help or provide help to someone who was struggling: "Some fullas in there they are very good writing and spelling but when they come to speaking English, they struggle and some of them I help them too...See that's the funny thing about it we all have different gifts", remarked Latu. In addition, working collaboratively on tasks built a sense of unity between the learners. Māori Tane Hard said that it was harder when the teacher gave them individual activities because "the class did not work together in a united way". Teachers actively encouraged the learners to help each other: "S/he prefers two heads is better than one", Tāmati noted. See the theme 'Peer relationships' for further discussion on collaborative learning practices.

Lessons usually ended with a feedback session in which the learners gave the teacher feedback on their learning and future learning goals: "S/he gives us this long sheet to fill out... what we need to improve on...feedback, this feedback sheet", explained Jaye. 
Sometimes, learners completed a formal assessment of learning in lieu of their usual class activities. Grey explained, "Teacher $X$ did one before Christmas and just wanted to know where we are all are at the moment and see if some have improved and some haven't". DOZIE\# also completed an assessment before Christmas which "came back three's for literacy and numeracy". This was similar to his last assessment. Consequently, he had been "kept on the programme". Tyson was aiming to achieve the highest score possible: "They told me that I'm doing pretty good...I think they're going to give me more assessments to do because like out of six for my writing I think I got four, so yeah just a couple off to get it perfect which is what I pretty much want".

Some learners asked their teacher for extra work to complete outside of class. Their teachers usually gave them worksheets to fill out. These were similar to the worksheets the learners completed in class. Zadok explained, "We get worksheets while we are there [in class] and we get worksheets for homework if you want to get more". Latu remarked, "Teacher $\mathrm{X}$ always gives me something for my homework and I take it back on Monday". Similarly, Māori said: "I get my book out and recap. I recap mostly every day actually. I've got a whole pile of it. I recap and I ask the tutor for homework".

\section{Lesson topics}

In general, the learners' enjoyed the lesson topics. They found them interesting and relevant to their present or future lives.

Jaye's class were currently focusing on stress management. One of their activities involved filling out a book on stress:

It's just to, when we get a ...sometimes we get stressed and it's to get out of the stress and those sort of things...lts helpful like when you go to work places and stuff if you're stressed out you can always think of the book that we learned.

Grey said his class had been "learning how to budget money, learning how to read taxes, tax income and GST". The class had also talked about the government supported superannuation scheme, Kiwisaver: "We were talking about our percentages and tax incomes off our Kiwisavers". He said that he had 
really enjoyed learning these topics because he didn't "really know too much about that sort of stuff" and it was "good to know". He remarked that most people in prison had "been brought up in a bit of [financial] problem".

Another numeracy-related topic had involved working out the cost of building a deck on a house:

I've learned how to, if we were to do a new decking on our house and buy all the materials, buy the planks of wood, the posting, the concreting and that, add all of them up on how much it would cost. To build the whole project. Sum it all up to the price.

Latu's class were also exploring business concepts. He was learning new words, such as 'business', and 'communication', and using these in sentences. Latu enjoyed the topic because he thought it was relevant to a work context:

So that's why I like how Teacher $X$ teaches us. Like, example, 'income' and 'business' and all those kind of things are really important to say. Like if you get a job or you have to wear a uniform. All those words come from the education.

The participants said that their teachers sometimes asked for their ideas on lesson topics. Zadok had suggested topics that would prepare the men for release. His teacher had integrated these into subsequent lessons:

I've suggested things that other guys thought was quite good that they hadn't thought of. So s/he's been able to do some research and get a good combination of the bread and butter subjects, as they call them, plus some new areas like talking about preparation when you leave for WINZ [see Glossary] and stuff like that and feelings about tenancy agreements and all that kind of stuff".

In addition, the learners' teachers asked the class what specific aspects of literacy and numeracy they wanted to work on. DOZIE\# said that his class had initially focused on punctuation. They had then worked on reading and writing, followed by multiplication and graphs. They were now looking at volume and area. 


\section{Level of difficulty of the work}

The learners were happy with the level of difficulty of the work. Grey felt the work was "not too hard...not too easy". Tyson enjoyed the challenging nature of the work:

They [the worksheets] are not too hard and they are not too easy, and there's also questions in there which will like, for us, hurt our minds. They are pretty good. Yeah it shows us they're not too easy.

If the learners found the work too difficult, they asked their teachers or peers for help, or worked on tasks collaboratively. Latu remarked: "Sometimes I say, 'Can you explain to me what that means'? S/he's good; they break it down". Occasionally, his teacher gave him easier work to complete: "When I say, 'Teacher X, this thing too hard for me', they give me another one". Māori Tane Hard explained, "Usually I just get help with it...or be a flash Māori and use the calculator!"

\section{Challenges}

Two learners indicated that on occasions they had found lessons "boring". However, overall, both enjoyed attending their weekly classes.

Grey said that when he first started the programme he didn't enjoy going to class because he wasn't interested in the topics and found the work difficult. However, after talking to his teacher about the issue the situation improved and he now looked forward to his weekly classes: "Now I take my books down and I ask, 'Oh is Foundations coming'?" (See 'Barriers to ALN learning in prison' for further information.)

Likewise, Tāmati enjoyed going to classes but said that the programme needed "a bit of an edge to it". He felt that more people would participate in the programme if lessons were "more fun". For Tāmati, this involved including more practical, hands on activities (for more information refer to 'Prisoners' overall feelings about the programme and suggestions for how it could be improved'). 


\section{Relationships between learners and teachers}

Learners and teachers had positive relationships with one another. When the men described their teachers they used words such as "patient", "friendly", "talented", "helpful", "always laughing", "humorous", "committed", "down to earth" .

DOZIE\# had a good relationship with his teacher: "Teacher X pushes us but we get there in the end...it's been mean as".

Jaye said, "Oh s/he's friendly and that you know; s/he helps us when, if we struggle. S/he'll go around and just ask us and say if we need help...Yeah s/he's always happy and that. S/he's always happy that s/he's teaching us".

Tyson remarked, "I feel happy with who is teaching us". He explained "S/he's not going too fast and s/he's not being too slow...S/he won't change the topic until s/he knows that we've all got it, which is pretty good". In addition, he said that his teacher was patient with the class:

S/he's not an asshole. Like if s/he is ready to work and we are still having our conversation about a totally different subject, s/he waits or get in on it with us. Like s/he's not impatient in making us work straight away. S/he's good... Everyone gets along with Teacher $X$.

He preferred his current teacher to a previous teacher who was "impatient" and wanted the class to "hurry up and start work". As a result, classes felt more like being at school: "S/he's alright... but everyone prefers Teacher X".

Māori talked about how people in his class showed respect for their teacher and one another: "They respect our teacher and they respect each other, we respect each other". In addition, he said that his teacher respected different cultures: "S/he will ask if s/he want to know the Māori word or Samoan word for that. S/he can pronounce them very good too. S/he's good in that manner". He compared his current teacher to a former teacher (at a different prison) who had less control over the class:

I think s/he was a bit too easy on some of them. S/he just let them get away with it and I noticed that and I said to her/him after the class, 'You're a bit easy on these fellas aren't you? S/he said I can't help it, I don't want know 
what to do with them. I says, 'Yeah, I know where they are from; they are from Unit $X$. They are the bad boys'. So s/he had to get rid two, three or four of them because of their attitude towards her/him. It was very abusive, swearing, right from the word go to finish, swearing.

Latu spoke highly of his teacher and listed their many positive qualities:

One thing I like about Teacher $X$, number one s/he's patient, number two s/he's humble and the other one s/he really has that passion. And s/he come on the level with us, you know the level of the inmate? And s/he always humour [sic], laughing.

In addition, he said his teacher was professional and "knew the boundaries": "We live in a different world here in the system, in the jail, and their job is really important to them too". Latu noted that his teacher offered the learners an opportunity to learn. However, it was up to the learner whether they took this or not: "You know s/he bring the fish to the table and s/he say, 'Ladies and gentlemen pick which fish you like'...S/he...can't tell you to pick this fish. It's your choice eh"?

Similarly, Grey remarked that learning came down to the individual and how much motivation they had:

I think it comes down to self motivation. If we really want to learn s/he gives that opportunity. It's up to us really. If we want to do better it's in our best interest to do it and learn and move on...S/he can't really force you can s/he? We're inmates. We're not really listening to a system anyway. I guess s/he can make a difference but that's how it goes. I guess it's your individual person if you want to help yourself.

Nevertheless, teachers could make a significant difference to learning. Tāmati said his teacher encouraged the learners even when they were feeling unmotivated to come to class:

Helpful, teacher just committed to, to teaching us really is not letting us have these days off. Like there's a lot of fellows that just want to not come and just pretend they're sick and s/he'll just say, 'No, no, no, he's coming, he's coming to course today. 
He recalled a time when he wanted to withdraw from the course but continued because of his teacher's encouragement:

S/he's helped me quite a bit...I had too much stuff on my mind, like family on the outside. I wasn't thinking properly about the course and l'd be in a bad mood and l'd go to course and just wouldn't work...and I thought if I was going to be like that I should just sign off. But then S/he had a talk with me and said, 'Oh come on [Tāmati], you've been with me for all these months'. So s/he sort of settled me down, and yeah, I just changed my attitude and just went back to work.

In addition, Tāmati liked his teachers' attitude towards the learners: "Like you know how people can get all smart and play up? S/he won't get all angry. S/he's really cool. S/he's really good towards us".

Zadok held his teacher in high regard. He described them as "multi-blessed and talented" with "awesome people skills". He said his teacher was quick to provide help, and went at a good pace:

S/he tends to have a knack of moving along at the right speed, not too fast or not too slow, which everyone appreciates because some teachers go like mad, and those that get left behind get really annoyed.

In addition, they helped the men to develop a sense of self- belief:

S/he always make people feel that they have contributed to the class by asking a personal question, it doesn't embarrass but basically just affirms people that they are all important in the class...S/he creates an ongoing increasing self belief that you can do it.

Like some of the other learners, Zadok said that his current teacher was better than his last. According to Zadok his previous Foundation Skills teacher (at a former prison) went too fast and said the "wrong thing". As a result, some of the learners got extremely frustrated and angry:

What happened over in Prison X, two or three just shut down...Yip, and were totally disobedient. A lot Teacher $X$ asked they just did the silent trick...I've been threatened...the teacher lost control. 
One participant in the study had slightly different views to that of the others. On our initial meeting, Māori Tane Hard said that he sometimes didn't get the help he needed from his teacher. However, on my second visit to check my findings with him, he informed me the issue had been resolved. This had been achieved through talking to his teacher about the problem. More information on this incident is presented later in the chapter (see 'Barriers to ALN learning in prison').

\section{Peer relationships}

Learners on the programme had positive relationships with one another. They preferred to work together on tasks rather than alone. Working collaboratively created a sense of unity among the learners and enabled someone struggling to be helped by others. In addition, the learners helped each other with tasks in their units such as writing letters or going over work completed in class. Conflicts between learners were rare, usually occurred when learners were first getting to know one another, and quickly resolved.

\section{Peer relationships in the classroom}

Tyson said that people in his class got "along real well": "Everyone just helps each other if we get stumped. No one puts anyone down. Everyone is just here to have a laugh pretty much and learn at the same time". Similarly, Jaye said, "We show each other respect...we encourage each other too".

Zadok said he was impressed at how well everyone in his class looked after one another:

\footnotetext{
I think the classroom environment has improved relationships tremendously because we are 'all in the same boat' as we say often. And l've been quite impressed at the, it's been amazing...the way a guy will help somebody who is really struggling and feeling thick as...No one is looked down on...People will be more willing to help and that's made me feel quite 'wow' you know that people, these evil men that get caught, look after each other quite well.
}

Tāmati said that the learners in his class encouraged one another, even when someone made a mistake: 
When they got an answer right, we'll just go, 'Shot bro' and give them a clap, and if they had gotten something wrong then we'll, you know, appreciate that they have tried. At least they gave it a go.

Latu said that the people in his class all knew "each other now" and had "fun together". His teacher encouraged the men to respect each other and not put other people down:

S/he's always telling us, 'Excuse me, we all see different; don't forget that'. You know we always have different multicultures in our class and this is a good thing about it, you know what I mean? Yeah we got Chinese, we've got Islander, we've got from America, Pakeha, you know what I mean, Māori. And it's really, really important...to respect other peoples.

In addition, he observed that the people in his class all had "different gifts". They used their different strengths to help one another with work.

Māori Tane Hard said that everyone in his class was at "different stages" of learning and assisted one another with tasks: "We all help each other...Some of us know a bit more than others so we just bring them up to date or explain the process of how to answer the question to them". In addition, he said that people had different preferred ways of learning:

We all have different learning capabilities and different learning ways and answering the question based on how we all learn differently is heaps easier. Some of us can learn by reading and some of us can't learn by reading as we don't understand what the words mean and some of us are just hands on practical.

Grey likewise observed that people in his class were at "different levels", but "none of them look at one another like he's better than the other". He said that the learners in his class were happy to help one another: "If someone needs a hand and somebody else knows how to do it, they just ask them, 'Can you help me with this?' They are more than happy to help, more than willing". 


\section{Peer support outside of class}

The learners sometimes helped each other with literacy and numeracy related tasks outside of class time.

Latu said that he often asked for help with "writing letters, things like that". Māori helped others who were having difficulty with their homework:

If they are having a problem with their mathematics they come into me, into my room and they hit me up and they bring it into me....In the unit... I show them how to break down the fractions and all that...the quickest way and the easiest way for them.

Similarly, Wirihana said that he sometimes helped others with homework as he liked to "help people who are not up to that level". In addition, he had assisted another learner with his story writing:

After school, he'd come to my cell and ask if me if he could borrow my dictionary because it's a thesaurus as well, so it give him heaps of meanings for one particular word....and he started writing these stories and was getting me to check them for punctuation, commas, you know? Stuff like that...'Cos he'd try to use the biggest words imaginable and really you only need a little one. So l'd help him and say, 'Nah, nah, that word is not used in this one, you can use it somewhere else'.

Zadok and a couple of other learners checked each other's' homework: "I often ask for extra homework and l've got a couple of guys who like doing extra homework as well so we often will double check each other's work".

\section{Challenges}

While relationships between learners were generally positive and supportive, occasionally there were instances of unease or conflict, usually when learners were first getting to know one another (see 'Barriers to ALN learning in prison' for further information).

Tyson recalled an incident that occurred shortly after he moved units and began attending a new class. He asked another learner for help with a question but the learner refused to help and swore at him. Tyson became angry and left the 
classroom to cool down. The next day, the learner apologised and relations between the two men improved. Tyson attributed the instance to the fact the man was quite competitive and liked to be the first to finish tasks.

Tāmati said that he was moved for a couple of months to a different unit and different Foundation Skills class. He was then transferred back to his previous unit and previous class. Tāmati preferred being back in his old class. He said it had a better "vibe" than the other class he attended. He attributed this to the fact he knew some of the learners in the class quite well:

I was with a couple of them when I was here the last time, and I sort of knew them straight away, but when I went to the other class I didn't know them. And it sort of...yeah it didn't feel right... it makes a big difference. I think that's what brings on the shyness too is 'cos we don't know these people.

\section{Improvements in learners' literacy and numeracy skills}

The majority of participants felt that the programme had helped them to improve their literacy and numeracy skills. The exception was one learner, who already had a high level of literacy and numeracy. Several of the learners remarked that other people had noticed an improvement in their skills.

Jaye said that the programme had helped him "heaps". For instance, his knowledge of times tables had improved, and he could read the Bible better than before:

It's helped me heaps. It's helped me learn more maths, more than I learned on the outside. My times tables are a bit better. I was already a good reader but just writing and figuring what the words mean are the things I was struggling with in English...It's helped me a lot. When I read my Bible I know what some of the words mean now...Gotta take those baby steps to improve.

Likewise, DOZIE\# felt that his literacy and numeracy had improved through the programme:

I know how to speed read and take down notes. Skimming and scanning... That was a new thing for me...And I guess really getting back to the old stuff which is taking down volume and areas. It's buzzing me out. And 
then running over graphs too. That's been a good one for me...some of us we done like how many cars you've owned. My one was about sale prices of properties here in Wellington for all the suburbs and that.

Grey remarked, "I can understand a lot more of the books I read now". He attributed this to the new reading strategies he had learned:

It's because I usually have my dictionary by my side and a word I don't know I'd look it up...and if not reading on and then you will usually fit the word into the sentence, on what they are talking about at the time.

In addition, he had learned how to convert a percentage reduction into a monetary value:

I've learned like percentages, learning how to how to go into a shop and there's like 30 percent. I've learned how to add the money up well now. And before I was like 30 percent, what's that? And I didn't really know or couldn't really do the maths behind doing the 30 percent.

Tāmati had likewise learned a range of new skills. When spelling unfamiliar words, he now sounded them out: "I just have a bit of a self talk to myself like how it sounds and then even if I get it wrong I got one letter in the wrong place or it's not there. Before I just used to straight guess it". He said that the skills he had learned were something he could continue learning outside of prison, and "use too on the outside".

Latu felt that he was "slowly" improving. However, he said that he still had "a long way to swim" and "a lot of work to do with education". His numeracy had improved to the point that he now did the same work as the other students: “Teacher X said, 'You are on their level now'. 'Cos before I was on the bottom level. So it was a big jump...I was 'wow'!"

Latu's literacy skills had also improved on the programme. He was learning how to write full sentences:

If I make a sentence with words I try to put it properly. Like for example...yesterday...those words 'children', 'business', 'baby', 'important', 'communication'. I had to make a sentence out of that...Like, 'Communication 
is really important'...For example, 'children', I could say, 'I have two boys and one girl. They are my children'. Business, well I could say, "My friend has got a business". But it's really not easy with business. I just had to try to make the sentence simple. So that's what I done yesterday.

In addition, he was learning how to break down unfamiliar words:

...A word I have learned is 'ing'. Like if you say 'looking', I'd be able to break that in half. 'Cos 'ing', cut him off. And I take him out and then I focus on the word now... And that's what Teacher $X$ said to me, 'Cut it in half, take him out, then try to focus now, spell those words now, the first words'.

He used a dictionary to help him with his literacy:

When I speak, whatever comes from my heart, I just go with that, and Teacher $X$ tries to correct that too. So I'm not saying it's always gonna be right but it's really good, it makes me feel good, when I grab the dictionary book. Because that's my main focus now. Is grab the dictionary book and let the teacher correct all my words.

Latu said that his boss in prison (Latu worked in a job in the prison) had noticed a change in him:

My boss said to me one day, 'You know [Latu], I got a good rugby team but there's a word to be really 'in there". And we are driving in the van, we are going to work, and I said to him, 'You are talking about the word commitment'. And he said, 'Mate, where's that word come from'? And we all had a laugh about it. And I said, 'Well, like you say, education...that's where the technology is'. So that's why I like how Teacher X teaches us; it's like we are going fishing.

Similarly, Māori Tane Hard thought that his literacy and numeracy had improved on the programme. He felt more "confident" about reading, and was happy with his progress in mathematics. In addition, his whānau had noticed an improvement in his writing:

They are actually quite surprised too. They're like, 'Bro you're freaking us out'. I'm like 'Why's that'? 'Half of these words we can't spell properly!'...Everyone has, my little brother, my mum and dad. And they are 
impressed because before I used to do layman's letters...real stink as conversations.

Zadok likewise felt that he had made significant gains in his literacy:

I've got a lot of clarification to do with English, which is one of my weakest subjects. Now it's getting stronger. I'm enjoying learning about adjectives and verbs... I spend more time in my dictionary than I ever have before in my whole life as a result of the Foundation course. It's given me a fresh desire to help myself and to read and to learn and to look up words I read in books which I never used to do. I'd read then forget. Now I read and write and look up and learn and practise putting them in a sentence.

One learner, Māori had slightly different views to the others. He said that he had already learned most of the skills "outside" (prison). However, he enjoyed attending Foundation Skills as he felt that it helped to keep his mind active.

\section{How learners used their new skills in prison}

The participants described how they had applied the skills they had learned on the programme inside prison. Examples included filling out P119s (see Glossary) reading (an important pastime within prison), and writing letters to friends and family. Through improving their literacy and numeracy skills, the learners were able to participate in a wider range of activities inside prison. In addition, learners gained more pleasure and understanding from existing activities.

DOZIE\# said he had used his new skills "in heaps of ways" including carving:

Like, with the graphs that helped me when I was doing the carving, because I didn't know how to draw so I was using block ways of doing it. So it kind of helped... When I watch TV, I try to work out the percentages and stuff...Writing letters to family.

As a result of the programme, Zadok had taken up playing Scrabble and doing crosswords:

I've started playing Scrabble as a result, so my word knowledge has increased...and l've caught a lot of people out saying wrong words in a 
Scrabble competition...By doing Foundations I am starting to do crosswords for the first time in my life.

In addition, he wrote more frequently to his friends and whānau:

My writing of letters has tremendously grown, the quality of them...And I'm enjoying writing letters which I never really used to do. I'd just do rough notes. Now I can write up to ten pages to my mother or friends. I can write because I can use better sentence construction but I also know how to speak out the words to spell them correctly.

In addition, he had written letters to various government agencies (such as the Justice Department, Legal Aid, Court of Appeal, and Health \& Disability Commissioner) about issues related to his sentence.

Māori Tane Hard had used his new skills to plan his workout sessions:

I suppose measurement is for measuring the distance you have to travel in order to accomplish the kilometres you want to run for workout sessions...its simple cause all we say is, 'Oh well five laps is a kilometre and a half'...We just added up all the metres.

In addition, he used his new skills to help plan his day:

I suppose maths is used in your whole day to like add up your times during the day. How much time you got to do a certain activity and then how much time is gonna be used while you do that activity. Scheduling times to be punctual when you have appointments to go to, classes to go to.

Several learners said they found it easier to fill in their P119s. Latu remarked, "The maths, it's helped me doing my shopping, P119s in here. Take the money off, you know? How much money you got left, all those kind of things". Tāmati explained, "When we get our P119s, I know a faster way of adding up how much it costs". Likewise, Tyson found filling out the form easier than before:

With our P119s, there're always decimal points in there; just with adding and moving a point...It's like something you fill out to get our food, like our chips and biscuits. How we have to add it, and where the decimal point goes when you finish. 
In addition, many participants found reading easier or more enjoyable. Jaye explained, "When I read my Bible I know what some of the words mean now". Tāmati explained that he could now "read like you're part of a character". Similarly, Grey said that reading now made more sense and was more "exciting":

When I am reading apostrophes and all that, knowing when to stop, then just read it and it sort of makes more sense. And I guess you can play it out like a role or read it so it's exciting...Like a movie; like how you would read a script.

However, Grey felt that the skills he had learned were more relevant to life outside of prison:

I can't really see where we have got a lot of doors open where we need to use this stuff. A lot is more to do with the outside world, which is good, because that's where we are lacking. We are lacking to stay out of this shit hole, and the more we know about, I guess the more education we have, the more experienced we are in way. We know what's right and what's wrong.

\section{Other effects of the programme}

The participants discussed other positive effects of the programme besides improved skills. The programme improved the men's self-worth and confidence and facilitated a process of personal change. In addition, it increased the men's interest and enjoyment in learning, enhanced their communication skills, and improved their thinking patterns. The learners' comments illustrate that attending ALN education had a powerful effect on the learners' attitudes and perceptions.

\section{Increased self-worth and confidence}

Wirihana said that attending the programme had reduced his sense of shame and isolation:

I have realised the commonness of not being able to read and write. It's not as unusual as I thought. I used to lie and say I left school in 5th form so they wouldn't look at me like I'm dumb.

Likewise, Latu remarked that he no longer felt embarrassed about his literacy and numeracy: 
It's making, it's relieving me, you know? Like I don't have to be embarrassing, you know what I mean? Before I was, 'Oh they were laughing at me', but now I say... 'No I don't care if you laugh at me, 'cos I'm going to be a better person':

He spoke about how the programme had improved his confidence:

When I get out, I won't feel, I won't have the fear any more. You know? I got the ability, competence, and you know, no more shy. Just go with the right attitude and just stay focused.

Similarly, Māori Tane Hard said that his confidence had improved through the programme:

I can read out loud with more confidence, without feeling embarrassed when you have to take a pause to carry on reading, and I can read almost any word now. But it's just learning the meaning of some of the words that I do read...In the past I used to find it difficult because I used to feel inadequate. I would have to miss half of the sentence and then try to come back to it.

Zadok explained that the programme had given him a sense of pride and personal accomplishment:

It's increased your hope level. It's increased your desire for self help and to get fresh pride in yourself...The pride that comes from achieving with effort and being able to be a positive influence on other inmates in my wing to consider doing a Foundation course. Because if someone who has got quite a good education background like myself can benefit from it greatly, well I believe the course helps anyone no matter what status...So it's a growing sense of self-improvement. So it's been quite positive. I've been quite amazed.

He felt that the programme could be "life changing" for men in prison through providing a sense of self-worth and hope:

A lot of guys, some guys have been here for years, and they are freaked to go outside. They don't know anything and they have got families that chop them off and they are just going to do something, end up back in here again. So that's why Foundations is important, because for me one of the most 
important things is getting some self-worth back into them, that they are valuable, there is some hope...so the best way to get hope is to get knowledge...this is a big one, this could be quite life changing for a guy in this situation. The benefits that come out of it can be huge, does that make sense?

\section{Increased interest and enjoyment in learning}

The majority of learners in the study had minimal education and no formal qualifications. Most had a history of negative learning experiences. The men talked about how the programme had increased their interest and enjoyment in learning, and given them an opportunity to learn.

Māori Tane Hard said that he had more "enthusiasm" to learn now. He noted that the programme had given him a "chance to learn": "When you succeed you feel a bit better". Similarly, Grey had developed a keen interest in learning:

Yeah I find it useful. I find it really useful. I ask to go to Foundations. Only because I have put my head into wanting to learn. Now I want to learn. When I started, when I first came in I was, 'Oh can you tell them I'm not coming today. I'm going to just stay in here and just gamble. l've got some chocolate bars on the table man" [laughs]. But now I take my books down and I ask, 'Oh is Foundations coming'? Because it's the only positive thing we're doing at the moment in here and that's it and doing our work outs.

Tyson remarked that he found the programme more enjoyable than school:

A lot different, like in here it's made it fun whereas in school it was pretty much dull and boring and I didn't really want to go, I wagged a lot, dropped out at 5th form. As soon as I could sign out I signed out. Just had no interest in it pretty much.

DOZIE\# likewise said that he had never liked maths back in school, but now enjoyed it: "Now numbers excite me". Jaye said the programme was "way better" than school: "I've learnt more in jail than I've learnt on the outside". Tāmati echoed this sentiment: “They've taught me so much stuff that I didn't know about". Wirihana remarked that the programme was a "vast improvement" on his 
previous experiences of education: "I feel like I want to keep learning with this group".

Several learners spoke about how their perceptions of the value of education had changed as they had grown older. Grey explained that he was "more mature now" and knew education was important. Latu said that when he was younger he just wanted to do his own thing and wasn't interested in school. However, he now felt education was highly important because it enabled people to manage the various tasks of daily life: "Now I think education is the key of life to me, well that's my opinion".

\section{Improved communication skills}

The programme helped to improve the prisoners' communication skills. Several individuals talked about how, as a result of their new writing skills, they could express themselves better in letters to their friends and family. This is a particularly significant finding given that letters are an important means of contact for prisoners and their whānau.

Māori Tane Hard explained, "Now that I can spell a bit better I am able to use words that I used to want to be able to use in order to express how I'm trying...to get what I'm trying to say across". Likewise, Tāmati said that his whānau were "shocked" at his letters: "It's making sense...It's not done by a primary kid". Zadok said that his friends and whānau enjoyed reading his letters more now: "I've had a lot of comments from my mother and my family and friends saying that they enjoy my letters a lot more now because of the new words I've been using". Grey felt the programme could help to improve communication within a relationship: "It can help you do even in a relationship more better because you know the more appropriate way to go about stuff. Learn more better educational wise. Learn better skills".

\section{Improved thinking patterns}

Māori Tane Hard was attending Foundation Skills and a Te Reo Māori course in prison. He described these as "positive things" in his life which gave him a "positive outlook". He chose to associate with other inmates in his unit that wanted to make positive changes in their lives: 
We have our brotherhood here, whakawhānaungatanga here. We socialise with those that want to move forward in their lives and those that don't want to move forward and just keep dabbling in their past, we don't want them in our association but we'll tautoko them any other way you want but if they want to stay where they are at, they stay there.

Similarly, Grey said that attending Foundation Skills had improved his thinking patterns:

I've been really just wanting to learn more and better my thinking patterns. I've been getting into a lot of self healing books which is really good because I'm pretty amazed by those self healing books. It's stuff I haven't been taught in life and if I'd known that stuff beforehand, maybe I wouldn't be in the predicament I'm in at the moment.

He passed what he had learned onto other inmates:

Usually my neighbours, that's what I give. I haven't got much to give you but what I do know that if you want to help yourself and succeed in the outside world and be that better man, then I do have good advice. And it's up to you, you can either take the good advice or you can just go round in circles. But most people know they are fucked when they come back to this hole. They sort of think, 'Oh I must be doing something wrong with where I'm at'.

Grey said that long term change required letting go of old habits, behaviours and attitudes:

We all want to be better role models for our children but you gotta look at yourself first and ask yourself where you want to be instead of always saying, 'I'm never going to be like my parents'. The more you say that, the more people I know who end up being like that. I think it's part of letting go of your past history, your upbringing and that...and not holding onto it. Because if you hold onto it every time you attempt to do a goal, you have a hiccup and it seems to brings you back down again...

He said that it was important to maintain a positive attitude when faced with obstacles: 
...Whereas you just have to be strong and every time you have a goal you have to look it in a positive way that it is meant to happen. Maybe I need to work on that little thing, eh? Work from there and move forward again. I guess it's part of training your mind to be more positive instead of negative. Sometimes when I hit ground bottom, I hit it and I probably dig myself a bigger hole than what I should be doing.

\section{Barriers to ALN learning in prison}

Participants' experiences of the Foundation Skills programme were generally very positive. However, some barriers to learning were identified. Firstly, over half the participants said that they, or other learners, sometimes had difficulty understanding the work. Secondly, specific learner attitudes and behaviours could interfere with learning. Other barriers included being uninterested in the topic, and experiencing personal issues related to significant others outside of prison. Learners who experienced these barriers often felt frustrated and angry about the issue, and some even wanted to leave the programme. However, all the men were able to successfully resolve the difficulties they were having, typically through talking to their teachers about the issue. This allowed them to continue to pursue their academic goals.

The following passages contain the stories of two participants - Grey and Māori Tane Hard. In the narratives, the learners discuss problems they experienced while on the programme and how these were resolved. Their stories were chosen for their rich description. Grey recalled that when he first began the programme he didn't understand or enjoy the work:

When I first came I had to tell [her/him] that some of the stuff I wasn't getting it and I was finding the classroom boring...because some of the places I didn't need help in. Well, realistically, I probably do need help in each one, but the ones that I know I struggle with the most are the main factors that I would like to address.

As a result, he didn't want to participate in class:

I guess when you know what you are doing you will sit down and learn the subject, when you don't know and you are getting confused everything goes 
out the door. Don't want to learn nothing...Because when I don't know what I'm doing I don't want to participate in it. Well I do, but I don't know how to.

Grey decided to talk to his teacher about the problem because he was getting angry in class: "I was getting stroppy and angry and I was coming in the class and I was like, 'Fuck you again, you idiot'. S/he's a good person". Grey's teacher listened to his concerns and the situation improved:

[It's] pretty good at the moment because I know what I am doing...S/he started teaching me stuff that I wanted to learn...So the best thing I got there was communication because I was getting grumpy and I wanted to leave the programme...lt really just comes down to the person and to let them know that you don't understand and if they could sit down and break it down for you.

Another barrier to learning identified by Grey was learners who dominate within the classroom:

I think when there's more the clever person that comes in he over-dominates some of the others...They are powering through all the work and we are like, 'Shhh man, let us do it', the ones who are finding it hard to do it. Just 'cos look, 'I can do this, I can do that'... well if you can do it what are you doing in here then? And then the ones who sort of go quiet is because we can't do it properly so let the one talking do all the talking...Where how I see it they don't get to learn because they go quiet.

Grey compared these experiences to being back at school:

It's like being at school. Like at school, the quiet one goes to the back of the class. And then, 'Ah fuck this shit'. Throw shit at the teacher and start a fight with that clever one over there [laughs]. That reality, that's how it is. If you don't know what they are speaking about you go all quiet and then you don't want to listen, you don't want to learn because you don't know what's going on.

Again, he observed that it was important to talk about problems so that they didn't become worse: "But I think the thing there is just let them know eh? 
...Communication. Communication is one of the worst fuck ups of human beings lives".

Māori Tane Hard shared similar sentiments to Grey. He observed that sometimes people had things on their minds (such as "Dear John" letters ${ }^{12}$ ), which could affect the other learners: "If one person's enthusiasm is not there at the time it rubs off on the rest of us". The teacher sometimes ended the class early if there was general lack of enthusiasm to learn.

Furthermore, on our initial meeting, Māori Tane Hard said that sometimes he and other people in his class had trouble understanding the work. This was exacerbated by several factors: the men often felt "insecure", "embarrassed" and "a bit shy" about asking for help; the teacher sometimes thought the learners already had the skills to do the work; and the teachers' explanations were often unclear:

S/he makes an effort to try to explain, but the way s/he explains things makes it a bit difficult to understand. I ask one question and s/he has 100 different ways to explain it. I've heard it from other students as well.... l like to ask a simple question and get a simple answer.

In addition, he felt that the teachers' approach to helping learners was not effective:

When an inmate approaches [her/him] and says he is having difficulty with something it would be helpful if s/he could take them aside and do it quietly with them so they don't feel dumb, and rather than expecting you to listen while there are a whole lot of guys talking. Makes it hard to focus.

On my second visit, Māori Tane Hard said the problem had been resolved. Similarly to Grey, this was accomplished through communicating about the issue. Firstly, together the learners addressed the stigma associated with asking for help:

\footnotetext{
${ }^{12}$ A letter written to a husband or boyfriend by his partner to inform him the relationship is over.
} 
We have all sort of come to an agreement where, It's okay bro, you don't need to feel that way because we are not all highly intelligent in here but we all have a certain skill that we can utilise in order to pull each other through.

In addition, the learners explained to their teacher that they needed more help with the work:

I think it was just being calm about it and just explaining to [her/him] that some of us left school and never got to actually learn some of the materials s/he is trying to teach us. So s/he just had to go into more details in order to be able to explain it to us.

Māori Tane Hard said the situation had improved "pretty hard out" and that his teacher now listened and let him explain what he was trying to say. He added that "when you can relate to the person teaching you, it makes learning more comfortable; your concentration is more there".

\section{Learners' overall feelings about the programme and suggestions for improvements}

Overall, participants' experiences of the Foundation Skills programme were extremely positive. They described the course as "very good, excellent", "useful", "life changing" and "positive". As a result of their experiences, the men said that they would recommend the programme to other inmates if they needed help with literacy and numeracy. Furthermore, the learners offered suggestions on how the programme could be improved. The following passages describe the participants' feelings about the programme in their own words.

\section{Comments on the programme}

Learners were happy with the Foundation Skills programme and looked forward to their weekly classes. Jaye stated "Foundation's all good". Māori Tane Hard remarked that he was "Loving it; helps me get back to a positive outlook on life". Likewise, Tyson said, "It's all good. I like it".

Māori was happy with the programme: "Very good, excellent. Very good with our teacher too. S/he's very very helpful...It helps me a lot whaea" (see Glossary). He 
felt that other inmates could benefit from the programme: "They need it...It would be an achievement to them, doing that Foundation".

Latu described the programme as "a spirit": It's a spirit that live on, you know? It's never dying. That's why I say it's like the wind. And the seed they just, with joy". He wanted to share what he had learned with others: "I get to say my story, you know, and share what I have learned. Yeah, 'cos I might be learning something from that too".

Zadok remarked, "It's been quite positive. I've been quite amazed". He stated that relationships were key to the programme: "I believe it's the synergy of being all together in one place, moving forward together with an excellent teacher, is probably the key l'd say". He said that the classroom environment helped to facilitate learning: "Being treated and respected in a decent facility has been a big help; where it has been warm and cosy and the group is not too big".

Wirihana thought the programme was much better than other courses he had done in prison: "I've been in jail a long time and done a lot of courses that were just like being in school but I didn't feel like I learnt anything, even though I got great marks". He continued to say, "You want to learn, but you don't want to learn like that". Wirihana thought a group learning environment was particularly good for people who found individual tuition "too overwhelming".

Like the other learners, Grey said that he was happy with the programme and would recommend it to other inmates that needed it: "Reckon it's an element of life education". He thought it was good that inmates now completed an intensive Foundation Skills course prior to undertaking T3 courses (see Glossary). Prior to the introduction of this initiative, Grey had attended a course in which the learners all failed because of literacy and numeracy issues:

They started to wonder why everyone had failed, so they looked back and seen what could help them improve on the next course...They done four weeks in here [Foundation Skills] before going down there to the Engineering, which was good, because it got everyone up to standards on what they were dealing with. When we got there it was like we were just thrown in the deep end. 
In addition, he said that the new T3 teacher was more responsive to learners' literacy and numeracy needs:

Before they were confused, calling our teacher a nerd. The teacher who they got down there now, s/he teaches in a shorter way. Whereas the other one was bloody confusing us more than anything, doing it their way, where other people up at their level would understand. We were going, 'No, no, you've gotta chop that stuff right down. We have mates who haven't been to school for the last 20 years or so, and you want to go and chuck us in the deep end'.

Incorporating literacy and numeracy education into T3 courses meant that prisoners were now better able to understand the work: "Now they've found the problem and they've dealt with it and now all those other people are sort of working, they understand it more".

\section{Suggestions for improvements}

Learners made various suggestions on how to improve the effectiveness of the existing programme. Māori suggested incorporating Te Reo Māori in lessons:

I strongly want my Te Reo. I would love to have Te Reo, if I could. I would like to see a change like that, even on paper, you know, as homework sort of a thing. Do it out, parts of the question, get our teacher to check it.

Latu felt it would be helpful to provide individual tuition alongside Foundation Skills for inmates (like himself) who needed it:

To be honest I'm really happy to where I am, but there's the main focus please I just hope I get a teacher...'Cos it's hard for Teacher $X$ to focus on me 'cos there's a lot of people in the class.

Zadok suggested updating the course materials for the course:

A lot of the initial appearance of content of the course comes across as a bit of old hat, outdated. I think it would be wise for people to look into the presentation of new materials, layout, artwork. Because if stuff is really old people just think, 'Oh they don't really care'.

Like Māori, he thought Te Reo Māori should be included in lessons: 
I think we should do some very basic Māori...to help people like me so that we can start getting our juices stirred up that, hey, this is quite good; there is a lot more to this.

In addition, Zadok felt that it was important for prison staff to show more support for the programme:

They need to show more support in their body language, attitudes and words they say that we aren't just a bunch of dumb asses going out to fill in time in the classroom. It's very important. Some guards can be overly aggressive and stroppy in the mornings.

He believed that prison officers played an important role in supporting education: "That has to be initiated by their OICs [see Glossary], going around and encouraging inmates to join up and then sometimes just sign them up and see how it goes anyhow".

Like Zadok, Wirihana felt that it was important for staff to support the programme: "There are a lot that are really good about it. But then you get others that go, 'How come you go to that dummies' class'?" In addition, Wirihana thought that if a person attending Foundation Skills was moved to a different unit, they should be able to attend classes in their new unit straight away: "I got moved and it wasn't my fault. I think I should have been put straight onto the programme instead of waiting. It's been three weeks so far". This issue is important given that prisoners are often moved from one unit or prison to another.

Grey felt the programme should have an end of year celebration like other courses at the prison:

We've never had a Christmas feed or something. They say they are going to do it for us. It's good to be, when they do that...Yeah, we're the only one that doesn't. We do pretty well in what we are doing. Well, when I see a classroom laughing and everyone communicating and everyone moving on in a subject all together I think that's something good. Something good to reward ourselves. 
In addition, he suggested awarding NZQA credits ${ }^{13}$ for work:

We used to get NZQA tickets...There should be a way of getting those tickets again...We could probably after doing the monthly stuff, what we've just done with gross, GST, tax and savings and budgeting, there's a NZQA course that's just come which we will probably all pass now because we've all worked on that subject for a month.

Lastly, Tāmati suggested that teachers could make lessons more "fun" by including more practical, hands-on activities:

Make it more fun I suppose. That will probably make people actually go...Like yeah, just needs a bit of an edge to it. Like if we're doing maths, make it fun. I don't know how to explain it. Make it like so people want to go, so you're not always at the desk. Like so you're always using things too. Not like doing maths and then using the calculator, not like that.

\section{Textual Description of Prisoners' Experiences of Foundation Skills}

In the final stage of phenomenological reduction, the researcher writes a textural description of the participants' experiences. This describes "what" the learners experienced in relation to the phenomenon (Moustakas, 1994, p. 98).

Participants' experiences of the Foundation Skills programme in this study were positive. All the participants valued the programme and looked forward to their weekly classes. They described the programme as "very good, excellent", "useful", and "life changing".

The men's hopes and aspirations for a better life and a better future had a significant influence on their decision to participate in learning and education. The men wanted to stay out of prison, support their children's learning, and work in a job they enjoyed. The participants were happy with the work they completed in class. They described it as "all good", "pretty cool", "helpful", "the right level of difficulty", "not too hard...and not too easy", and "relevant to outside". Two

${ }^{13}$ These were available to prisoners completing the National Certificate of Employment Skills (NCES), which was later replaced by Foundation Skills. 
participants indicated that occasionally they found lessons "boring". However, overall they both enjoyed attended classes.

Relationships between learners and teachers on the programme were positive. The participants described their teachers as "patient", "friendly", "talented", "helpful", "always laughing", "humorous", "committed" and "down to earth". Foundation Skills teachers involved the learners in the planning of their own learning. Learners had supportive relationships with one another. The participants preferred working collaboratively on tasks as this allowed people to help one another and created a sense of unity in the class. The men sometimes helped one another with literacy and numeracy related tasks outside of class time. Instances of conflict between learners were rare, usually occurred when learners were first getting to know one another, and were quickly resolved.

Sometimes participants encountered barriers to their learning, such as difficulties with the work or specific learner attitudes and behaviours. The men addressed problems in a positive manner, through talking to their teachers about the issue. In this way, problems were resolved and learners could continue to work towards their learning goals.

The participants talked about the benefits they had gained from attending the programme. One benefit identified was improved literacy and numeracy skills. The participants applied the new skills they had learned to various tasks inside prison, such as story writing, carving, letter writing, reading, P119s (see Glossary), planning workouts, and playing games. Some learners engaged in new activities as a result of the programme, while others gained more enjoyment from existing activities.

Other benefits identified by the participants included improved self-worth and confidence, increased interest and enjoyment in learning, enhanced communication skills, and improved thinking patterns. The participants' newfound interest in learning was significant given that most of the men had not enjoyed school and had minimal education. 
As a result of their experiences, the learners said that they would recommend the programme to other inmates who needed help with literacy and numeracy. In addition, they provided ideas on how to improve the effectiveness of the existing programme.

\section{Imaginative Variation}

Following the phenomenological reduction process is imaginative variation. The researcher imagines all the "possible structural qualities or dynamics that evoke the textural qualities" using universal themes such as "time, space, relationship to self, to others; bodily concerns, causal or intentional structures" (Moustakas, 1994, p. 181). Through the process of imaginative variation, the researcher develops a structural description which describes "how" the phenomenon was experienced by the participants.

\section{Structural Description of Prisoners' Experiences of Foundation Skills}

Two key factors precipitated learners' experiences of ALN education in this study. One was the circumstance of being in prison and having access to ALN training. The other was the individual's realisation of the benefits of improved literacy and numeracy skills for their current and future lives.

Time was another significant factor in my participants' experiences of ALN education. The men's current literacy and numeracy difficulties were influenced by their past experiences of education. Most of the participants had not enjoyed school, and had left formal education very early. The majority had been unemployed prior to prison. The men's goals and aspirations for a better life and a better future were a significant factor in their decision to improve themselves academically.

Another important factor in my participants' experiences of ALN education related to their self-perceptions and relationships with others. The men developed new attitudes and perceptions through attending the programme, such as increased self-worth and confidence, increased interest and enjoyment in learning, and improved thinking patterns. The programme also enhanced the men's 
communication skills, and provided an opportunity for them to develop pro-social relationships with other inmates and Foundation Skills teachers.

Space was a final important factor in the learners' experiences of ALN education. The men were inmates in one of New Zealand's largest prisons for minimum to high security prisoners. Within the prison environment, the men viewed the classroom as a positive space where people could have fun and learn at the same time, and take risks without fear of ridicule. Teachers helped to create a safe space for learning through attending to individual learning needs and encouraging respectful and supportive behaviour.

\section{Synthesis}

Synthesis is the final process of the transcendental phenomenological model. According to Moustakas (1994), this involves the "intuitive integration of the fundamental textural and structural descriptions into a unified statement of the essences of the experience of the phenomenon as a whole" (p. 100). The aim is for the reader to gain a sense of what it would be like to experience the phenomenon for themselves (Polkinghorne, 1989).

\section{Essence Statement}

The essence of participants' experiences of Foundation Skills was an increased interest and enjoyment in learning and education. The men all valued the programme and the opportunity to learn collaboratively. The participants' aspirations for a better life and a better future for themselves and their whānau had a significant influence on their decision to learn and participate in education. Identified benefits of the programme included improved literacy and numeracy skills, increased self-worth and confidence, greater interest and enjoyment in learning, enhanced communication skills, and improved thinking patterns. Positive classroom relationships and a supportive learning environment helped to facilitate learning success. Barriers to ALN learning were also identified; these included difficulties with the work and specific learner attitudes and behaviours. Effective communication between teachers and learners helped to resolve these barriers. As a result of their experiences, the learners said they would 
recommend the programme to other inmates who wanted to improve their literacy and numeracy skills.

\section{Concluding Remarks}

In this chapter, I described the main findings of this study on prisoners' experiences of Foundation Skills. The findings were outlined according to key transcendental phenomenological data analysis procedures: phenomenological reduction, imaginative variation and synthesis. For the learners in this study, participating in ALN education was an enjoyable and rewarding experience. The findings show that ALN education provides prisoners with benefits, and that the nature of the learning environment and quality of classroom relationships has an important influence on learning. 


\section{CHAPTER 5: \\ Discussion}

This chapter discusses the findings of the study in relation to previous research and theorisations of ALN education. This is followed by a description of the role of the researcher in the study.

\section{Key Findings}

This phenomenological study sought to improve knowledge of prisoners' experiences of Foundation Skills, an intensive ALN programme delivered in New Zealand prisons. The study found that the essence of the participants' experiences of Foundation Skills was an increased interest and enjoyment in learning and education. The men all valued the programme and the collaborative nature of the classroom. The men's goals and aspirations for a better future strongly influenced their decision to reengage with education. Identified benefits of the programme included improved literacy and numeracy skills, increased selfworth and confidence, greater interest and enjoyment in learning, enhanced communication skills, and improved thinking patterns. Positive classroom relationships and a supportive learning environment helped to facilitate successful learning. Barriers to ALN learning included difficulties with the work and specific learner attitudes and behaviours. These barriers were resolved through effective communication practices between teachers and learners. All the participants said they would recommend the programme to other inmates who wanted to improve their literacy and numeracy skills.

\section{Links to Prior Research}

This study echoes prior research highlighting the benefits of ALN education for prisoners (see for example Geraci, 2000, Taylor \& McAtee, 2003). For the learners in this study, these benefits included improved literacy and numeracy skills, increased self-worth and confidence, increased interest and enjoyment in learning, enhanced communication skills, and improved thinking patterns. 
Like previous studies (Hawley et al., 2013; Honeycutt, 1995; Loewen, 1997), the current research shows that supportive classroom relationships and a positive learning environment are important for motivation and achievement. The learners in this study got on well with their teachers and peers and enjoyed attending their weekly classes. Teachers contributed to these outcomes through attending to individual learning needs and through modelling and encouraging supportive behaviours.

In keeping with previous research (Hawley et al., 2013; Loewen, 1997), the study indicates that prison staff can influence learning. A few of the learners expressed disappointment that some prison staff appeared to reinforce the stigma associated with low literacy and numeracy. These learners felt that it was important for all prison staff to support the programme, as this could influence prisoners' perceptions and attitudes towards learning.

Similar to Boudin (1993) and Muth (2008), this study highlights the benefits of using collaborative learning approaches in prison. My participants' strong preference for working collaboratively on tasks may be partly attributed to cultural factors. The majority of my participants were Māori, and research shows that this group of learners tend to prefer collaborative learning approaches (May, 2009). In addition, relationships have been found to be central to learning success for Māori (see for example Penetito, 2010).

Lastly, this study adds to the prior literature by highlighting how prisoners use the skills they learned in class inside prison. For the learners in this study, activities included writing letters and stories, reading books, completing P119s, planning workouts, scheduling appointments, and carving. In addition, the research identifies barriers to ALN learning not previously highlighted in the literature, such as difficulties with the work and specific learner attitudes and behaviours. It shows that prisoners were able to overcome these barriers through effective communication practices.

\section{Links to Prior Theory}

While this study privileges the perspectives of prisoners in relation to ALN education, it is nonetheless useful to consider the research in the context of prior 
theorisations of ALN. This can help to identify whether or not the research supports existing theory. A social practices approach and Māori perspectives of literacy were used as the theoretical framework for this research. These theories influenced some of the questions I asked participants, as well as the structural description of the participants' experiences developed through the process of imaginative variation (Moustakas, 1994).

A central assumption of a social practices approach and Māori perspectives of literacy is that literacy is embedded within everyday social and cultural practices (Ivanic et al., 2006; Māori Adult Literacy Working Party, 2001; May, 2009). Relationships are an integral feature of these perspectives on literacy. Similarly, this study found that relationships have an important influence on ALN learning in prison. The study participants had developed supportive relationships with their teachers and peers, and this had a positive influence on their motivation and achievement. Some learners talked about how their motivation to learn had waned at certain points, but how they had continued due to the actions of their teachers. Others talked about how they enjoyed working with and helping other learners with tasks.

In addition, both approaches acknowledge the existence of multiple literacies (Street, 2005b; Zepke, 2011). The social practices approach makes an important distinction between dominant (formal) and vernacular (informal, everyday) literacies (Barton \& Hamilton, 1998). In this study, participants generally engaged in dominant literacies in the Foundation Skills classroom and vernacular literacies outside of class. In class, the men completed formal activities (e.g., worksheets, specific literacy games) designed to improve their literacy and numeracy skills and were regularly assessed using standardised tests. Conversely, the men engaged in a range of informal literacies in their units, such as writing letters to friends and family, story writing, reading for leisure, organising personal fitness sessions, filling in P119s, planning their day, playing games (e.g., Scrabble), and carving.

It appears that the classroom had potential to be viewed as a 'third space' for learning in that it provided opportunities for prisoners to incorporate their personal literacies (Wilson, 2000, 2007). For instance, Foundation Skills teachers 
responded to individual learning needs, and many learners viewed classes as an opportunity to socialise and work with other inmates within a positive environment. Furthermore, within the constraints of the prison classroom, teachers worked with learners to create meaningful contexts for learning by basing lessons on anticipated future tasks and learners' interests (e.g., managing a budget, filling out government applications). By these means, they attempted to make lessons relevant to the learners, as indicated by a social practices approach (Ivanic et al., 2006).

An interesting finding of this study was that participants' dominant literacies appeared to support their vernacular literacies. For example, one man used the mathematical skills he had learned in class to figure out how many times he would need to run around his unit to achieve his fitness goals. Another used his recently acquired mathematical knowledge to plot out squares for carving, and to work out the cost of sale items on TV. Others used their new found literacy skills to enhance their letter writing. Some of the men's families commented favourably on these changes. It appears that the role of dominant literacies in supporting people's vernacular literacies has been given limited attention in the literature to date (Barton \& Hamilton, 1998; Street, 2005b).

A further common feature of a social practices approach and Māori perspectives of literacy is that both emphasise the value of indigenous literacies in addition to English language literacy (Māori Adult Literacy Working Party, 2001; Potter et al., 2011; Rawiri, 2007; Street, 2005b). This study found that some participants (both Māori and Pākehā) wanted to learn Te Reo Māori as well as English literacy. One learner attended a Te Reo Māori course as well as Foundation Skills. He described these as "positive things" in his life, which gave him a "positive outlook". Others suggested it would be helpful to integrate some Te Reo Māori into existing Foundation Skills classes.

Lastly, both perspectives assume that adult learners have different motivations, backgrounds and strengths (Ivanic et al., 2006; May, 2009). Likewise, learners in this study talked about how people in their class had different "gifts". All the learners spoke positively about the collaborative learning environment in which they worked, as it allowed them to help one another by drawing on individual 
strengths. Furthermore, some learners talked about how working collaboratively created a sense of unity in the class, as well as a sense of moving forward together.

\section{Role of the Researcher}

This section examines the role of the researcher in the study. Three issues are discussed: (1) My personal influences on the study, (2) My experiences of establishing relationships in a prison context, and (3) My efforts to demonstrate reflexivity as a researcher.

\section{Personal influences on the study}

Qualitative researchers usually acknowledge the influence of their personal thoughts and feelings on the research (Morrow, 2007). This issue is somewhat fraught in transcendental phenomenology, as the Epoche process requires researchers to set aside their preconceptions and biases in order to view the phenomenon "as if for the first time" (Moustakas, 1994, p. 85). Moustakas (1994) acknowledges that the Epoche process may be difficult to achieve entirely, but notes it may help to reduce researcher bias. In conducting this research, I discovered that it was difficult to separate my thoughts and feelings from the study. For instance, my research interests, such as how culture influences learning, influenced some of the questions I asked participants. In addition, I had to be careful not to let my own interpretations overshadow my participants' descriptions. Nevertheless, I found transcendental phenomenology a useful approach through which to describe human experience and ensure participants voices are privileged in the research process.

\section{Establishing relationships in a prison setting}

Qualitative researchers attempt to develop collaborative relationships with research participants based on values such as equality, cultural awareness, and respect (Morrow, 2007). This helps to create a safe environment wherein people feel comfortable discussing personal experiences (Laverty, 2003). However, there are specific issues involved in developing relationships in a prison setting. The first of these relates to establishing rapport and trust. The other relates to staying safe and guarding against manipulation. 


\section{Developing rapport and trust}

It may be difficult for researchers to develop rapport in a prison setting. Patenaude (2004) states that "the three constituent groups within the prison (inmates, correctional staff, and administration) share a distrust for outside researchers because neither group can completely control what the latter will discover and report" (p. 79). His suggested guidelines for developing rapport include being respectful, expressing genuine interest in participants and the topic, accurately reporting participants' experiences, and protecting confidentiality.

Patenaude's (2004) guidelines helped me to develop positive relationships with both prison staff and prisoners. In addition, my prior knowledge of the prison environment helped. I knew there were often delays in prison, and prepared accordingly. This enabled me to conduct the research in a calm and relaxed manner. Further to this, I found that demonstrating culturally responsive research practices was important. Prisoners responded well to my use of Te Reo Māori and Pasifika greetings, as well as my knowledge and interest in tikanga Māori.

\section{Staying safe and avoiding manipulation}

Conducting interviews in a prison setting presents some level of physical risk to the researcher. The Department of Correction's (n.d.-b) Guidelines for researchers working with prisoners outlines rules and safe working practices. In addition, it has been suggested professionals working with prisoners need to guard against manipulation (see for example Allen \& Bosta, 1981; Tulloch, 2013). Manipulation may take various forms (e.g., requests for small items and flattering comments), is usually subtle to begin with, and can eventually lead to threats and requests for illegal goods. Good practice for professionals working in prison includes engaging in self-reflection, maintaining professionalism, seeking advice from staff, and adhering to security rules (Allen \& Bosta, 1981; Tulloch, 2013).

In this study, several participants made personal requests. While it is unlikely that the learners who made these requests intended to be manipulative, I was aware of the need to demonstrate caution. In one instance, a participant sent a letter to the university addressed to me. He requested that I write back with news of the study's progress. I sought advice from my contact person at the prison who advised me not to contact the prisoner directly. Instead, they asked that I email 
them a report of my progress which they could send to all units involved in the study.

\section{Demonstrating reflexivity}

I attempted to demonstrate reflexivity in this study through keeping a journal of my experiences. Writing down my thoughts and feelings helped me to reflect on my behaviour (e.g., What did I do well today? What could I have improved on?), and thereby improve my research practice.

\section{Concluding Remarks}

This chapter provided a summary of my research findings and considered these in relation to previous research and theory on the topic. My findings support previous research which shows that ALN education is beneficial for prisoners, and that the nature of the learning environment and classroom relationships has an important influence on learning. In addition, the study findings accord with a social practice approach and Māori views of literacy which highlight the existence and value of multi-literacies. Overall, this research highlighted for me how important it is establish positive relationships with participants and other key stakeholders involved in a study, as this has a significant influence on the research process and its outcomes. I also discovered the value of keeping a personal record of my experiences, as this enabled me to demonstrate reflexivity as a researcher and ultimately improve my research practice. 


\section{CHAPTER 6: \\ Conclusion}

This chapter summarises the main findings of the study. Implications of the study for policy and practice and suggestions for further research are identified.

\section{Summary}

This phenomenological study sought to address a gap in the current literature by exploring prisoners' experiences of Foundation Skills, an intensive ALN programme delivered in New Zealand prisons. The study found that the essence of the participants' experiences of Foundation Skills was an increased interest and enjoyment in learning and education. The men all valued the programme and the opportunity to learn collaboratively. The participants' aspirations for a better life and a better future for themselves and their whānau had a significant influence on their decision to reengage with education. Benefits of the programme, as well as factors that support or create barriers to learning were identified. As a result of their experiences, all the men said they would recommend the programme to other inmates who wanted to improve their literacy and numeracy skills.

The findings of the study are in keeping with previous research which shows that participating in ALN education is beneficial for prisoners (Department of Corrections, 2009; Jensen \& Reed, 2006; Vacca, 2004; Wilson, 2007). Further, it provides evidence that the quality of classroom relationships and the learning environment are important for student motivation and achievement (Hawley et al., 2013; Honeycutt, 1995; Loewen, 1997). The study adds to the literature by illustrating how prisoners use the skills they learn in class inside prison. In addition, it identifies barriers to ALN learning not previously highlighted in the literature, and potential solutions to these barriers.

The findings of the study were found to be generally consistent with a social practices approach and Māori perspectives of literacy (Barton \& Hamilton, 1998; Māori Adult Literacy Working Party, 2001; Rawiri, 2007; Street, 2005b). Namely, 
the research highlights that prisoners engage in a range of dominant and vernacular literacy practices within prison, develop their skills through both formal and informal processes of learning, and value deepening their knowledge of both English language literacy and Te Reo Māori.

\section{Implications}

The findings of this study indicate that intensive ALN programmes have potential to be an important element of rehabilitation given the benefits they provide to prisoners. Furthermore, teachers can help to create an environment conducive to learning through attending to individual learning needs, demonstrating respect and warmth towards learners, and encouraging learners to support and respect one another. Correctional staff can also support learning success through demonstrating supportive attitudes and behaviours towards learners involved in ALN education and challenging the stigma associated with low literacy and numeracy. Finally, given that most participants in this study wanted to learn both English language literacy and Te Reo Māori, it may be helpful to incorporate Māori views of literacy into the existing Foundation Skills programme. This aligns with the Department's best practice guidelines: "Best practice and working effectively with Māori means we need to involve and include Māori-centric support mechanisms throughout the offender's pathway" (Campbell \& More, 2013, p. 27). Integrating these findings into policy and practice may help to improve the effectiveness of existing ALN policies and programmes and thereby contribute to rehabilitation aims.

\section{Limitations of the Study}

This study explored a small group of prisoners' experiences of a specific ALN programme (Foundation Skills), at one prison, at one point of time. No claim was made to represent the experiences of other prisoners involved in ALN education, including those attending Foundation Skills. Furthermore, as based on one point in time, it cannot inform a longitudinal perspective. The essence statement in this study represents the experiences of my participants, as described by myself the researcher. Moustakas notes (1994) that the "essences of any experience are never totally exhausted" and further research may yield new insights (p. 100). 
A further limitation is that I did not specify a minimum participation time when establishing the inclusion criteria for the study. As a result, some of my participants were relatively new to the programme. Lastly, participants in phenomenological studies are typically asked several broad questions about their experiences of a phenomenon (Moustakas, 1994). However, I also asked my participants a number of specific questions related to my research interests (such as the role of culture in learning). In hindsight, it might have been helpful to have limited my range of questions to ensure that participants' concerns guided the discussion at all times.

\section{Limitations of Transcendental Phenomenology}

As a research approach, transcendental phenomenology has a number of strengths (Moerer-Urdahl \& Creswell, 2004). For example, it has systematic methods of data analysis that are helpful for new researchers, and emphases participant description rather than researcher interpretation. In saying that, I found the data analysis process in this approach overly rigid. For instance, themes began to emerge intuitively to me during the interview process, prior to identifying significant statements in my transcripts. Later analysis validated these initial themes. This suggests that it may be helpful to allow a degree of flexibility in data analysis while still adhering to the procedures outlined.

\section{Suggestions for Future Research}

This study provides insights into male prisoners' experiences of Foundation Skills. Future research could explore female prisoners' experiences of the programme. This may help to identify whether female prisoners have qualitatively different experiences and learning needs to that of men. Furthermore, it would be useful to explore the experiences of Foundation Skills teachers to identify elements of best practice and any issues requiring attention. In addition, it may be helpful to examine prisoners' transitions from Foundation Skills onto further education and training, perhaps using an ethnographic approach or case study research, to ascertain whether individuals are maximising their newly gained skills. Lastly, future research could examine the effectiveness of one-to-one literacy programmes in prison, such as Storybook Dads (Joyce, 2013), given the limited research on the topic. 
Continued advances in the quality of prison education depends on researchers being willing to accept the challenges of working in prison and prison authorities continuing to encourage and support such work. Qualitative research conducted by academics or other professionals can validate research conducted by prison staff and identify issues amendable to intervention (Patenaude, 2004). In addition, research with prisoners may help to improve existing education policies and programmes, and thereby support rehabilitation aims (Prisoners Education Trust et al., 2009; Reuss \& Wilson, 2000). This point is emphasised by Reuss (2000):

\footnotetext{
Researchers should be given every opportunity to develop methods of understanding what 'goes on' in prison classrooms because prisoner education is not to be lightly dismissed as something that simply keeps inmates 'occupied' for a few hours each day. It offers, potentially, a 'way forward' whilst doing time (p. 47).
}

\section{Concluding Remarks}

This study described prisoners' experiences of Foundation Skills, an intensive ALN programme delivered in New Zealand prisons. The findings highlight the value of ALN education for prisoners and the importance of supportive classroom relationships and a positive learning environment for learning. The research illustrates the benefits of listening to the voices of prisoners, who have much to contribute to prison education practice and policy.

\section{Ahakoa iti, he pounamu ${ }^{14}$}

Although it is small, it is of greenstone

\footnotetext{
${ }^{14}$ Māorilanguage.net (2014).
} 


\section{References}

Allen, B., \& Bosta, D. (1981). Games criminals play: How you can profit by knowing them. Petaluma, California: Rae John.

Artemiev, R. (2008). Literacy in corrections inmate employment (Unpublished Master's thesis). Massey University, NZ.

Barton, D., \& Hamilton, M. (1998). Local literacies: Reading and writing in one community. London: Routledge.

Behan, C. (2008). From outside to inside: Pedagogy within prison walls. In R. Wright (Ed.), In the borderlands: Learning to teach in prison and alternative settings (pp. 119-135). San Bernardino: California State University.

Benseman, J., Sutton, A., \& Lander, J. (2005). Foundation learning project: Working in the light of evidence, as well as aspiration. A literature review of the best available evidence about effective adult literacy, numeracy and language teaching. Auckland: Auckland UniServices.

Bishop, R., \& Berryman, M. (2006). Culture speaks: Cultural relationships and classroom learning. Wellington: Huia.

Black, S. (1989). Contextual issues and the functioning abilities of low literate prisoners. Australian Journal of Adult Education, 29(2), 8-15.

Black, S. (1991). Literacy and prisoners: Reassessing popular perceptions. Australian Journal for Adult Literacy Research and Practice, 2(1), 3-15.

Black, S. (2001). Prisoners, literacy practices and politics. Paper presented at the ACEA conference: Learning for new life: Not just doing time, Charles Stuart University, Bathurst. Retrieved from http://www.acea.org.au/Pages/2001 \%20papers.htm

Boudin, K. (1993). Participatory literacy education behind bars: AIDS opens the door. Harvard Educational Review, 63(2), 207-232.

Boudin, K. (1995). Critical thinking in a basic literacy program: A problem-solving model in corrections education. Journal of Correctional Education, 46(4), 141-144.

Bowman, J. (in press). Assessing the literacy and numeracy of prisoners. Practice - The New Zealand Corrections Journal.

Bulliff, R. (2013). Embedded literacy and numeracy. Practice - The New Zealand Corrections Journal, 1(1), 34-37.

Bulliff, R., \& Griffiths, E. (2012, June). The challenges and outcomes from implementing an embedded literacy and numeracy programme in a prisoner vocational training environment. Paper presented at The National Centre of Literacy and Numeracy for Adults Symposium and the Workplace Literacy and Numeracy Hui, Auckland University of Technology, NZ. Retrieved from www.literacyandnumeracyforadults.com/Resources/355684

Bulliff, R., \& Young-Loveridge, J. (2012, June). "Maths is no longer the ogre I thought it was": Reflecting on the impact of teaching on prison students' learning and understanding of mathematics. Paper presented at the 19th 
International Conference of Adults Learning Mathematics (ALM19), Auckland University of Technology, NZ.

Campbell, N., \& More, U. (2013). Working effectively with Māori. Practice - The New Zealand Corrections Journal, 1(1), 27-33.

Carr, B. (2000). Behind the fences: Case study of a literacy teacher in a prison classroom. Paper presented at the Annual Meeting of the American Educational Research Association, New Orleans, LA.

Casey, H., Cara, O., Eldred, J., Grief, S., Hodge, R., Ivanic, R., McNeil, B. (2006). "You wouldn't expect a maths teacher to teach plastering..." Embedding literacy, language and numeracy in post-16 vocational programmes - The impact on learning and achievement. London: National Research and Development Centre for Adult Literacy and Numeracy.

Clark, C., \& Dugdale, G. (2008). Literacy changes lives: The role of literacy in offending behaviour. London: National Literacy Trust.

Collins, M. (1995). Shades of the prison house: Adult literacy and the correctional ethos. In H. Davidson (Ed.), Schooling in a "total institution": Critical perspectives on prison education (pp. 49-63). Westport, CA: Bergin \& Garvey.

Council of Europe. (2013a). Convention for the protection of human rights and fundamental freedoms. Retrieved from http://conventions.coe.int/Treaty/ EN/Treaties/html/005.htm

Council of Europe. (2013b). Recommendation No. R (89) 12 of the Committee of Ministers to member states on education in prison. Retrieved from https://wcd.coe.int/ViewDoc.jsp?id=666811

Council of Europe. (2013c). Recommendation Rec (2006) 2 of the Committee of Ministers to member states on the European Prison Rules. Retrieved from https://wcd.coe.int/ViewDoc.jsp?id=955747

Creswell, J. (2007). Qualitative inquiry and research design: Choosing among five approaches (2nd ed.). Thousand Oaks, CA: Sage.

Davis, T., Holcombe, R., Berkel, H., Pramanik, S., \& Divers, S. (1998). Informed consent for clinical trials: A comparative study of standard versus simplified forms. Journal of the National Cancer Institute, 90(9), 668-674.

Department of Corrections. (n.d.-a). Effectiveness for Māori guide. Wellington: Author.

Department of Corrections. (n.d.-b). Guidelines for researchers working with prisoners. Wellington: Author.

Department of Corrections. (n.d.-c). Volunteer handbook. Wellington: Author

Department of Corrections. (2009). Prisoner skills and employment strategy 2009-2012. Wellington: Author.

Department of Corrections. (2012). Annual report: 1 July 2011-30 June 2012. Wellington: Author. Retrieved from http://www.corrections.govt.nz/resources /annual-reports5.html

Department of Corrections. (2013a). Corrections news Jan-Feb 2013.

Retrieved from http://www.corrections.govt.nz/resources/latest_news2

/corrections_news2.html 
Department of Corrections. (2013b). Education and training. Retrieved from http://www.corrections.govt.nz/working_with_offenders/prison_sentences/e mployment_and_support_programmes/education_and_training.html\#fsp

Department of Corrections. (2013c). Education, job skills, and working prisons. Retrieved from http://www.corrections.govt.nz/resources/education,_job_ skills,_and_working_prisons.html

Department of Corrections. (2013d). Rimutaka prison. Retrieved from http://www.corrections.govt.nz/about_us/contact_us/our_locations/rimutaka_ prison.html

Department of Corrections. (2013e). Specialist units. Retrieved from http://www.corrections.govt.nz/working_with_offenders/prison_sentences/e mployment_and_support_programmes/rehabilitation_programmes/specialist _units.html

Department of Corrections. (2013f). Statement of intent 2013-2016. Retrieved from http://www.corrections.govt.nz/resources/statement_of_intent_20132016.html

Devine, N. (2007). Prison education in Aotearoa New Zealand: From justice to corrections. New Zealand Annual Review of Education, 16, 55-72.

Devine, N. (2010). Prison education: A cautionary tale from the murky world of meta-analyses. In M. Thrupp \& R. Irwin (Eds.), Another decade of New Zealand education policy: Where to now? (pp. 119-129). Hamilton, New Zealand: Wilf Malcolm Institute of Educational Research.

Freire, P. (1970). Pedagogy of the oppressed. New York: Seabury.

Freire, P., \& Macedo, D. (1987). Literacy: Reading the word and the world. South Hadley, Massachusetts: Bergin \& Garvey.

Geraci, P. (2000). Reaching out the write way. Journal of Adolescent \& Adult Literacy, 43(7), 632-634.

Glasgow, J. (1994). Accommodating learning styles in prison writing classes. Journal of Reading, 38(3), 188-195.

Giroux, H. (1987). Introduction: Literacy and the pedagogy of political empowerment. In P. Freire \& D. Macedo (Eds.), Literacy: Reading the word \& the world. South Hadley, Massachusetts: Bergin \& Garvey.

Gordon, R. (2000). Prison education: One inmate's experience. In D. Wilson \& A. Reuss (Eds.), Prison(er) education: Stories of change and transformation (pp. 9-24). Winchester, UK: Waterside Press.

Hawley, J., Murphy, I., \& Souto-Otero, M. (2013). Prisoner education and training in Europe: Current state of play and challenges. Retrieved from http://ec.europa.eu/education/more-information/doc/prison_en.pdf

Hollingsworth, T. (2008). My story. In R. Wright (Ed.), In the borderlands: Learning to teach in prison and alternative settings (pp. 101-112). San Bernardino: California State University.

Holzer, H., Raphael, S., \& Stoll, M. (2003). Employment barriers facing exoffenders. New York: Urban Institute Re-entry Roundtable.

Honeycutt, R. (1995). A study of inmates' perceptions of an effective reading program. Journal of Correctional Education, 46(1), 6-9. 
Hughes, E. (2000). An inside view: Prisoners' letters on education. In D. Wilson \& A. Reuss (Eds.), Prison(er) education: Stories of change and transformation (pp. 138-157). Winchester, UK: Waterside Press.

Ivanic, R., Appleby, Y., Hodge, R., Tusting, K., \& Barton, D. (2006). Linking learning and everyday life: A social perspective on adult language, literacy and numeracy classes. London: National Research and Development Centre for Adult Literacy and Numeracy.

Jensen, E., \& Reed, G. (2006). Adult correctional education programs: An update on current status based on recent studies. Journal of Offender Rehabilitation, 44(1), 81-98.

Johnson, B., \& Christensen, L. (2008). Educational research: Quantitative, qualitative, and mixed approaches (3rd ed.). Thousands Oaks, California: Sage.

Joyce, D. (2013, December 11). Reading makes better prison dads. Hastings Mail, p. 9.

Kerehoma, C., Connor, J., Garrow, L., \& Young, C. (2013). Summary report: A model for successful Māori learners in workplace settings. Wellington: Ako Aotearoa.

Kerka, S. (1995). Prison literacy programs. Retrieved from http://www.ericdigests. org/1996-1/prison.htm

Kett, M. (2001). Literacy work in Wheatfield prison, Dublin, Ireland. Journal of Correctional Education, 52(2), 63-67.

Knowles, M. (1984). The adult learner: A neglected species (3rd ed.). Houston: Gulf.

Lane, C. (2010). Adult literacy and numeracy in New Zealand - Key factors. Wellington: Ministry of Education.

Laverty, S. (2003). Hermeneutic phenomenology and phenomenology: A comparison of historical and methodological considerations. International Journal of Qualitative Methods, 2(3), 1-29.

Lawes, E. (2009). Literacy and life skills for Pasifika adults: Results from the Adult Literacy and Life Skills (ALL) survey. Wellington: Ministry of Education.

Loewen, R. (1997). Transition to the community; Prison literacy programs and factors which lead to success in the community. Brandon, Manitoba: The John Howard Society.

Macfarlane, A. H. (2004). Kia hiwa ra! Listen to culture - Mãori students' plea to educators. Wellington: New Zealand Council for Educational Research.

Mageehon, A. (2003). Incarcerated women's educational experiences. Journal of Correctional Education, 54(4), 191-199.

Māori Adult Literacy Working Party. (2001). Te kawai ora: Reading the world, reading the word, being the world. Wellington, Author.

Māorilanguage.net. (2014). Phrase drills - Kīanga. Retrieved from http://www.maorilanguage.net/phrase_drills/phrase_drills_lesson.cfm?learni ngsubcategoryid $=16$ 
Massey University. (2010). Proverbs - Ngā whakataukī. Retrieved from http://www.massey.ac.nz/massey/maori/maori-language-month/korerokawhe/proverbs.cfm

May, S. (2009). Hangaia te mātāpuna o te mōhio: Learning foundations for Māori adults. Wellington: Ministry of Education.

Meatheringham, B., Snow, P., Powell, M., \& Fewster, M. (2007). Improving literacy for adult prisoners and offenders. In S. Dawe (Ed.), Vocational education and training for adult prisoners and offenders in Australia. Research readings (pp.177-196). Adelaide, South Australia: National Centre for Vocational Education Research.

Meyer, L. H., Penetito, W., Hynds, A., Savage, C., Hindle, R., \& Sleeter, C. (2010). Summary of the evaluation of Te Kotahitanga: 2004-2008. Wellington: Ministry of Education.

Ministry for Culture and Heritage. (2013). History of the Mãori language - Te wiki o te reo Māori. Retrieved from http://www.nzhistory.net.nz/culture/maorilanguage-week/history-of-the-maori-language

Ministry of Education. (2001). More than words: The New Zealand adult literacy strategy. Wellington: Author.

Ministry of Education. (2010). Tertiary education strategy 2010-15. Retrieved from http://www.minedu.govt.nz/NZEducation/EducationPolicies /TertiaryEducation/PolicyAndStrategy/TertiaryEducationStrategy.aspx

Ministry of Education. (2013). The Adult Literacy and Life Skills survey: Education, work and literacy. Retrieved from http://www.educationcounts. govt.nz/publications/series/ALL/33225/1

Moeller, M., Day, S., \& Rivera, B. (2004). How is education perceived on the inside?: A preliminary study of adult males in a correctional setting. Journal of Correctional Education, 55(1), 40-59.

Moerer-Urdahl, T., Creswell, J. (2004). Using transcendental phenomenology to explore the "ripple effect" in a leadership mentoring program. International Journal of Qualitative Methods, 3(2), 19-35.

Morrow, S. (2007). Qualitative research in counseling psychology: Conceptual foundations. The Counseling Psychologist, 35(2), 209-235.

Moustakas, C. (1994). Phenomenological research methods. Thousands Oaks, CA: Sage.

Muñoz, V. (2009). The right to education of persons in detention. Retrieved from http://www.ohchr.org/EN/lssues/Education/SREducation/Pages/AnnualRepo rts.aspx

Muth, B. (2008). Radical conversations: Part one social-constructivist methods in the ABE classroom. Journal of Correctional Education, 59(3), 261-281.

National Centre of Literacy and Numeracy for Adults. (2013). Assessment tool. Retrieved from http://www.literacyandnumeracyforadults.com/resources /356174

National Health Committee. (2010). Health in justice: Kia piki te ora, kia tika! Improving the health of prisoners and their families and whānau. Wellington: Ministry of Health. 
Nelson Mandela Centre of Memory. (2012). Lighting your way to a better future: Speech delivered by Mr N R Mandela at launch of Mindset Network, July 2003. Retrieved from http://db.nelsonmandela.org/speeches/pub_view.asp? pg=item\&ItemID=NMS909\&txtstr=powerful\%20weapon

New Zealand Association for Research in Education. (2010). NZARE ethical guidelines 2010. Retrieved from http://www.nzare.org.nz/researchethics.html

New Zealand Government. (2013). New advisory group to support prisoner education. Retrieved from http://www.beehive.govt.nz/release/new-advisorygroup-support-prisoner-education

New Zealand Qualifications Authority. (2013). Adult literacy and numeracy education. Retrieved from http://www.nzqa.govt.nz/providers-partners /assessment-and-moderation/assessment-of-standards/assessmentsupport-material/adult-literacy-and-numeracy-education

Office of the Ombudsman. (2005). Ombudsmen's investigation of the Department of Corrections in relation to the detention and treatment of prisoners.

Retrieved from http://www.ombudsman.parliament.nz/search?q= Ombudsmen\%E2\%80\%99s+investigation+of+the+Department+of+Correctio ns+in+relation+to+the+detention+and+treatment+of+prisoners

Paasche-Orlow, M. (2012). Low literacy and informed consent. Retrieved from http://www.bu.edu/irb/files/2012/05/Low-Literacy-and-Informed-Consent.pdf

Papen, U. (2005). Adult literacy as social practice more than skills. London: Routledge.

Parkhill, F., \& Davey, R. (2012). Report to accompany Beeby fellowship. Retrieved from http://www.nzcer.org.nz/system/files/BEEBY\%20Report $\% 20 \% 202012$.pdf

Parliamentary Counsel Office. (2013). Corrections Act 2004. Retrieved from http://www.legislation.govt.nz/act/public/2004/0050/latest/DLM 294849.html

Patenaude, A. (2004). No promises, but l'm willing to listen and tell what I hear: Conducting qualitative research among prison inmates and staff. The Prison Journal, 84, 69-91.

Penetito, W. (2010). What's Māori about Māori education? Wellington: Victoria University Press.

Polkinghorne, D. (1989). Phenomenological research methods. In R. Valle \& S. Halling (Eds.), Existential-phenomenological perspectives in psychology (pp. 41-60). New York: Plenum Press.

Potter, H., Taupo, K., Hutchings, J., McDowall, S., \& Isaacs, P. (2011). He whanau matau, He whanau ora: Maori adult literacy and whanau transformation. Wellington: New Zealand Council for Educational Research.

Prisoners Education Trust, Inside Time, \& RBE Consultancy Ltd. (2009). Brain cells: Listening to prisoner learners. London: Author.

Rawiri, A. (2007). Whanganui Iwi and adult literacy: Ngā Whiringa Muka. Indigenous community-based participatory adult literacy research. Paper presented at the International Adult Literacy Conference "The Power of 
And", Auckland, NZ. Retrieved from workbase.org.nz/media/41989/ 2.2paper.pdf

Reuss, A. (1999). Prison(er) education. The Howard Journal of Criminal Justice, 38(2), 113-127.

Reuss. A. (2000). The researcher's tale. In D. Wilson \& A. Reuss (Eds.), Prison(er) education: Stories of change and transformation (pp. 25-48). Winchester, UK: Waterside Press.

Reuss, A., \& Wilson, D. (2000). The way forward. In D. Wilson \& A. Reuss (Eds.), Prison(er) education: Stories of change and transformation (pp. 172-182). Winchester, UK: Waterside Press.

Satherley, P., \& Lawes, E. (2009). Literacy and lifeskills for Māori adults. Wellington: Ministry of Education.

Searcy, J. (2008). An assessment of correctional education, programs, and services on inmate recidivism (Unpublished doctoral dissertation). Northcentral University, Arizona.

Shaw, D. M., \& Berg, M. (2009). Jail participants actively study words. Journal of Correctional Education, 60(2), 100-119.

Shethar, A. (1993). Literacy and "empowerment"? A case study of literacy behind bars. Anthropology \& Education Quarterly, 24(4), 357-372.

Shippin, M. (2008). A pilot study of the efficacy of two adult basic literacy programs for incarcerated males. Journal of Correctional Education, 59(4), 339-347.

Smiling-Hall, R., \& Killacky, J. (2008). Correctional education from the perspective of the prisoner student. Journal of Correctional Education, 59(4), 301-320.

Social Exclusion Unit. (2002). Reducing re-offending by ex-prisoners. London: Author.

Spener, D. (1992). The Freirean approach to adult literacy education. Retrieved from http://www.cal.org/caela/esl_resources/digests/freireqa.html

Stino, Z., \& Palmer, B. (1999). Motivation women offenders through processbased writing in a literacy learning circle. Journal of Adolesent \& Adult Literacy, 43(3), 282-291.

Storybook Dads. (2013). Welcome to storybook dads. Retrieved from http://www.storybookdads.org.uk/

Street, B. (1995). Social literacies: Critical approaches to literacy development, ethnography, and education. New York: Longman.

Street, B. (2005a). The hidden dimensions of mathematical language and literacy. Language and Education, 19(2), 135-140.

Street, B. (2005b). Understanding and defining literacy: Paper commissioned for the EFA Global monitoring report. United Nations Educational, Scientific and Cultural Organization.

Sudore, R., Seth Landefeld, C., Williams, B., Barnes, D., Linquist, K., \& Schillinger, D. (2006). Use of a modified informed consent process among 
vulnerable patients: $A$ descriptive study. Retrieved from http://www.ncbi.nlm.nih.gov/pmc/articles/PMC1831581/

Sutherland, A. (2006). From classroom to prison cell: Young offenders' perception of their school experience (Unpublished doctoral dissertation). Victoria University of Wellington, NZ.

Tangaere, A. R. (1997). Māori human development learning theory. In P. Te Whaiti, A. McCarthy, \& M. Durie (Eds.), Mai i rangiatea: Māori wellbeing and development (pp. 46-59). Auckland: Auckland University Press.

Taylor, R., \& McAtee, R. (2003). Turning a new page to life and literacy. Journal of Adolescent \& Adult Literacy, 46(6), 476-480.

Te Ara - The Encyclopedia of New Zealand. (2014). Kōrero taiao sayings from nature. Retrieved from: http://www.teara.govt.nz/en/photograph/8891/themeanings-of-mountains

Te Kupenga Mātauranga o Taranaki. (2011). Summary report: Tahia te marae, tahia te wānanga. Wellington: Ako Aotearoa.

Te Puni Kōkiri. (2011). Te whakapiki i te pānui me te tatau mō ngā kaimahi Māori: Improving literacy and numeracy for the Māori workforce. Wellington: Author.

Tertiary Education Commission. (2008a). Learning progressions for adult literacy and numeracy: Background information. Wellington: Author.

Tertiary Education Commission. (2008b). Literacy, language and numeracy action plan 2008-2012. Wellington: Author.

Tertiary Education Commission. (2009). Strengthening literacy and numeracy: Theoretical framework. Retrieved from http://www.literacyandnumeracy foradults.com/resources/356028

Tertiary Education Commission. (2012). Adult literacy and numeracy implementation strategy. Retrieved from http://www.tec.govt.nz/TertiarySector/Tertiary-Education-Strategy/Literacy-and-Numeracy-ImplementationStrategy/

Tewksbury, R., \& Stengal, K. (2006). Assessing correctional education programs: The students' perspective. Journal of Correctional Education, 57(1), 13-25.

The Shannon Trust. (2012). Toe by toe: Prison project. Retrieved from http://www.toe-by-toe.co.uk/prison_project.html

Tilley, E., Sligo, F., Shearer, F., Comrie, M., Murray, N., Franklin, J., Watson, B. (2007). Voices: First-hand experiences of adult literacy learning and employment in Wanganui. Palmerston North: Massey University, Department of Communication \& Journalism.

Tulloch, B. (2013). Guarding against manipulation by criminal offenders. Retrieved from http://www.bfcsa.nsw.gov.au/_data/assets/pdf_file/0010 /223759/ Guarding-against-Manipulation-by-Criminal-Offenders.pdf

US Department of Education. (2007). Literacy behind bars: Results from the 2003 national assessment of adult literacy prison survey. Washington DC: Author.

United Nations. (2013). Basic principles for the treatment of prisoners. Retrieved from http://www.un.org/documents/ga/res/45/a45r111.htm 
United Nations Educational, Scientific and Cultural Organization. (2012). Prison family learning programme. Retrieved from http://www.unesco.org/uil/litbase /?menu $=9$ \&programme $=108$

United Nations Office on Drugs and Crime. (2013). Standard minimum rules for the treatment of prisoners. Retrieved from http://www.unodc.org/pdf/ criminal_justice/UN_Standard_Minimum_Rules_for_the_Treatment_of_Pris oners.pdf

Vacca, J. (2004). Educated prisoners are less likely to return to prison. Journal of Correctional Education, 55(4), 297-305.

Vaccarino, F., Comrie, M., Franklin, J., Sligo, F., \& Murray, N. (2009). A case study exploring the interconnections between literacy, employment and the library in Wanganui Prison's self-care units. Palmerston North: Massey University Department of Communication, Journalism and Marketing.

Victoria University of Wellington. (2007). Human ethics policy. Retrieved from http://www.victoria.ac.nz/fgr/current-phd/ethics

Video Verite. (2008). L.I.F.E. Program. Retrieved from http://www.videoverite.tv/ pages/film_hdysm_life-program.html

Wenger, E. (1999). Communities of practice. Learning, meaning, and identity. Cambridge: Cambridge University Press.

Wilson, A. (2000). There is no escape from third-space theory: Borderland discourse and the "in-between" literacies of prisons. In D. Barton, M. Hamilton, \& R. Ivanic (Eds.), Situated literacies: Reading and writing in context (pp. 54-69). London: Routledge.

Wilson, A. (2002, September). Reading a library - writing a book: Prisoners' day to day engagement with literacy/ies. Paper presented at the Annual Conference of the British Educational Research Association, University of Exeter, England.

Wilson, A. (2007). "I go to get away from the cockroaches": Educentricity and the politics of education in prisons. Journal of Correctional Education, 58(2), 185-203.

Winslow, E., \& Hagan, P. (2003). Making research forms more readable. Retrieved from http://www.ttuhsc.edu/research/hrpo/irb/files/informed_ consent_article.pdf

Workbase. (2002). Case study of te whare ako: The house of learning. Auckland: Author.

Wright, R. (2001). What the students are saying: Literacy as dwelling. Journal of Correctional Education, 52(2), 84-89.

Wright, R. (Ed.). (2008). In the borderlands: Learning to teach in prison and alternative settings. San Bernardino: California State University.

Zepke, N. (2011). Navigating between Māori particularism and economic universalism in adult literacy provision in Aotearoa New Zealand: The case of a Wānanga. Discourse: Studies in the Cultural Politics of Education, 32(3), 431-442. 


\section{Appendices}




\section{Appendix A: Approval for Research Proposal}

30 July 2012

Lana Moriarity

214a Onepu Road

Lyall Bay,

Wellington

Dear Lana

Approval for research proposal

I am pleased to advise that all permissions for your proposal Offenders' perspectives of literacy and numeracy education in prison within Aotearoa, New Zealand have been completed, and I am now able to give formal approval for your research. Please read and sign the enclosed Research Agreement, and return it in the prepaid envelope provided. A second copy is provided for your own records.

Please liaise with Carolina Lukkien in Strategic Analysis and Research at the Department of Corrections to discuss any logistical or administrative issues. Carolina can be contacted on 044603087 or email carolina.lukkien@corrections.govt.nz.

I wish you well with the research, and look forward to hearing of the outcomes.

Yours sincerely

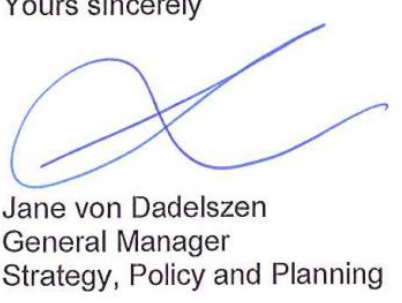

Enclosures Research agreement $x 2$ Postage paid envelope 


\section{Appendix B: Description of Participants}

The participants involved in the study are described below. The learners' names have been changed to protect confidentiality.

\section{Latu}

Latu, an older man of Pasifika descent, was located in a low-medium security unit. He was enthusiastic to be involved in the study and often used metaphors to convey his thoughts and feelings.

Latu was in a gang from an early age and never went to school. Nonetheless, he was fluent in several Pasifika languages. Latu wanted to improve his literacy and numeracy so that he could build a new life for himself and his children once released from prison. Two of his main goals were to get a driver licence and find a job.

Latu enjoyed attending Foundation Skills and liked his teacher. However, he wanted some additional one-to-one tuition, as he was below the level of the other learners in the class.

\section{Tāmati}

Tāmati, a young Māori man, was located in the pods. He was quietly spoken and sometimes asked me to clarify questions that he did not understand.

Tāmati left school at the age of 13, and went straight into seasonal work, picking potatoes and strawberries. He had a national certificate for coaching rugby and league and his learners licence. Prior to prison, he collected scrap metal and worked in forestry and farming. His goal was to work in the army or fisheries once he left prison.

Tāmati had been in two different Foundation Skills classes with the same teacher, with whom he had a good relationship. Although he didn't like the work to begin with, he made a commitment to keep going and started to enjoy it. Tāmati's goals were to pass his skills onto his children and get a good job when he left prison. 


\section{Māori}

Māori, who was in his late sixties, was located in a low risk unit. Māori was happy to share his experiences of Foundation Skills and used Te Reo intermittently throughout our interview.

Māori left school when he was 15 years old and then worked on the family farm. He then went into the army, and later worked as a truck driver. Māori was retired prior to prison.

Māori gained immense enjoyment from Foundation Skills and found his teacher very helpful. He enjoyed helping other inmates in his class and unit. Māori particularly valued the respect shown among people in his class. He wanted to do the programme to keep his mind active and recap topics that would be useful outside prison.

\section{Wirihana}

Wirihana identified as part Māori and part New Zealand European, and was in his early forties. Recently, he had transferred units and had requested to continue Foundation Skills in his new unit.

Wirihana left school at the age of 12 , and then worked on the family farm and mowed lawns for money. He first went to prison in his early twenties, and taught himself to read and write with the help of other inmates. While in prison, he had also completed qualifications in Farming, Production Management, Forestry, Joinery, Advanced Fencing, and Painting.

Wirihana enjoyed Foundation Skills and described his teacher as "down to earth". He said that one of the benefits of the programme was realising that he wasn't alone, and that other people had ALN difficulties. He enjoyed helping other learners in his class. Wirihana's long term goals were to complete more courses while in prison and support his granddaughter's education.

\section{Zadok}

Zadok, a Pākēha man in his late fifties, was housed in a low risk unit. He was very interested in the research and eager to share his experiences. 
Zadok left school after $6^{\text {th }}$ Form with University Entrance. He then worked in a range of professional roles and completed papers towards a commerce degree. However, over his career, Zadok had experienced literacy and numeracy difficulties that had led him to make mistakes and created barriers to promotions. He attributed these problems to disrupted schooling as a child.

Zadok gained great pleasure from attending Foundation Skills and spoke highly of his teacher and classmates. He took pride in his role as the class joker. Zadok sometimes missed classes due to poor health, but another learner helped to keep him up to date by bringing him homework.

\section{Tyson}

Tyson was a young Māori man located in the pods. He was quietly spoken and disclosed rich, detailed information on his experiences.

Tyson left school in $5^{\text {th }}$ Form and then began a mechanics course. However, he was unable to complete the course as it was cancelled. He had no formal qualifications and was unemployed prior to prison.

Tyson had been on Foundation Skills for around one month. He enjoyed the programme and liked his teacher. Tyson wanted to do the course so that he could do a mechanics course outside prison, and help his three young children with learning. Tyson had also registered for a small motors course, but was unsure if he would get to start or finish it before he left prison.

\section{DOZIE\#}

DOZIE\# was a young Māori man in one of the specialist units. He was quiet and polite, and gave brief replies to my questions.

After leaving school at aged 14, DOZIE\# worked in the fisheries, and then as a general labourer. He had no qualifications and was unemployed prior to prison.

DOZIE\# was happy with Foundation Skills and with his teacher. He had learned a range of skills on the course, which he had applied to various activities inside prison, such as watching television (e.g., working out the discount price on sale 
items) and carving. His future goal was to transfer to a prison near his home and slowly reintegrate back into the community and with his partner.

Jaye

Jaye, a young man of Pasifika descent, was in a specialist unit of the prison. He appeared shy, and often looked down when speaking.

Jaye was 16 years old when he left school. He worked in furniture removal up until he went to prison. He had no formal qualifications.

Jaye liked going to Foundation Skills and got on well with his teacher. He was doing the course so that he could do a carpentry course after prison. Jaye said that his literacy and numeracy had improved a lot on the course. For example, his time tables were better, and he understood the Bible better than before. His current goal was to continue to improve his vocabulary.

\section{Māori Tane Hard}

Māori Tane Hard, who was in his late thirties, was in a low-medium security unit. He was open, friendly and talkative.

Māori Tane Hard had trouble at school as he had dyslexia; he left at aged 13. Afterwards, he attended a literacy course and a Te Reo Māori course but ended up in prison. He was working towards a diving certificate prior to his recent sentence.

Māori Tane Hard had attended Foundation Skills on and off for over three years and found the programme very helpful. He wanted to improve his academic skills so that he could finish his diving course, get a good job, and meet his responsibilities as a father. Māori Tane Hard was doing a Te Reo Māori course in addition to Foundation Skills. He described them as "positive things" in his life which gave him a "positive outlook".

\section{Grey}

Grey was a Māori man in his early thirties with multiple scars and tattoos. Our interview took place in the pods, where he provided rich insights into his experiences of learning. 
Grey left school in 3rd Form, after which he became involved in crime. Grey enjoyed working in kitchens. He started a hospitality course before coming to prison but had trouble with the theory component of the course due to literacy difficulties. As a result, he was unable to complete the qualification.

Grey decided to attend Foundation Skills so that he could undertake further training in the future and prevent his son from becoming involved in crime. When he initially began the course he didn't understand the work and found the topics boring. He talked to his teacher about the problem and the issue was resolved. Grey now looked forward to his weekly classes and had grown to enjoy learning. He had particularly enjoyed exploring business-related topics, such learning how to read taxes, tax income and GST, as he felt these were relevant to life outside of prison. 


\title{
Appendix C: Information Sheet and Consent Form
}

\section{Prison education}

\section{Information Sheet}

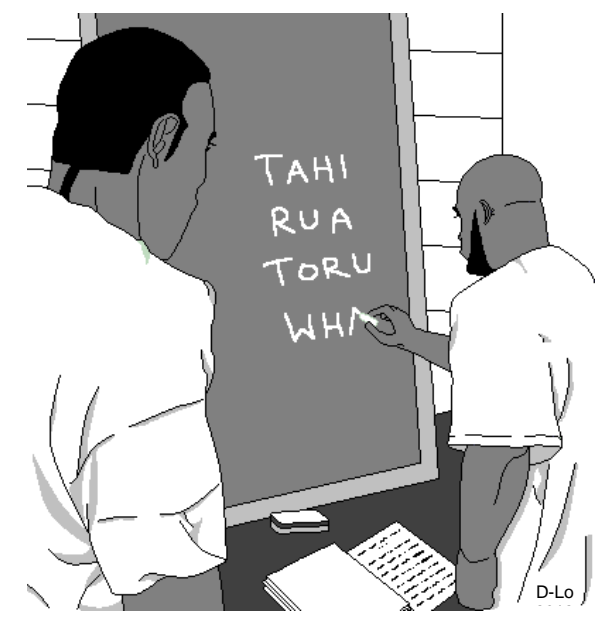

\author{
Kia ora, Talofa Lava, Hello
}

My name is Lana Moriarity. I am doing a Masters of Education at Victoria University.

I am doing a project for my course. I would like to hear your views on learning (ako) in prison.

Your views could help to improve learning and teaching in prison.

\section{Who can take part?}

You can take part in this study if you attend Foundation Skills.

Once I have a list of volunteers, I will randomly select 10 people to interview (e.g. I will draw ten names out of a hat to decide who to interview).

I hope to interview 5 Māori and 5 non-Māori men.

\section{What does it involve?}

We will have a short talk (kōrero). It will take no more than an hour. I will use a tape recorder if that is okay with you.

I will visit you again to check my findings with you.

\section{Your rights}

You can say yes or no. It is up to you whether you take part. 
If you take part you can:

- Withdraw from the study up to a week after our interview

- Refuse to answer any questions

- End the interview at any time

- Ask for the tape recorder to be turned off

- Have a written copy of your interview

- Have a summary of the findings

Privacy

Our talk will be private.

- I will keep your information in a locked file.

- The information will only be seen by me, my supervisor and the person who transcribes (writes down) the tape recordings.

- All materials (e.g. tape recordings and files) will be destroyed at the end of the project.

- Your name will not be used in the final report

\section{How I will use the information}

I will use your information to write some reports. I may talk to others about the findings. The Department of Corrections may use the reports to improve learning and teaching in prison.

\section{What to do next}

If you would like to talk to me, I would be very grateful if you could sign the attached form.

\section{Want to know more?}

I am happy to answer any questions you have.

\section{Thank you!}

Thank you for taking the time to read this letter and for your help.

Ngā mihi nui

Lana 
Whàia te mātauranga hei oranga mō koutou tatou

Seek after learning for the sake of your wellbeing, your whänau and future generations.

This research has been assessed and approved by Victoria University Faculty of

Education Ethics. If you are not happy with the project for any reason, please contact:

Dr Stephanie Doyle

Supervisor

Victoria University of Wellington

PO Box 600

Wellington 6140

Phone: 044636657

Dr Allison Kirkman

Conveyer of the Human Ethics Committee

Victoria University of Wellington

PO Box 600

Wellington 6140

Phone: 044635676 


\section{Prison education consent form}

Name:

Please tick the box if you agree:

$\square \quad$ I have been given enough information about the research.

$\square$ I agree to talk to Lana about my experiences of learning in prison.

$\square$ I understand that I can stop the interview at any time and that I don't have to answer any questions I don't want to.

$\square \quad$ I am happy for our talk to be tape recorded.

$\square \quad$ I understand that what I say will be used to write a report but that my real name will not be used.

$\square \quad$ I understand that I can withdraw from the study at any time.

$\square \quad$ I would like Lana to give me a summary of the findings (in person).

$\square \quad$ I would like a written summary of the findings.

\begin{tabular}{l|l}
\hline Signature: & Date:
\end{tabular}

Address (to send report):

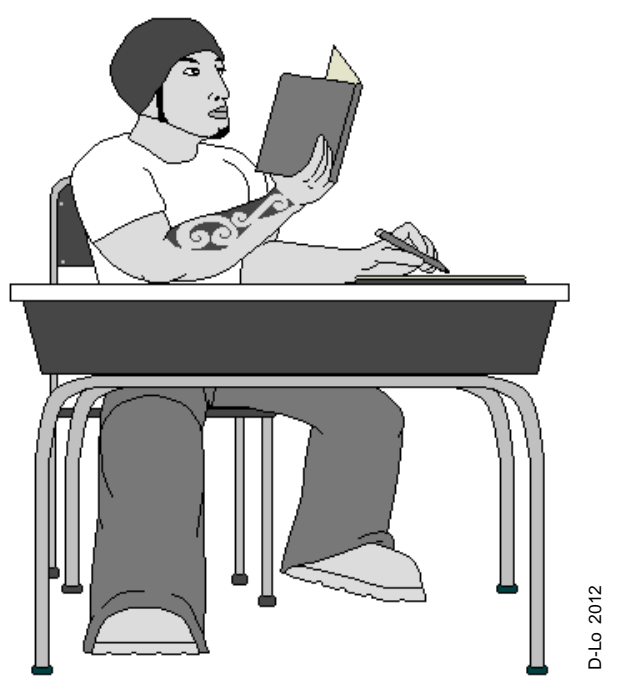




\section{Appendix D: \\ Themes and Examples of Significant Statements}

\begin{tabular}{|c|c|}
\hline Themes & Examples of Significant Statements \\
\hline Motivations for joining the programme & $\begin{array}{l}\text { "My goal is to be with my kids, to build a new life, } \\
\text { start all over again. So if I really just have a go, } \\
\text { give myself a chance, maybe I can get there, one } \\
\text { day". } \\
\text { "At the end of the day the most important thing for } \\
\text { me is preparing myself for when I'm out there } \\
\text { because I have to be a father when I get out there. } \\
\text { It's my turn to step up. I want to step up. I don't } \\
\text { want to carry on being a dickhead asshole the rest } \\
\text { of my life. Otherwise what's the point in living? } \\
\text { There's better things out there for me". } \\
\text { "...because you know having three kids I didn't } \\
\text { want them to grow up to ask me questions I didn't } \\
\text { know or have no clue about". } \\
\text { "... when I get out of prison I want to be a } \\
\text { mechanic, I want to do a mechanic course and I'm } \\
\text { pretty sure there's maths in the mechanics, so } \\
\text { yeah I think it will help me". } \\
\text { "I think it's better for myself, you know, with looking } \\
\text { for job, filling out forms...for a license, or for how to } \\
\text { use your money too, like income". } \\
\text { "There was nothing else to do so I thought l'd put a } \\
\text { bit of knowledge in my head". }\end{array}$ \\
\hline Classroom activities and routines & $\begin{array}{l}\text { "We do warm up papers, Maths, or sometimes } \\
\text { English...Just to what do you call it? Warm up our } \\
\text { minds". } \\
\text { "As soon as we come in s/he likes to play } \\
\text { Hangman with us to figure out what we are } \\
\text { learning today. Then s/he pretty much gets straight } \\
\text { into it. S/he will put some examples on the board of } \\
\text { what we will be doing and then s/he will hand us } \\
\text { our worksheets to do...We do them individually but } \\
\text { we end up helping each other if people get stuck". } \\
\text { "We play the spelling game heaps, with these } \\
\text { cards..." } \\
\text { "[They give] us this long sheet to fill out... what we } \\
\text { need to improve on...feedback, this feedback } \\
\text { sheet" } \\
\text { "We are doing this stress book at the moment...Its } \\
\text { helpful like when you go to work places and stuff if } \\
\text { you're stressed out you can always think of the } \\
\text { book that we learned". }\end{array}$ \\
\hline
\end{tabular}




\begin{tabular}{|c|c|}
\hline Themes & Examples of Significant Statements \\
\hline $\begin{array}{l}\text { Relationships between learners and } \\
\text { teachers }\end{array}$ & $\begin{array}{l}\text { "Everyone gets along with Teacher X". } \\
\text { "S/he's not an asshole. Like if s/he's ready to work } \\
\text { and we are still having our conversation about a } \\
\text { totally different subject, s/he waits or s/he gets in } \\
\text { on it with us". } \\
\text { "Oh, s/he's friendly and that, you know. S/he helps } \\
\text { us when, if, we struggle". } \\
\text { "Helpful, teacher just committed to, to teaching us } \\
\text { really is not letting us have these days off...S/he } \\
\text { gives us that encouragement to come to course". } \\
\text { "S/he's always happy and that. S/he's always } \\
\text { happy that s/he's teaching us". } \\
\text { "The teacher normally chooses the topics and if } \\
\text { some of us haven't got it by the end of one session } \\
\text { we will stay on that topic the next time we come, } \\
\text { so s/he won't change the topic until s/he knows } \\
\text { that we've all got it, which is pretty good. Or } \\
\text { sometimes s/he will ask us what we want to learn } \\
\text { next week". }\end{array}$ \\
\hline Peer relationships & $\begin{array}{l}\text { "Everyone gets along real well". } \\
\text { "Everyone just helps each other if we get stumped. } \\
\text { No one puts anyone down. Everyone is just here to } \\
\text { have a laugh pretty much and learn at the same } \\
\text { time". } \\
\text { "If they are having a problem with their } \\
\text { mathematics...they bring it into me....In the unit..." } \\
\text { "S/he doesn't expect us to do it on our own. S/he, } \\
\text { you know, prefers two heads is better than one". } \\
\text { "...We all have different gifts". } \\
\text { "Some of us know a bit more than others so we } \\
\text { just bring them up to date or explain the process of } \\
\text { how to answer the question to them". }\end{array}$ \\
\hline $\begin{array}{l}\text { Improvements in learners' literacy and } \\
\text { numeracy skills }\end{array}$ & $\begin{array}{l}\text { "I can understand a lot more of the books I read } \\
\text { now. It's because I usually have my dictionary by } \\
\text { my side and a word I don't know l'd look it up... and } \\
\text { if not reading on..." } \\
\text { "I can read out loud with more confidence, without } \\
\text { feeling embarrassed when you have to take a } \\
\text { pause to carry on reading..." } \\
\text { "I just have a bit of a self talk to myself like how it } \\
\text { sounds...Before I just used to straight guess it". } \\
\text { "I've always been onto it when it comes to plus but } \\
\text { my timetables was a bit down but yeah I've picked } \\
\text { up on that... Ratios, fractions...pretty much the } \\
\text { whole array of it". } \\
\text { "They are actually quite surprised too. They're like, } \\
\text { 'Bro you're freaking us out'. I'm like, 'Why's that'? } \\
\text { 'Half of these words we can't spell properly!" }\end{array}$ \\
\hline
\end{tabular}




\begin{tabular}{|c|c|}
\hline Themes & Examples of Significant Statements \\
\hline $\begin{array}{l}\text { How learners used their new skills in } \\
\text { prison }\end{array}$ & $\begin{array}{l}\text { "Yeah it's helped me a lot. When I read my Bible I } \\
\text { know what some of the words mean now". } \\
\text { "I have used it in heaps of ways...Like with the } \\
\text { graphs that helped me when I was doing the } \\
\text { carving. Because I didn't know how to draw so I } \\
\text { was using block ways of doing it..." } \\
\text { "I suppose measurement is for measuring the } \\
\text { distance you have to travel in order to accomplish } \\
\text { the kilometres you want to run for workout } \\
\text { sessions..." } \\
\text { "...I'm enjoying writing letters which I never really } \\
\text { used to do. I'd just do rough notes". } \\
\text { "...Scheduling times to be punctual when you have } \\
\text { appointments to go to, classes to go to". } \\
\text { "The maths, it's helped me doing my shopping, } \\
\text { P119s in here. Take the money off...how much } \\
\text { money you got left, all those kind of things". }\end{array}$ \\
\hline Other effects of the programme & $\begin{array}{l}\text { “...Like I don't have to be embarrassing, you know } \\
\text { what I mean? Before I was, 'Oh they were laughing } \\
\text { at me'. But now I say, 'No, no...I don't care if you } \\
\text { laugh at me 'cos I'm going to be a better person". } \\
\text { "I have realised the commonness of not being able } \\
\text { to read and write. It's not as unusual as I thought". } \\
\text { "It's a growing sense of self-improvement. So it's } \\
\text { been quite positive. I've been quite amazed". } \\
\text { "In here it's made it fun whereas in school it was } \\
\text { pretty much dull and boring..." } \\
\text { "Given me a chance to learn....When you succeed } \\
\text { you feel a bit better". } \\
\text { "Yeah and help you do, even in a relationship more } \\
\text { better because you know the more appropriate } \\
\text { way to go about stuff". }\end{array}$ \\
\hline Barriers to ALN learning in prison & $\begin{array}{l}\text { "Like when I first came I had to tell [her/him] some } \\
\text { of the stuff, I wasn't getting it, and I was finding the } \\
\text { classroom boring. I was getting stroppy and angry } \\
\text { and I was coming in the class and I was like fuck } \\
\text { you again, you idiot. S/he's a good person." } \\
\text { "It was more about the case of feeling insecure } \\
\text { and embarrassed and a bit shy about being able to } \\
\text { ask for help". } \\
\text { "If one person's enthusiasm is not there at the time } \\
\text { it rubs off on the rest of us". } \\
\text { "I had too much stuff on my mind, like family on the } \\
\text { outside... I'd go to course and just wouldn't work, } \\
\text { wouldn't do anything". } \\
\text { "So the best thing I got there was communication } \\
\text { because I was getting grumpy and I wanted to } \\
\text { leave the programme". } \\
\text { "I think it was just being calm about it and just } \\
\text { explaining to [her/him] that some of us left school } \\
\text { and never got to actually learn some of the } \\
\text { materials s/he's trying to teach us". }\end{array}$ \\
\hline
\end{tabular}




\begin{tabular}{|l|l|}
\hline Themes & Examples of Significant Statements \\
\hline $\begin{array}{l}\text { Learners' overall feelings about the } \\
\text { programme and suggestions for } \\
\text { improvements }\end{array}$ & $\begin{array}{l}\text { "Very good, excellent. Very good with our teacher } \\
\text { too...It helps me a lot whaea". } \\
\text { "Foundation's all good". } \\
\text { "Loving it. Help me get back to a positive outlook } \\
\text { on life". } \\
\text { "We used to get NZQA tickets... There should be a } \\
\text { way of getting those tickets again..." } \\
\text { "That's a big issue, the comments the some of the } \\
\text { staff make. Like there are a lot that are really good } \\
\text { about it. But then you get others that go, 'How } \\
\text { come you go to that dummy's class?" } \\
\text { "I strongly want my te reo....I would like to see a } \\
\text { change like that, even on paper, you know, as } \\
\text { homework sort of a thing". }\end{array}$ \\
\hline
\end{tabular}

